\title{
Comportamiento sismico de Estructuras de Concreto Reforzado
}

\section{ABSTRACT}

In the first part of the paper, the general goals and current practice in seismic-resistant design and construction of buildings is reviewed. The importance of construction aspects, such as quality control of materials, workmanship, field inspection, and maintenance and durability of the building, area then briefly discussed. The second part of the paper is devoted to a discussion of the problems encountered in building design. The state-of-the-art and state-of-the-practice is reviewed in: (1) the establishment of design earth quakes; (2) the selection of structural materials and structural systems; (3) the prediction of the mechanical behavior of the structure, which involves modeling of the structure, structural and stress analyses, and the proportioning and detail ing of members, connections and supports; and (4T a reliability analyses of the final design. Emphasis is placed on the establishment of design earthquakes and the proper selection of the structural system and structural material. Then performance of different structural systems during recent moderate and severe earthquakes are illustrated and compared. Finally recommendations are formulated for educational, research and development needs for improving the prediction of seismic performance of structures.
RESUMEN

En la primera parte de este artículo se revisan los objetivos generales y la práctica actual del diseño y construcción de edificios sismo-resistentes, a continuación se describe brevemente la importancia de los aspectos constructivos, como el control de calidad de materiales, mano de obra, inspección en campo, mantenimiento y durabilidad del edificio. En la segunda parte se revisa el estado del arte, así como el estado de la práctica respecto a: (1) definición de los sismos de di seño (2) selección de los materiales y sistemas estructurales (3) predicción del comportamiento mecánico de la estructura, lo cual abarca la idea lización de la misma, el análisis estructural y de esfuerzos, y el dimensionamiento de los miembros, asf como sus detalles, conexiones y apoyos y (4) un análisis de confiabilidad del diseño fi nal. Se ilustra y compara el comportamiento de diferentes sistemas estructurales durante sismos recientes de intensidad media y severa. Al final se llega a recomendaciones de tipo didáctico, de investigación y desarrollo, con el objeto de poder predecir el comportamiento de las estructuras durante sismos. 


\section{Comportamiento sísmico de Estructuras de Concreto Reforzado ** Vitelmo V. Bertero"}

Las últimas décadas han sido testigas de muchos avances en el campo de la Ingeniería Sísmica; sin embargo muchos Investigadores y la mayoría de los profesionistas dedicados a este campo sienten que el diseño y la construcción de las estructuras resistentes al sismo sigue siendo un arte y no una ciencia. Uno de los aspectos criticos al hacer tal diseño y construcción es el juicio usado por cada ingeniero; el mejor camino para desarrollar este juicio es mediante investigaciones en campo del comportamiento de las estructuras ya construídas durante temblores, así como un profundo análisis de los daños observados. Estas observaciones y análisis proporcionan evidencias invaluables no sólo respecto a la efectividad de los Reglamentos sobre sismos y a los procedimientos empleados en el diseño, sino que también son la prueba verdadera de la efectividad de los procedimientos analiticos disponibles.

La observación del comportamiento sísmico de las estructuras de concreto reforzado,durante los movimientos del terreno debidos a sismos moderados y severos, abarca desde agrietamientos mínimos hasta el colapso total. Con base en estos colapsos y en la resistencia comparativamente menor respecto a las estructuras de acero así como la diferente ductilidad por peso unita rio del concreto reforzado "no confinado", se ha sugerido que las estructuras de concreto son más vulnerables a los sismos. Sin embargo como Bresler afirma (ref 1) muchas estructuras de concreto han soportado sismos intensos y daños minimos, lo cual da a entender que las estructu ras, por ser de concreto, no necesariamente son más vulnerables al sismo. Sin tomar en cuenta el material usado, las estructuras que sean diseñadas apropiadamente tendrán un buen comportamiento, aunque el concreto reforzado pueda ser menos tolerante respecto al procedimiento o cal i dad constructiva (mano de obra) y al mantenimien to. Debido a lo anterior, con objeto de tener una resistencia sismica eficiente en las estructuras de concreto, debe prestarse especial atención a todos los factores involucrados en el com protamiento sismico de la estructura. No es suficiente hacer un diseño en el cual se hayan tomado en cuenta todos los requisitos mencionados en los Reglamentos sismicos mas recientes. El comportamiento de una estructura en un sismo, de pende en gran medida de su estado al momento de presentarse el sismo y no simplemente en cómo penso el diseñador que se iba a comportar. Por tanto, deben tomarse en cuenta el mantenimiento y reparación de las estructuras, a todo lo largo de su vida de servicio; tambien deberian considerarse los aspectos generales relaclonados con el diseño y la construcción de la estructura.

\footnotetext{
* Profesor, Escuela de Ingeniería, Universidad de Cal ifornia, Berkeley ** Traducido por el Editor y Comité Editorial
} 
OBJETIVOS

Los principales objetivos de este articulo son (1) revisar los diferentes factores que pueden afectar el comportamiento sismico de las estruc turas; (2) examinar el comportamiento sísmico de diferentes sistemas estructurales de concreto, haciendo hincapie en las causas de tal comportamiento; (3) formular las necesidades didac ticas, de investigación y desarrollo para prede cir y mejorar el mencionado comportamiento; (4) llamar la atención en la necesidad de una mayor cooperación entre los profesionales, investigadores, tecnicos del gobierno y fabricantes de materiales de construcción con objeto de obtener una construcción que tenga una eficiente re sistencia a los sismos.

Se admite que todo lo que aqui se presenta está basado en gran parte en las investigaciones $y$ problemas de diseño en los cuales el autor ha intervenido recientemente: diseño sismo-resistente de edificios y tanques de almacenamiento de liquidos. Solamente los problemas relacionados con el comportamiento de edificios se mencionan en este articulo.

En la primera parte del articulo se revisan los objetivos generales y la practica actual del di seño y construcción de edificios resistentes a sismos. Se describe brevemente la importancia de los aspectos constructivos, como el control de calidad de materiales, mano de obra, inspección en campo, mantenimiento y durabilidad del edificio. La segunda parte del artículo está dedicada a los problemas que se presentan al di señar edificios. Se revisan el estado del arte as $f$ como el estado de la práctica respecto a: (1) definición de los sismos de diseño; (2) selección de los materiales y sistemas estructura les; (3) predicción del comportamiento mecánico de la estructura, lo cual abarca la idealiza- : ción de la misma, el análisis estructural y de esfuerzos, y el dimensionamiento de los miem- bros así como sus detalles, conexiones y apoyos; y (4) un análisis de confiabilidad del diseño final. Se enfatiza la definición de los sismos de diseño y la apropiada selección del material $y$ de el sistema estructural por emplear. A conti nuación se ilustra y compara el comportamiento de diferentes sistemas estructurales durante sis mos de intensidad media y severa. Al final se llega a recomendaciones de tipo didáctico, de investigación y desarrollo con el objeto de poder predecir el comportamiento de las estructuras durante los sismos. Aunque se examinan los aspectos relacionados con la sensiblidad humana a la vibración estos aspectos deben ser tomados en cuenta en un enfoque completo para hacer el análisis y el diseño de estructuras sismo-resis tentes.

\section{OBJETIVOS GENERALES Y PRACTICAS EN EL DISENO $Y$ CONSTRUCCION SISMO-RESISTENTE}

La filosofra usada en el diseño de edificios sis mo-resistentes ha sido muy bien establecida y propone prevenir daños no estructurales que pudieran resultar de movimientos frecuentes del terreno de menor intensidad; prevenir el daño no estructural que pudiera presentarse en movimientos poco frecuentes de intensidad media; evitar el colapso o daños serios por movimientos ocasionales de intensidad alta. Esta filosofía está completamente de acuerdo con el concepto de diseño completo y razonable (ref 2). sin embargo las metodologías que se usan comúnmente en el diseño se quedan cortas en cuanto a reflejar los objetivos de la filosofía que hemos mencionado (ref 3 ).

En el diseño completo y razonable debe reconocerse que el daño al edificio puede provenir de diferentes efectos sismicos: (1) colapso del te rreno debido a efectos de ondas sísmicas o de rupturas de una falla (2) vibraciones transmiti das por el terreno a la estructura (3) ondas sismicas marinas (Tsunamis) o disturbios de 
este tipo, ast como "seiches" en los lagos; (4) otro tipo de fenómenos como incendios o flujos causados por fallas de presas y desliza mientos de tierra. Se hizo una breve descripción de estos riesgos en la ref 4 . .

El efecto sismico que tiene mayor importancia para el Ingeniero Estructurista y que es el que se toma en cuenta en el diseño sismico de los reglamentos, es la respuesta o vibración de un edificio debida al movimiento del terreno que pudiera presentarse en su cimentación. En la mayorla de los casos el daño proveniente de otros efectos es mayor que el debido al de la vibración del edificio. Sin embargo, los procedimientos para medir la probabilidad de tales riesgos y estar de acuerdo con ellos, ge neralmente quedan fuera del alcance de la lnge nierfa Estructural, por lo cual no se incluyen en los reglamentos. Por lo general el único medio de evitar daños debido a estos efectos, es elegir otro sitio para construir, decisión que depende de las dependencias oficiales del gobierno. De cualquier modo, el Ingeniero debe tener cuidado con los diferentes riesgos sismicos y debe aconsejar a su cliente respecto a los peligros potenciales que se presentan por construir en tal o cual sitio.

Aunque este articulo sరlo considera el daño es tructural causado por sismos a traves del movi miento del terreno en la cimentación, el autor reconoce que el efecto de otros factores tanto en la demanda como en la capacidad de un edifi cio debe tomarse en cuenta al evaluar la posibilidad de daños en el mismo durante su vida útil. Estos otros factores incluyen la edad de la estructura, las modificaciones que se le hagan respecto a su uso y destino, o sea las condiciones de tipo socio-económico, modificaciones de tipo estructural o no estructural, daños por incendio y su reparación, y por alti mo la corrosión (ref 3 ).
ASPECTOS CONSTRUCTIVOS Y DE MANTENIMIENTO

Como ya se hizo notar anteriormente, la respuesta y el daño de una estructura ante cualquier tipo de excitación, depende de cómo se hizo realmente la construcción y no de cómo penso el diseñador que se iba a comportar; aún más, hay una intima relación entre el dise ño y la construcción; el tener una buena calidad de la mano de obra depende en gran parte de la sencillez en el detalle de los miembros, conexiones y apoyos; esto es especialmente válido para estructuras de concreto reforzado, en las cuales es posible (sobre el papel y aún en especimenes de laboratorio) detallar el re.. fuerzo de una manera tal que se pueda lograr una mejora importante en el comportamiento sis mico. Sin embargo en el campo tales detalles de diseño pueden ser demasiado elaborados y económicamente inaceptables. Un diseño solo puede ser efectivo si se puede construir.

Las inspecciones que se han hecho en el campo acerca de los daños que ocurren durante los sismos, han revelado que un gran porcentaje de daños y fallas se han debido al bajo control de calidad de materiales estructurales $y / 0$ pobre mano de obra, estos problemas podrian haber sido corregidos si la construcción hubiera sido cuidadosamente inspeccionada durante su proceso. En muchos otros casos los daños, incluyendo los colapsos, pueden ser atribuidos a un mantenimiento inapropiado de los edificios durante su vida de servicio. Enseguida se pre sentan y tratan brevemente estos aspectos cons tructivos y de mantenimiento.

Control de cal idad

El analisis de los ensayes en fábrica de varillas de acero reforzado, pruebas de campo en cilindros de concreto y estudios de resistencia de materiales en especímenes tomados de las estructuras, muestran considerables variaciones en las 
caracteristicas mecánicas. Por ejemplo, las figs. 1 y 2 muestran los diagramas de la frecuencia de distribución de pruebas de control de campo para dos mezclas de concreto de peso normal usadas en los Edificios de Servicios del 0live View Medical Center, en el Valle de San Fernando (ref 5); las figs. 3 y 4 muestran diagramas similares para el Acero A-15 de las varillas de refuerzo. En la tabla 1 se muestra un resumen de estadisticas de evaluación hechas a partir de los datos de pruebas. En la tabla 2 se presenta una comparación entre los valores observados y calculados para el módulo de elasticidad del concreto a compresión. Los valores observados fueron obte nidos de pruebas de laboratorio en especimenes extrardos en el sitio de la construcción.

En vista de la variación en las caracteristicas mecánicas de los materiales estructurales las recomendaciones de los Reglamentos STsmicos actuales, especifican resistencias minimas y maximas del material, y recomiendan que el diseño se base en las mismas; lo que da lugar a un diseño poco confiable y puede llevar a diseños del lado de la inseguridad. Esto es especialmente cierto para el diseño de conexiones de concreto reforzado.

Mano de obra e inspección

Un ejemplo típico de mano de obra deficiente, resultado de una inspección descuidada se muestra en la fig. 5. Aunque fueron diseñadas apro piadamente, las columnas con refuerzo en espiral del Edificio de Servicio del Hospital 0live View fallaron prematuramente durante el sis mo de San Fernando en 1971, debido a que el re fuerzo en espiral fué inapropiadamente colocado, terminándolo debajo del paño inferior de la trabe. Como no se dio el confinamiento necesario en las secciones criticas, se desperdi cio el buen confinamiento del concreto a lo largo de toda la longitud de la columna. Es primordial asegurarse de la calidad en las estructuras de concreto para garantizar su buen comportamiento durante los sismos.

Mantenimiento

Para asegurar que el comportamiento de un edifi cio bajo condiciones de sismo corresponde al considerado en el proceso de diseño, es importante que se pueda supervisar el edificio duran te su construcción. Una cuidadosa labor de coordimación, garantiza que el diseño, asi como el detallado, esten correctamente ejecutados en el campo y que la integridad estructural se man tenga a lo largo de la vida de la estructura. Las alteraciones en el sistema estructural, as $P$ como en los componentes no estructurales no deberían permitirse sin pedir primero el consejo del diseñador original u otro experto en el cam po del diseño sismico-resistente. Las fallas tipicas debidas a la falta de un mantenimiento adecuado, incluyen fallas en las vigas (usualmente por cortante) debidas a las aberturas dejadas para el paso de ductos y las fallas por cortante en vigas y columnas, las cuales generalmente se deben a la adición o remoción parcial de las divisiones o rellenos. Como se muestra en la fig. 6, la adición de rellenos puede, por disminución del claro de las vigas o la altura libre de las columnas, incrementar considerablemente el cortante a desarrollarse durante un temblor severo, y ésto puede provocar una falla frágil de estos elementos.

CARACTERISTICAS GENERALES DEL DISEÑO RESISTENTE A SISMOS

Una construcción resistente a sismos eficiente, necesita una atención cuidadosa en el diseño sismico total, en la construcción, y en el proceso de mantenimiento. Las fases de este proce so incluyen: evaluación del riesgo sismico y re presentación de movimientos del terreno (es decir, establecer los sismos de diseño); selección 
de la estructuración adecuada y predecir el comportamiento mecánico del sistema suelo-estructura; proporcionamiento y detallado de los elementos estructurales con sus conexiones $y$ apoyos; anslisis de la factibilidad del diseño obtenido y finalmente, la construcción y mante nimiento del edificio durante su vida de servi cio.

Los principales aspectos de diseño que pudieran ser conslderados junto con sus interrelaciones, están sintetizados en el diagrama de flujo mostrado en la fig. 7. De acuerdo con este diagrama el primer y quizás el paso más diffcil es establecer los sismos de diseño.

Selección de los sismos de diseño

Se presenta un breve resumen del estado del ar te y el estado de la práctica en el establecimiento de los sismos de diseño. Más detalles acerca del estudio de estos aspectos de diseño se pueden encontrar en las referencias 6-9. Los problemas generales involucrados en la predicción de la respuesta sismica de un edificio se muestran en la fig. 8. El primer problema es la estimación exacta de los movimientos del terreno en la cimentación del edificio, $X_{3}$. Para un sismo de magnitud especif ca, $M_{L}$ y una distancia focal, $R_{1}$, parece anal $\bar{T}$ ticamente factible calcular los movimientos de la base de roca para el sitio dado del edificio, $X_{1}$, si el tipo de falla es conocida $\left|X_{1}=f\left(R_{1}, M_{L}\right)\right|$. La predicción de $X_{3}$, debe considerarse para los efectos de los estratos del suelo que se tiene por debajo y en la peri feria de un edificio. Estos efectos pueden ser clasificados en dos grupos: uno es relacio nado a la influencia de las caracteristicas di namicas de diferentes estratos de suelo durante la transmisión de $X_{1}$ a la superficie de terreno libre, $A$; el btro esta relacionado con la interacción entre la estructura y el suelo de cimentación, simbolicamente representados por el factor 1. Hay gran incertidumbre respecto a los valores reales de A e I y se pueden presentar errores mayores al tratar de determinar estos dos factores, usando las técnicas de ansa $l$ is is disponibles. Aün si $x_{1}$ pudiera predecir se con precisión de Ingenierla, tratar de determinar la influencia de las condiciones del suelo en $x_{1}$, para llegar a $x_{2}$ y $x_{3}$ resultarla en un gran rango de amplitud de los valores previstos. El comportamiento del suelo puede resultar muy sensible a la intensidad de las ondas stsmicas, así como a la proporción de los esfuerzos que pudieran inducirse. Es por esto que el análisis del diseñador no debe depender exclusivamente de un solo anális is deterministico, también deben tomarse en cuenta las posibles variaciones en $A$ e 1 .

El segundo problema, es predecir las deformaciones del edificio. La evaluación precisa de $x_{4}$, para cualquier punto de una estructura re quiere establecer sus tres componentes de rotación. La predicción de $x_{4}$ para un edificio específico y un movimiento especifico del terreno, depende de los efectos combinados de todas las excitaciones que se presentan en un edificio y de sus caracteristicas dinamicas. Generalmente las principales excitaciones sobre una estructura durante un sismo severo son debidas a: (1) fuerzas gravitacionales, $G(t)$, con los efectos asociados de cambios volumétri cos producidos por deformación del material de la estructura, especialmente en el concreto; (2) cambios en las condiciones ambientales, $E(t)$, tales como esfuerzos producidos por cam bios de temperatura y (3) cuando menos tres componentes de translación por el sacudimiento de la cimentación, $x_{3}(t)$.

Como se indica en la fig. $8, x_{4}$ puede obtenerse multiplicando $x_{3}$ por un operador dinámico, D. A pesar de que esto es una expresión simple, las suposiciones involucradas en la evaluación numérica de $X_{3}$ y $D$, dan lugar a que la evaluación numérica exacta de $X_{4}$ sea diffcil. 
Es fácil definir el valor critico de $x_{3}$ como aquel que lleva a la estructura a su máxima respuesta; sin embargo, la cuantificación espe cifica, aunque factible para la respuesta elás tica (ref 10) se complica en casos en que se tenga una respuesta no lineal.

Como se muestra en la ec. 1a. las caracteristi cas dinámicas de todo el sistema, las cuales pueden cambiar continuamente con la deformación de la estructura dentro de su rango inelástico, pueden resumirse denominándolas como los valores instantáneos de: (1) masa, $M(t)$; (2) coeficiente de amortiguamiento, $\zeta(t)$ y (3) función de resistencia, ( $R$ vs $\left.x_{4}\right)(t)$. También pueden representarse como se muestra en la ec. $1 b$, por los valores instantăneos de: (1) perfo do fundamental, $T(t)$; (2) coeficiente de amor tiguamiento, $\zeta(t)$; ( 3 ) resistencia a la fluencia, $R_{f}(t)$ y (4) capacidad de absorción y disi pación ${ }^{y}$ de energía indicada a través de la ductulidad instantănea disponible, $\mu(t)$, la cual es una función de $x_{4}(t)$.

$$
\begin{aligned}
x_{4}(t)= & F\left\{\left[G(t), \Delta E(t), x_{3}(t)\right],[M(t), \zeta(t),\right. \\
& \left.\left.\left(R \text { vs } x_{4}\right)(t)\right]\right\}:
\end{aligned}
$$

$$
\begin{aligned}
X_{4}(t)= & \overbrace{F\left\{\left[G(t), \Delta E(t), X_{3}(t)\right],\right.}^{\text {Caracteristicas dinámicas }} \\
& \begin{array}{r}
\text { Caractertsticas dinamicas del } \\
\text { sistema suelo-estructura }
\end{array} \\
& {\left.\left[T(t), \zeta(t), R_{y}(t), \mu(t)\right]\right\} }
\end{aligned}
$$

El análisis de los parámetros en las ecs. 1a. y $1 b$. indica la magnitud de los problemas involucrados al predecir la respuesta a los movimientos producidos en el terreno por los sismos El primer problema es que la predicción de $x_{4}$ depende de $x_{4}$. Otro problema es que todos esos parámetros son función del tiempo, aunque la fuerza de gravedad y las condiciones ambientales tienden a permanecer como constantes durante la duración de un sismo. Es necesario consi derar dos efectos importantes en las excitaciones y respuestas debido al tiempo: primero, el efecto de las fuerzas de inercia desarrolladas por la masa, y segundo, el efecto de la rapidez del cambio en la intensidad de las deformaciones. Esta variación puede ser lo suficientemen te grande para afectar considerablemente las cá racteristicas mecánicas estáticas de los materiales con las cuales se predicen generalmente las caracterfsticas dinámicas del sistema total suelo-estructura, $T(t), E(t), R(t)$ y $\mu(t)$. El valor de $\triangle E(t)$ representa algo más que los esfuerzos debidos a los cambios ambientales ocurridos durante el movimiento sismico critico del terreno, $x_{3}$, también toma en cuenta el esfuerzo y la deformación existentes en el momento del sismo debido a:

(1) cambios de temperatura previos o contracción, los cuales causan esfuerzos residuales $\sigma$ relajación de esfuerzos deterioros por la edad y la corrosión; (2) degradaciones en la resistencia y la rigidez debida a una exposición previa a vientos de gran intensidad, incendios o sismos; (3) otras perturbaciones o movimientos en la cimentación; y (4) cambios en la resistencia y rigidez causados por alteraciones, reparaciones o endurecimiento. Cualquiera de estas condiciones pueden afectar de modo significativo los factores de respuesta estructural que deben considerarse al determinar las capaci dades de resistencia $y$ de deformación. Para finalizar debe notarse que $\Delta E(t)$ también afecta a (R vs $x_{4}$ ) ( $t$ ).

Como se ha citado con anterioridad, para predecir una respuesta estructural, se requiere: (1) definir las caracteristicas dinámicas de la posible excitación critica, $x_{3}$; (2) datos de confianza sobre las caracteristicas mecánicas del sistema suelo-estructura y (3) establecimiento de la interacción entre el edificio y la 
excitación critica.

Conceptualmente, el sismo de diseño debería ser aquél que produce el movimiento critico del terreno, o sea, el que lleva a la estructura a su respuesta critica. Sin embargo, la aplicación de este concepto simplista en la practica puede encontrar serias dificultades. Esto por que, primero el movimiento del terreno es muy complejo, y segundo porque aún para un sistema estructural especifico, la respuesta critica puede variar de acuerdo con los diferentes estados limites que pudieran controlar el diseño. Adicionalmente, las caracteristicas del sismo de diseño (o movimiento del terreno) podrá depender del problema del diseño que se tenga en ese momento. Si el problema es obtener solamente las fuerzas de diseño sismico para un di seño preliminar, el sismo de diseño podría especificarse en la forma de espectro de respues ta suavizado. Si se considera solamente al di seño final (dimensionamiento detallado de las regiones criticas de la estructura) o el estudio de la confiabilidad de un diseño seleccionado, sera necesario especificar la historia de los movimientos del terreno. En este senti do, el establecimiento del sismo de diseño ade cuado es análogo a la selección de los diagramas esfuerzo-deformación del material apropiados para predecir el comportamiento mecánico de las estructuras.

El movimiento del terreno es una función compleja del tipo y características del mecanismo de generación, la naturaleza de la estructura geológica involucrada, las condiciones topogra ficas y del suelo próximas al sitio. Una simplificación acostumbrada en el diseño, es considerar solamente acciones no concurrentes de las componentes del terreno horizontales $y$ translacionales. Para sitios cerca del epicen tro, puede ser necesario evaluar la respuesta estructural a la acción simultánea de las seis componentes del terreno y considerar en forma realista la interacción suelo-estructura, más que emplear los movimientos del terreno previstos en el campo libre.

En la actualidad es muy diffcil predecir exacta mente la respuesta de un edificio a este compli cado movimiento del terreno, ya que, dependiendo de la función y tipo de la estructura, el di seño puede estar controlado por diferentes esta dos límites. En el pasado se ha reconocido que cuando menos deben considerarse dos casos principales de estados limites: uno en el cual el diseño se controla por estados lifmite de servicio, y el otro, por estados I Imite de resistencia. En el primero, la estructura debe permane cer dentro de su rango elástico-lineal de comportamiento para evitar fallas de funcionamiento; en el último se podría tolerar un comportamiento inelástico hasta el punto de colapso dinámico incipiente. Al examinar los daños en edificios resultantes de recientes movimientos sismicos del terreno severos, se ha visto que aunque algunos edificios estuvieron lejos de al canzar el estado limite de colapso, el grado de los daños no estructurales fue tan grande como para constituir una falla. Por tanto se vió ne cesario considerar explicitamente una tercera categorfa de estados 1 imite basados en el riesgo de daño (ref 3) que pudiera llenar el vacio entre condiciones adecuadas de servicio por un lado y la seguridad contra el colapso por el otro.

A continuación se presenta un resumen de los mé todos para especificar los sismos para cada uno de estos estados 1 imite principales (ref 6 ).

Estados 1Pmites de servicio

Los reglamentos 5 ismicos han especificado sismos de diseño en función de una zonificación es pecificada, de un factor de intensidad de sitio, - como en la mayorla de los reglamentos modernos, como la aceleración máxima o efectiva en 
el sitio. Sin embargo, generalmente resulta inadecuado depender solamente de tal aceleración. Recientemente se han sugerido los siguientes métodos: espectro de respuesta, histo ria del movimiento del terreno y el diseño basado en el analisis de vibraciones aleatorias. En los casos en que los estados 1 imite de servicio controlan el diseño, las estructuras deberfan permanecer esencialmente dentro de su rango elástico. Para estos casos y para estructuras localizadas a distancias moderadas del foco, normalmente se acepta que uno de los mejores modos de especificar el sismo de diseño es por medio de un espectro de respuesta elástica lineal suavizada (ERELS). Tal espectro se puede construir a partir del analisis estadístico de espectros elasticos obtenidos de acelerogramas apropiados (reales o simulados), o escalando velocidad y desplazamiento mạximos del terreno, a partir de factores amplificación espectrales obtenidos estadistica mente para diversos valores de amortiguamiento.

Sismos para el diseño por resistencia última

La comparación de las fuerzas laterales de diseño obtenidas a partir del ERELS y las especi ficadas en los reglamentos actuales, indica que serla sumamente costoso diseñar todas las estructuras para que resistieran elásticamente un sismo de intensidad alta. Se pueden usar fuerzas de diseño menores que las obtenidas a partir del ERELS, aprovechando la capacidad inelastica de disipación de energía de la estructura. Las deformaciones inelasticas deben mantenerse dentro de límites aceptables, impuestos por la capacidad disponible de deforma ción de la estructura o bien por el grado de daños no estructurales usualmente asociados con tales deformaciones. A partir del espectro de respuesta para diseño inelástico (ERDI), se pueden obtener cargas de diseño preliminar derivadas de estimar la respuesta dinámica no lineal de modelos estructurales con idealiza- ciones histereticas realistas, sujetos a diversos movimientos del terreno con caracteristicas correspondientes al sitio. Debido a lo complejo de tal análisis dinámico no lineal comúnmente se usan métodos más simples en los cuales se obtiene el ERDI modificando directamente un ERELS. El ERELS se modifica usando factores obtenidos de analisis de respuesta elastoplásti cos de un solo grado de libertad. Sin embargo, estos métodos se basan en resultados obtenidos con un número limitado de registros de movimien to del terreno, por lo cual debe tenerse precau ción al aplicarlos a sitios que puedan estar su jetosa movimientos del terreno significativamen te diferentes. Aưn más, estos métodos púden no ser aplicables a sistemas de múltiples grados de libertad o en los casos en que el compor tamiento histerético real difiera de la idealización elastoplástica supuesta.

La validez de derivar el ERDI directamente del ERELS, puede cuestionarse seriamente debido a que los tipos de excitación que inducen la res puesta maxima en los sistemas elásticos e inelásticos son fundamentalmente distintos. La información usada para calcular el ERELS no es suficiente para predecir la máxima respuesta dinámica inelástica y deberra completarse con datos respecto a la duración de los sacudimien tos fuertes del terreno asi como la cantidad, secuencia y caracteristicas de pulsos de acele ración intensos y relativamente largos (por ejemplo incrementos grandes de la velocidad del terreno) que puedan esperarse.

La necesidad de esta información adicional pue de basarse en una revisión de los resultados obtenidos al aplicar la teorla de vibraciones para calcular el valor del factor de amplifica ción dinámica $D$, de sistemas simples de un grado de libertad (fig. 9). En el caso de un sistema elástico-lineal, la excitación dinámica critica es de típo periódico, teniendo una frecuencia igual a la del sistema, por que éste 
induce el fenómeno de resonancia. Para este tipo de excitación, el factor de amplificación dinámica $D$, puede alcanzar un valor máximo aproximadamente igual á $1 /(2 \xi)$. Ast para valores de $\xi$ del rango 2 a $10 \%$, $D$ puede alcanzar valores del rango de 25 á 5 . Puesto que el va lor máximo de $D$ para una excitación impulsiva es solamente 2, los pulsos largos y severos de aceleración no son generalmente crlticos para respuestas elastico-lineales. Sin embargo, en un sistema inelástico, tales pulsos largos pue den llegar a ser criticos. Esto es particular mente cierto para una estructura que tenga una resistencia de fluencia histerética, $R_{y}<M \ddot{X}_{3}$, donde $M$ es la masa de la estructura. En el ca so de sistemas elasto-plásticos, la existencia de pulsos periódicos de aceleración corta en los movimientos del terreno, contribuye solo a llevar la respuesta del sistema hasta su nivel de fluencia. Una vez que el sistema empie za a fluir, disminuye el fenómeno de resonancia, debido a que la energra disipada aún por deformaciones inelásticas pequeñas es equivalente a muy altos valores de $\xi$. Por lo tanto, no es de esperarse que se presenten deformacio nes inelásticas muy grandes durante cada incur sión en la fluencia. Aunque la presencia de pulsaciones cortas y periódicas puede provocar una serie de inversiones de fluencia, es dudoso que el número de estas inversiones l leguen a producir un fenómeno de fatiga ante pocos ci clos. Esto es debido a que la cantidad de deformaciones inelásticas que se desarrollan en cada inversión por lo general resulta tan pequeña, que el número de ciclos requeridos para que se produzca la fractura es mayor que el ná mero de ciclos que se pudieran presentar en el mas fuerte y prolongado movimiento imaginable en un sismo real. Lo anterior indica que los factores de amplificación que pueden emplearse para la máxima aceleración del terreno, para obtener la máxima respuesta lineal elástica de una estructura, generalmente están controlados por el fenómeno de resonancia. No obstante, pueden inducirse deformaciones mayores con solo presentarse un pulso prolongado que tenga una aceleración efectiva igual o un poco mayor que la correspondiente a la resistencia a la fluen cia de la estructura. La acción repetida de pulsos de aceleración largos y severos, puede conducir a la acumulación de deformaciones inelásticas lo suficientemente grandes para llevar a uno $\sigma$ a la combinación de los dos tipos de fa llas que se ilustran en la fig. 10, o sea fatiga antes pocos ciclos y colapso incremental ("crawling"). De estos dos, el autor considera que la estructura deberia diseñarse para la falla de tipo colapso incremental por ser la critica. Por lo general, para llegar a la fractura del material estructural son necesarios tantos ciclos de inversión de deformaciones inelás ticas, que es dudoso que tal falla pudiera presentarse por el número de pulsos severos que po drian ocurrir aún en el más fuerte $y$ prolongado movimiento de un sismo real.

Debe quedar claro a partir del estudio anterior, que el sismo de diseño no es único aún para un sitio dado. El movimiento crítico del terreno depende del tipo de comportamiento que se supone controlará la respuesta del edificio en tal - cual lugar, o bien de los estados I Imites que controlan el diseño.

Los resultados de que actualmente se dispone sobre la respuesta de sistemas de un solo grado de libertad ante fuerzas impulsivas, muestran que, en el caso de movimientos del terreno debidos a sismo, mientras mayor sea la intensidad de la aceleración efectiva de un pulso res pecto a la resistencia a la fluencia de la estructura, es más corto el tiempo para llegar a la aceleración máxima y también que mientras mayor sea la duración del pulso en relación al periodo fundamental de la estructura, mayor se rá la deformación inelástica que se desarrolle. Con objeto de determinar en forma cuantitativa el sismo de diseño inelástico, de todos modos 
se requiere determinar; (1) la magnitud de los pulsos de aceleración prolongada que se pueden presentar durante un sismo; (2) la forma en que se pueden definir estos pulsos. Se pueden consultar las ref 6-9 para intentar resolver estos problemas.

\section{Estructuración}

Como se resume en el diagrama de flujo de la fig 7 , en este paso el diseñador debe seleccionar el sistema estructural, as $T_{\text {como el ma- }}$ terial estructural y el tipo de componentes no estructurales. Para encontrar soluciones apro piadas a los problemas que se presentan en este paso, se requiere la participación del Arqui tecto, del Ingeniero Estructurista y de los fa bricantes de materiales.

Importancia de la estructuración apropiada

La sofisticación al seleccionar el sistema estructural, los materiales estructurales y los componentes no estructurales, es mucho más importante que la sofisticación en el analisis. Independientemente de qué tan sofisticado pueda ser el método de análisis, el Ingeniero no puede asegurar que un sistema estructural mal concebido pueda comportarse en forma satisfac toria durante un sismo severo.

A partir de la ec 1, claramente vemos la impor tancia de la estructuración dentro del proceso de diseño completo. Las fuerzas de inercia de penden de la masa, amortiguamiento y las propias caracteristicas estructurales (rigidez, resistencia a la fluencia, resistencia maxima, y capacidades de absorción y disipación de ener gral, por ello las decisiones hechas para escoger la estructuración y los materiales a emplearse, juegan un importante papel en el compor tamiento sísmico de la estructura durante su vi da útil. Antes de tratar la selección apropiada del sistema estructural sismo-resistente, dentro de los diferentes sistemas de concreto reforzado resistente a cargas laterales que en la actualidad se utllizan en la construcción de edificios, se estudiarán separadamente los problemas generalmente relacionados con la selección de la configuración y planificación del edificio y su sistema estructural, as $r$ como de los materiales estructurales y no estructurales sin embargo debemos reconocer que estos tres están intimamente relacionados.

Tanto el Arquitecto como el Ingeniero deben entender cómo las decisiones que se tomen respecto a la estructuración del edificio, pueden crear efectos sismicos serios en la estructura (ref $11,12,13)$.

Selección de la configuración apropiada del edificio

Una de las decisiones más críticas relacionadas con la capacidad de un edificio para soportar sismos, consiste en escoger su forma básica y configuración. Las estructuras pueden ser de muy diferentes tipos y configuraciones, por lo cual obviamente no existe una configuración ideal especifica para un determinado tipo de edi ficios. Sin embargo, existen ciertos principios básicos que pueden servir de gura para el diseño sismo-resistente, los cuales pueden ser usados como base al seleccionar configuraciones arquitectónica y estructuralmente adecuadas.

Principios básicos del diseño sismo-resistente

1. El edificio y la estructura deben ser ligeros (evitando masas innecesarias).

2. El edificio y la estructura deben ser simples, simetricos y de forma regular en plan ta y elevación para evitar fuerzas torsiona les significativas.

3. La estructura debe tener suficiente rigidez lateral inicial para evitar daños significativos bajo movimientos sismicos menores y 
moderados, y resistencia (estabilidad de resistencia y rigidez) bajo las inversiones repetidas de deformaciones que pudieran inducirse a traves de un sismo intenso. Mientras más rígida sea la estructura, menos sensible será a la interacción de los componentes no estructurales; mientras más fuerte sea, menor sera la sensibilidad a los efectos de una falla repentina de los elementos no estructurales interactuantes.

4. La estructura debe tener una distribución uniforme y continua de la resistencia, rigidez y ductilidad.

5. La estructura debe tener el mayor número posible de lineas de defensa estructural, por ejemplo, puede estar compuesta de varios subsistemas estructurales dúctiles que interactúen o estén interconectados por elementos estructurales muy dactiles (fusibles estructurales) cuyo comportamien to inelástico permita que la estructura en cuentre un camino que se aparte de un esta do critico de respuesta dinámica.

6. Las estructuras deben detallarse de tal mo do que el desarrollo de las deformaciones inelásticas se presente en zonas previstas.

7. Las estructuras deberán tener resistencia $y$ rigidez balanceada entre mienbros, conexiones, y apoyos.

8. La resistencia y la rigidez del edificio en conjunto debe ser compatible con la resistencia y rigidez del suelo de cimentación.

A continuación se hace un breve estudio de los principios anteriores.

1 El edificio y la estructura deben ser ligeros.

Es de suma importancia que en el diseño sismo-resistente, el diseñador reconozca desde el principio del diseño, que las fuer zas dinámicas sobre una estructura se pueden controlar con la selección apropiada de los sistemas estructurales y a través de la cantidad y distribución de las masas del edificlo, tal como se muestra para la interrelación de la ec. 1. La importancia de reducir las masas reactivas (masas que pueden reaccionar al movimiento de la cimentación del edificiol, se puede ver al observar la ecuación diferencial básica indicada en la fig 11 para un sistema de un solo gra do de libertad sujeto al movimiento del terreno. Es claro, de esta ecuación, que la carga efectiva, $P_{\text {ef }}$ resultante del movimien to del terreno, es equivalente a la masa reactiva $M$ de la estructura y la aceleración del terreno, $\ddot{v}_{g} \equiv \ddot{x}_{3}$. Mientras menor sea $M$, menor será la fuerza sismica.

2 El edificio y la estructura deben ser sencillos, simetricos $y$ de forma regular en planta y elevación.

La observación de los daños por sismo demues tra que mientras más simple sea el edificio, mejor será el comportamiento a igualdad de los demás parámetros. Como observó Dowrick (ref 12), existen dos razones principales para esto: en primer lugar, es mucho más fácil entender el comportamiento respecto a un sismo para un edificio simple que en uno com plejo; en segundo lugar, es mucho más fácil entender, formular dibujos y construir detalles estructurales sencillos para un edificio simple. La simetría y regularidad en planta y en elevación es recomendable en gran parte por las mismas razones. La simetria es importante en ambas direcciones. La falta de simetrla conduce a efectos de torsión que son diffciles de evaluar en forma apropiada y que pueden ser muy destructivos. Estas consideraciones muestran que la configuración ideal en planta sería la circular. Para una planta rectangular, lo más apropiado serla emplear un cuadrado. El arreglo en planta con ángulos y salientes debe 
evitarse. Respecto a la regularidad del sistema estructural en su altura, debe tener se en mente que cualquier deficiencia en con tinuidad y simetrla en la distribución de las masas y en las caracteristicas estructu rales de un piso puede ocasionar problemas muy serios. Mientras que es relativamente más sencillo estimar el centro de rigidez para los edificios de un solo piso, es difI cil hacerlo para los diferentes pisos de un edificio de varios niveles.

Es conveniente limitar la altura de los edificios de acuerdo con ciertas limitaciones de esbeltez. Dowrick (ref 12) recomienda una relación altura/ancho igual o menor de 3 ó 4. Mientras más esbelto sea un edificio, peores serán los efectos de volteo por sismo y mayores los esfuerzos en las columnas exteriores. Las fuerzas de compresión por volteo pueden ser particularmente diferentes de tratar, aún más, debe tenerse en cuenta que el momento de volteo en la base, tiene que ser resistido por la cimentación. En algunos sitios las condiciones del terre no pueden ser tales que la cimentación afec tará grandemente las proporciones del conjunto y el arreglo en sentido vertical de la estructura, tanto por razones prácticas como económicas.

A menudo el diseñador no puede satisfacer las reglas anteriores debido a muchos impedimentos, tales como la forma del sitio y los requisitos de funcionamiento. Por ello es importante que el diseñador entienda cla ramente cómo se puede ver afectado el comportamiento debido a variaciones en la sime trla tanto en planta como en elevación.

3 Rigidez $y$ tenacidad.

Existen dos filosoflas acerca de cual siste ma es mejor, el rigido o el flexible. Esto depende de muchos factores; no existe una respuesta anica a este problema. Cada sistema tiene ventajas y desventajas que el disenador debe considerar con cautela; en las ref 12 y 13 se presentan tratamientos deta1 lados de estas ventajas y desventajas; en tanto que las estructuras flexibles se asocian generalmente con marcos, las estructuras rigidas quedan ejemplificadas por los muros de cortante o marcos contraventeados. Para edificios con masas reactivas similares, mientras más flexible sea el sistema suelo-estructura, mâs bajo será su periodo fundamental. Por tanto los edificios flexibles son especialmente apropiados para lugares en que las condiciones geológicas y del subsuelo pueden garantizar movimientos del terreno de alta frecuencia. Sin embargo, si el subsuelo local filtra la mayor parte de la frecuencia alta, la estructura de un edificio rigido estara sujeta, durante su respuesta elástica, a fuerzas sismicas menores que las de uno flexible.

Es costumbre afirmar que las estructuras flexibles son más dúctiles que las rigidas, esto depende de qué se entienda por ductilidad. Por lo general ello no es cierto, sobre todo si se considera la ductilidad útil del edificio. Al desarrollar gran ductilidad por desplazamiento, el desplazamiento relativo entre niveles para los edificios flexibles puede ser tan grande que no sea aprovechable debido al gran daño no estructural, y a los efectos $P-\Delta$. Como se hizo notar antes, una investigación de costos de daños por terremotos recientes (San Fernando, Managua y particularmente Guatemala) reveló que la mayor proporción de los costos se tuvo debido a los desperfectos no estructurales en edificios con sistemas estructurales flexibles. A esta desventaja hay que agregar el problema de molestias, (por la sensibilidad humana a las vibraciones) 
ocasionadas a los ocupantes de los edificios; en estructuras flexibles estas vibraciones pueden ser provocadas aun por temblores menores, por lo cual pueden presentarse frecuente mente durante la vida del edificio.

Otra importante ventaja de un edificio con estructuras rígidas es que ésta es considera blemente menos sensible a los efectos destructivos que pueden ser causados por la interacción de los elementos no estructurales, lo cual, como se mencionará después, constituye un problema muy serio.

4 Distribución Uniforme y Contínua de la Resistencia, Rigidez y Ductilidad (Tenacidad).

La debilidad estructural de un edificio queda al descubierto con los movimientos del te rreno durante un sismo. Esta debilidad por lo general se origina en los cambios bruscos de resistencia, rigidez y ductilidad. Dowrick (ref 12) recomienda una serie de reglas para dar a la estructura la posibilidad máxima de soportar un sismo severo. Del aná lisis de las recomendaciones de Dowrick, clą ramente se ve que entre más simple, simétrica y regular sea la estructura, será más fácil que cumpla con dichas recomendaciones. Sin embargo, estas recomendaciones implican restricciones al diseño arquitectónico por 10 que a veces son dificiles de aceptar. Los daños estructurales severos que han sufrido algunos edificios modernos durante temblores recientes demuestran la importancia que tiene el evitar cambios bruscos en la rigidez lateral. Posteriormente se estudiará el com portamiento de algunos de estos edificios. Un buen ejemplo es el comportamiento de edificios con un "piso débil". Estos sistemas de "piso débil" pueden llevar a problemas graves durante sismos severos, como lo han demostrado la inspección de los daños debidos a sismo, así como estudios analíticos.
Un diseño eficiente de marcos rigidos de concreto reforzado, requiere que se desarrolle la deformación inelástica de las trabes antes que la de las columnas. La filosofía de diseño para considerar como dúctil a un marco resistente a momento, requiere que en todas y cada una de las uniones viga-columna se formen articulaciones plásticas solamente en las trabes. Las razones para esto son: (1) debido a la presen cia de fuerzas axiales significativas la ductilidad disponible de las columnas es me nor que la de las vigas, y todavía más importante, (2) la formación de deformaciones inelásticas en la columna puede llevar al desarrclio en la estructura, de un mecanismo parcial de fluencia, del tipo con despla zamiento lateral, que requeriría deformaciones inelásticas en las columnas considerablemente mayores que las que normalmente pueden admitir. Esta última razón se ilustra en la fig 12. Park (ref 14) encontró que cuando el diseño era tal que se producía un desplazamiento parcial de la columna (fig 14a), para obtener un factor de ductilidad total de desplazamiento, $\mu_{\delta r}=4$, la relación de la ductilidad necesaria para la sección de columna $\mu_{\phi c}=\left(\phi_{\mu c}\right) /\left(\phi_{y c}\right)$ era de 122, considerablemente mayor que el valor que podría desarrollarse en columnas de con creto reforzado. No obstante, si primero se forman las articulaciones plásticas en las trabes, para llegar al mismo $\mu_{\delta r}=4$, la relación de ductilidad de curvatura de la trabe tendría que ser menor de 20 , valor que fácilmente se obtiene si se refuerzan adecuadamente las trabes.

No puede dejar de insistirse en la importan cia de prevenir la formación de articulacio nes plásticas en las columnas ( $y$ por lo tan to un mecanismo de desplazamiento lateral parcial). No sólo deben diseñarse las 
trabes y columnas con la resistencia que evi te las articulaciones plásticas en columnas, sino que tambiên deben añadirse elementos no estructurales (divisiones, muros y canceles) que puedan aumentar la resistencia de las trabes (fig. 13).

5 Lineas múltiples de defensa estructural.

Este tema ha sido tratado por Bertero (ref 15) Paulay (ref 16), Mahin y Bertero (ref 17) y Fintel y Ghosh (ref 18). Una estructu ras deberia tener el mayor grado posible de hiperestaticidad tanto interna como externa. La resistencia sismica de una estructura diseñada económicamente, depende de su capacidad para absorber y disipar mucha energra, introducida sobre todo por repetición de deformaciones plásticas en las zonas criticas de sus miembros. De esto se concluye que mientras la estructura tenga una mayor conti nuidad y monolitismo, tendrá mayor posibilidad de que se formen articulaciones plásticas y su capacidad de disipación de energla será tembién más al ta.

Según se mencionó anteriormente, en las estructuras en general as 1 como en las sismoresistentes, es aconsejable tener un al to grado de hiperestaticidad; no obstante, esto no es suficiente. Es necesario que la disipación de energla se distribuye en la planta y altura de la estructura completa, esto hace que la estructura sea eficiente para re sistir cargas, y que tenga suficiente ductilidad y un comportamiento histeretico estable bajo repeticiones cfclicas de cargas reversibles. Esto puede obtenerse previendo una secuencia apropiada de fluencia, o sea que las articulaciones plásticas se deberlan formar primero en las zonas menos criticas y reparables. Por tanto, se dara la mayor protección a las zonas o elementos con mayores cargas gravitacionales. El disefiador debe establecer una Jerarquía respecto a los niveles de resis tencia probables que desea proporcionar a cada elemento estructural. Los sistemas estructurales de edificios que son diseñados para una gran capacidad de disipación de energia deben estar compuestos de subsistemas dúctiles que interactien y esten interconectados por elementos estructurales muy dúctiles (fusibles estructurales). Los fusibles estructurales o elementos disipadores de energia deben diseñarse y detallarse adecuadamen te, $y$ los otros elementos que interconectan deben estar provistos de la suficiente capacidad de reserva de resistencia para asegurar que se disponga de los fusibles escogidos aun para las máximas deformaciones que el sistema en conjunto pudiera tener que soportar. Buenos ejemplos de la diferencia en tre hiperestaticidad y ilneas múltiples de defensa son el uso de pocos muros en cantile ver en comparación con el uso de una serie de muros acoplados, donde las trabes y muros son diseñados de tal manera que las trabes constituyen los fusibles estructurales. Pos teriormente se tratará en detalle el caso del Edificio del Banco de América en Managua, el cual es un buen ejemplo de lineas múltiples de defensa.

6 Control de la localización de las regiones inelásticas criticas.

Este principio está relacionado intimamente con los 5 y 7 . Como se mencionó en el principio 5 , se obtienen ventajas considerables al establecer una secuencla adecuada de regiones de fluencia. En este sentido, el con creto reforzado es un material muy versatil, pues el proyectista puede prever la posición de las zonas inelásticas criticas al detallar el refuerzo en las mismas. En las ref 19-21 se trata un ejemplo de las ventajas de controlar que las articulaciones plasticas 
se localicen lejos del paño de la columna, evitando as $r$ la degradación de rigidez debido al deterioro de la adherencia en la unión viga-col umna.

7 Equilibrio de resistencia y rigidez entre los miembros, conexiones $y$ apoyos.

"Una cadena se rompe en su eslabơn más débij" No tiene sentido emplear elementos fuertes, rígidos y dúctiles si no se conectan en forma apropiada. Es común que los edificios sufran daños severos o se caigan por no tener las conexiones adecuadas. Varios investigado res (ref 13), han tratado el tema de la deficiencia en el anclaje $y$ adherencia del refuer zo principal en las conexiones trabe-columna de estructuras de marcos rigidos. Apartir de observaciones hechas durante sismos recientes de cierta intensidad en estructuras de marcos rigidos tridimensionales, las especificaciones reglamentarias para el refuerzo lateral en las secciones criticas de las trabes y columnas, as $r$ como para cortan te en los nudos, se han vuelto más estrictas, y ahora resulta que la parte debil de la cadena está en el anclaje del refuerzo principal en los nudos (ref 19-21).

8. La estructura y el sistema suelo-cimentación deben tener rigideces y resistencia compat $i-$ bles.

Para que un diseño sismo-resistente sea eficiente, es primordial que se tenga una acción integral y compatible entre la superestructura, subestructura y subsuelo durante todo el tiempo que dure la respuesta total del sistema suelo-estructura ante un movimiento del te rreno. A pesar de los crecientes intentos de analizar la interacción suelo-estructura con técnicas analíticas sofisticadas, todavia hay bastante incertidumbre sobre cómo se trasmiten el cortante en la base y el momento de volteo de la estructura al suelo, y sobre como conservar la integridad estructural de la cimentación ante deformaciones diferenciales del suelo. Selección del material estructural

A fin de hacer una buena selección de un material estructural, debe conocerse su comportamiento mecánico bajo las condiciones dinámicas impuestas por la respuesta de una estructura a todos los niveles de excitación dinámica por sismos.

Caracteristicas mecánicas deseables para los materiales estructurales en la construcción sismo-resistente

Los materiales estructurales deben tener al ta capacidad de absorción y disipación de energra por peso unitario. Para ello deben tener:

(1) alta resistencia (a tensión y compresión) por peso unitario; (2) alta rigidez por peso unitario; (3) alto amortiguamiento interno por peso unitario; (4) alta tenacidad peso unitario; (5) alta resistencia a la fatiga ante pocos ciclos; y (6) comportamiento histerético estable ante inversiones repetidas de deformación. Además, el material estructural debe ser homogeneo y fácilmente adaptable para formar conexiones de bastante resistencia que ten gan las mismas características que el material.

Para escoger el mejor material en la construcción sismo-resistente se pueden emplear (como se ve en la fig. 14) diagramas sencillos de es fuerzos por peso unitario versus deformación, para los diferentes materiales estructuraies que se usan. De la fig 14 se ve que el concre to simple de peso normal no es recomendable por su debilidad a la tensión, lo cual requiere que sea reforzado. La falta de ductilidad en el concreto reforzado usual obliga a emplear 
concreto confinado. La tabla 3 , versión modificada de la de Dowrick (ref 12) da un indice de para que son adecuados diferentes materiales estructurales. Esto dependerá de la calidad propia de los materiales en una región determinada, la calidad de la mano de obra local $y$ otras consideraciones técnicas, económicas y politicas.

Al usar diagramas como el de la fig 14, que se ha obtenido de pruebas estándar seudo-estáti cas, debe tenerse en mente que el comportamien to de los materiales bajo condiciones dinámicas debidas a excitaciones sismicas es bastante diferente del comportamiento bajo condiciones estáticas, especialmente en los tres siguientes aspectos. Primeramente, bajo carga dinámica se modifica la relación esfuerzo-deformación proveniente de condiciones estâticas, y da lugar a diferentes deformaciones y capaci dades de absorción y disipación de energía. En general, las características mecánicas de los materiales tienden a mejorar con el incremento de la velocidad de carga. Segundo, la carga dinámica puede modificar el tipo de falla, propiciando una falla frâgil. Por ello deben tratarse cuidadosamente la interacción e influencia de la tendencia a fracturas en condiciones como restricciones severas, esfuerzos residuales, discontinuidades, grietas, espesores de materiales y Juntas, y transmisión de es fuerzos de un material a otro en construcción compuesta. Tercero, la carga dinámica puede pro ducir falla por fatiga: al respecto, es de espe clal interes la fatiga ante pocos ciclos.

La información disponible referente al comportamiento de elementos estructurales sujetos a rapidez de deformaciones del orden de las espe radas ante sismos reales, indican que sus efec tos podrian despreciarse (ref 22). Sin embargo, los datos son escasos y aún hay carencia de una información racional acerca del comportamiento de miembros y componentes estructura- les reales, bajo condiciones de carga de fatiga ante pocos ciclos y con deformaciones rápidas.

Como el concreto reforzado es una combinación de varillas de acero de refuerzo y concreto (que a su vez es un material compuesto), existen muchos tipos diferentes de materiales en el concreto reforzado que se emplea hoy en día. Las posibles combinaciones dependen de los dife rentes tipos de agregado (normal o ligero) y acero de refuerzo (presforzado o no-presforzado) que se usen, y también depende de si se cuela en obra o es precolado. Parece ser que en el futuro tendrán mucho uso los precolados, y concreto ligero parcialmente presforzados. En la actualidad el tipo más apropiado de concreto re forzado en construcción sismo-resistente es el concreto reforzado de peso normal, ya que la tecnología del concreto ligero y los problemas de elementos prefabricados todavía no se han es tudiado satisfactoriamente.

El valor relativamente nayor de la resistencia por peso unitario del concreto ligero sugiere la conveniencia de su empleo. En la fig 15 se puede apreciar la ventaja de emplear concreto ligero confinado.

Resulta muy atractivo usar concreto ligero en la construcción sismo-resistente por la reducción considerable de peso y por consiguiente de masa. Desafortunadamente, debido a su menor módulo de elasticidad, se han usado en varios casos mezclas de muy alta resistencia a compresión, para asi obtener una mayor rigidez. Se han hecho estudios en Berkeley (ref 23-25), re lativos al comportamiento del concreto confinado y no confinado, para diferentes tipos de agregado, obteniendo deformabilidades grandes. No obstante, la efectividad del concreto, en el comportamiento sísmico de estructuras de concre to, debe basarse no sólo en el aumento de la ca pacidad de deformación, sino también en la capa cidad del concreto confinado para soportar gran 
des deformaciones sin perder resistencia. Por lo tanto, el confinamiento debe también aumentar la resistencia a compresión del concreto pa ra poder compensar la pérdida de resistencia al reducirse la sección transversal por el aplasta miento y desprendimiento del recubrimiento.

En la fig 16 se ilustran algunos resultados obtenidos en el estudio de la ref 23 . Estos resultados muestran que para diferentes concretos, las dos condiciones mencionadas, incremento de la deformabilidad y resistencia a compresión se cumplen en una extensión variable y la efectivi dad del confinamiento es altamente sensible al tipo de agregado usado. La efectividad del con finamiento se caracteriza por dos constantes del material $k_{0} y k_{u}$, que se definen relacionan do la resistencia a compresión incrementada, $f_{c}$, con la presión de confinamiento, $f_{r}$.

La máxima resistencia a compresión $f_{c}^{*}$ máx se obtiene después de cierta deformación $\varepsilon_{0}^{*}$, y se puede definir como:

$$
f_{c \text { máx }}^{*}=f_{c}+k_{o} f_{r}
$$

en donde $f_{c}$ es la resistencia a compresión del mismo concreto, pero no confinado. Para deformaciones muy grandes, $\varepsilon_{u}^{*} \gg \varepsilon_{0}^{*}$, la resistencia a compresión por lo general disminuye a un valor $f * \underset{c u}{*}$, y se puede definir como:

$$
f_{c u}^{*}=f_{c}+k_{u} f_{r}
$$

La presión de confinamiento, $f_{r}$, depende de las características geométricas y del material del refuerzo en espiral, y se puede expresar como:

$$
f_{r}=\frac{2 A_{s p} f_{s}}{D_{c}}=\frac{1}{2} \rho_{s} f_{s}
$$

donde $\rho_{s}$ es la relación del volúmen del refuerzo en espiral al volúmen total del núcleo $y f_{s}$ es el esfuerzo que ha sido desarrollado por el refuerzo en espiral. Suponiendo que el alambre dúctil de la espiral fluya cuando la deformación longitudinal del concreto esté en el rango de $\varepsilon_{0}^{*}$ a $\varepsilon_{u}^{*}, y$ que el endurecimiento por deforma ción es despreciable dentro del rango de estas deformaciones del concreto, además que $f_{s}$ es igual a. $f_{y} y$ que $f_{r}$ puede calcularse para valo res dados de $A_{S p}, D_{C} Y$ s de la ec 4 , entonces los valores de $k_{0} y k_{u}$ pueden obtenerse de las ecs 2 y 3 empleando los resultados de ensayes. En la tabla 4 se muestran estos valores para cinco diferentes tipos de concreto usados en el estudio. Los primeros investigadores han demos trado que el coeficiente de efectividad del con finamiento, $k$, varía con la intensidad de la presión lateral y con la deformación unitaria longitudinal. Sin embargo, para desarrollar el criterio $\mathrm{ACl}$ del refuerzo en espiral (sección 10.9.2 del ACl $318-71)$ y el de otros criterios similares basados en el confinamiento del concreto, se ha tomado un valor constante de $k$, de 4.0 a 4.1 .

Como se ve en la Tabla 4, los valores de $k$ para concreto de peso normal, varían dentro del rango 0 a 7.0. Para las dos presiones laterales $\left(0.13 \mathrm{f}_{c}\right.$ y $\left.0.32 \mathrm{f}_{\mathrm{c}}\right)$ los valores de $k_{\mathrm{o}}$ bajo la máxima compresión son 7.0 y 5.0 , respectivamente, y los valores de $k_{u}$ para la resistencia $u 1-$ tima son 0.0 y 3.1 , respectivamente. Con base en estos valores, y notando que el concreto se comporta relativamente dúctil para un amplio rango de deformaciones ( $f i g$ 16), puede justificarse un valor constante de $k=4.0$ para el con creto de peso normal, como E-5, sobre todo para $f_{r}=0.32\left(f_{c}\right)_{10}$. Para concretos 1 igeros $B-3$, $B-5, R-3$ y $R-5$, los valores de $k_{u}$ varían entre -1.0 y 4.4 . Los valores negativos de $k_{u}$ indican que la falla a compresión en el concreto confinado puede ocurrir para valores abajo de la resistencia a compresión del concreto no con finado. Para las dos presiones laterales $f_{r}=0.1\left(f_{c}\right)_{10}$ y $f_{r}=0.3\left(f_{c}\right)_{10}$, los valores de $k_{0}$ para compresión máxima van de 1.0 a 4.4 y 
los valores de $k_{u}$ para la resistencla ditima están dentro del rango -1.0 :2.1. Con base en estos resultados para agregados similares a aquellos usados en esta investigación, deberla tomarse un valor de $k$ entre 1.0 y 2.0 al desarrollar criterios basados en el incremento de resistencia debida al confinamiento del concre to ligero. Por ello, para tales casos la canti dad del acero de refuerzo en espiral necesario para una columna de concreto ligero puede ser de 2 a 4 veces mayor que la normal prescrita por el $\mathrm{ACl}$. Debido a las limitaciones geometricas ocasionadas por el tamaño del alambre de la espiral y espaciamiento minimo, seria virtualmente imposible formar una espiral que permitiera un colado normal del concreto.

En la fig. 17 se señala el efecto del coeficiente variable $k$. En esta figura se ha grafi cado en un eje el valor de la pérdida de capacidad de carga axial debida al desprendimiento del recubrimiento de las columnas con refuerzo en espiral, $y$ en el otro eje el valor de $k$, para lo cual se ha supuesto que la espiral se diseñó de acuerdo con el $\mathrm{ACl}$. Esta perdida de capacidad se expresa como una relaclón y se deriva como sigue:

$$
\text { Pérdida }=0.85 f_{c}^{\prime}\left(A_{g}-A_{c}\right)-k_{f} A_{c}
$$

y aplicando la ec. 4:

$$
\text { Pérdida }=0.85 \mathrm{fl}_{\mathrm{c}}^{\prime} \quad\left(A_{g}-A_{c}\right)-0.50 \mathrm{k}_{F_{s}} f_{s} A_{c}
$$

De acuerdo con el ACl, $\rho_{s}=0.425\left|\left(A_{g} / A_{c}\right)-1\right|$ $\left(f_{c}^{1 / f_{s}}\right)$. Sustituyendo esta expresión en la ec. (5) y dividiendo entre $0.85 \mathrm{fl}_{c} \mathrm{~A}_{g}$, se obtiene la siguiente relación:

$$
\frac{\text { Perdida }}{0.85 f_{c}^{\prime} A_{g}}=1-\frac{A_{c}}{A_{g}}-0.25 k\left(1-\frac{A_{c}}{A_{g}}\right)
$$

Los valores tipicos dentro de los cuales varía $A_{c} / A_{g}$ para columnas cuadradas con refuerzo en espiral son de 0.40 a 0.60 , ( $A_{c}$ es el área del núcleo y $A_{g}$ el área bruta); para columnas circulares la relación varia entre 0.50 y 0.70 .

En la fig 17 se grafica la relación de perdida contra valores tipicos de $A_{c} / A_{g}$ y claramente se aprecia que para valores de $k$ menores de 4 las perdidas resultan muy importantes.

Ya que la mayorla de las recientes sugerencias y requisitos para mejorar el diseño sismo-resis tente de las estructuras de concreto se apoya en los efectos benéficos del confinamiento sobre el comportamiento del concreto, se estudia rán brevemente los resultados obtenidos en las referencias 23-25 y su relación con la predicción del comportamiento sismico:

1. Las caracteristicas de la deformación del concreto confinado están muy ligadas al tipo de agregado o la magnitud relativa de la presión del confinamiento. El módulo de elasticidad del concreto a compresión varla no sólo con el peso unitario y la resistencia a compresión, sino también con el tipo de agregado que se use. El valor del módulo de elasticidad usando el criterio ACl puede dar resultados sobrevalua dos y con ello afectar los valores que se estimen para los periodos naturales, $T$, de las estructuras de concreto reforzado. Este efecto deberla tomarse en cuenta en el análisis por sismo, permitiendo las correspondientes variaciones en el valor de $T$.

2. El confinamiento para todo tipo de agregados resulta efectivo para lograr una mayor capacidad de deformación, es decir, deformaciones grandes altimas. Esta propiedad es el factor mas importante para mejorar el comportamiento de elementos zunchados, ya que compensa en algo las perdidas de resistencia y rigidez del concreto bajo cargas ciclicas. 
3. El incremento de la resistencia a compresión gracias al confinamiento, es del orden del doble para el concreto de peso normal respecto al concreto ligero. Por lo tanto, hay que tener cuidado al usar las ecuaciones obtenidas de resultados para el concreto normal al predecir el comportamiento del concreto ligero.

4. La baja efectividad del confinamiento en algunos concretos puede dar por resultado el tener perdidas considerables en la capacidad a compresión al producirse el desprendimiento del recubrimiento en los elementos de concreto reforzado. Esto es de fundamental importancia en el diseño sísmico de columnas de concreto, ya que deben ser capaces de soportar en todo momento, los efectos de las cargas gravitacio nales y los momentos de volteo.

Seleccion de los componentes no estructurales

Los elementos no estructurales deben estar integrados de manera apropiada o aislados efect $i$ vamente del sistema estructural básico, si se pretende evitar daños excesivos en la construc ción y riesgos de accidentes bajo movimientos inducidos por sismo. Algunos elementos del edificio, como los muros perimetrales de relle no, revestimiento, divisiones interiores, muros de mamposterla que no son de carga, muros contra incendio, estructuras para escalera y otros ductos verticales, pueden ser estructuralmente de mucha importancia debido a su inter acción con la estructura (aunque sean no estructurales bajo solicitaciones normales) bajo movimientos del terreno producidos por sismos.

Los efectos de la interacción pueden agruparse en dos categorlas (ref 12): (1) efectos de los elementos no estructurales en la respuesta del sistema estructural, y (2) efecto de la respuesta del sistema estructural sobre los elementos. Mientras más flexible sea el sistema estructural básico, peores serán los efectos de los componentes no estructurales.

Efecto de la respuesta del sistema estructural sobre los elementos no estructurales.

Al empezar a moverse una estructura, cualquier cosa que esté apoyada o ligada con aquélla tam bién se deformará y a menos que esté diseñada apropiadamente, es probable que pueda dañarse - destruirse. La inspección de daños por sismo indica que la mayorla de las estructuras flexibles, diseñadas y construldas de acuerdo con los reglamentos sismicos actuales, han so portado los movimientos resultantes de sismos de gran intensidad. No obstante, los elementos no estructurales sufrieron daños tales que realmente se consideró una falla completa desde el punto de vista económico. Este tipo de fallas incrementan los riesgos para la seguridad de las personas (fig 18). La mayorla de las veces, la falla de estos elementos, se pro duce por la carencia de conexiones o apoyos apropiados.

Efecto de los elementos no estructurales en la respuesta del sistema estructural.

Cuando los elementos no estructurales (tales como muros de mamposterla que no cargan, divisiones, muros contra incendio, etc.), tienen cierto grado de rigidez, pueden influir considerablemente en la respuesta estructural, aún cuando solo soporten una pequeña parte de la carga vertical. Para poder estimar la posible respuesta del edificio, es necesario considerar los elementos no estructurales que existen al momento de presentarse solicitaciones extre mas. Varios ejemplos ilustran la necesidad de inclurr estos elementos no estructurales en el anălisis y diseño.

1. Las divisiones disminuyen la esbeltez de los miembros causando el problema ya muy conocido de las columnas y vigas cortas ( $f i g$ ). 
2. Las divisiones o muros de relleno cambian en forma significativa las caracterlsticas dinamicas de las estructuras.

En la fig 19 se muestra la influencia de los muros de relleno y divisiones a partir de trabajos analiticos y experimentales hechos en Berkeley (ref 26); se estudio un modelo a esca la $1: 3$ de un subconjunto de los tres pisos inferiores y una y media crujias (fig 20) de un edificio prototipo de once pisos de concreto reforzado. El perfodo fundamental considerando solo el marco de la estructura se estimo en $1.3 \mathrm{seg}$. Los elementos de relleno se diseñaron y construyeron de acuerdo con los siguientes lineamientos:

1. los miembros estructurales (sobre todo las columnas) deberfan tener gran ductilidad rotacional y resistencia a la degradación por cargas cíclicas de cortante reversibles.

2. debería lograrse una degradación paulatina de los tableros por medio de refuerzo con sepa raciones pequeñas; $y$

3. el espesor de los tableros debería limitarse de manera tal que la resistencia al agrieta miento del muro de relleno, en cualquier nivel siempre fuera menor que la combinación de resistencias al cortante disponible en las colum nas de ese nivel.

Para hacer hincapié en la importancia de los muros de relleno, se hara una comparación de los resultados obtenidos para una estructura con muros de relleno y otra sin estos muros.

Estructura sin muros de relleno.- En la fig 21 se muestra la curva carga-deformación obtenida del ensaye efectuado con un marco sin muros de relleno. De acuerdo a este ensaye, la capacidad fue de $50 \mathrm{KN}$ (11 kips) * y la rigidez tangencial inicial fue bastante baja, $6 \mathrm{~K} \mathrm{~N} / \mathrm{mm}$

(*N. del T. 1 kip $=0.454$ ton)
$(34 \mathrm{k} / \mathrm{in})$.

Con base en la teorla rígido-plástica de primer orden, la resistencia predicha fue $70 \mathrm{~K} \mathrm{~N}$ (15.7 kips), o sea un valor de $40 \%$ en exceso, debido a la fiexibilidad lateral y al consiguiente efecto $P-\Delta$.

Estructura con muros de relleno. - En la fig 22 se muestran los efectos de dos clases de muros de relleno. Las curvas de esta figura se obtu vieron a partir de graficas de las envolventes correspondientes a los resultados de la ref 26 . La comparación de las curvas indica que debe tomarse en consideración el efecto de los muros de relleno para estimar la resistencia y rigidez de la estructura. Las estructuras con múros de relleno, bajo cargas de servicio, se comportan como vigas de gran peralte monoliticas, con una rigidez lateral inicial de al menos $250 \mathrm{~K} \mathrm{~N} / \mathrm{cm}(143 \mathrm{k} / \mathrm{in})$ o un incremento de al menos $500 \%$ con respecto al marco sin muros de relleno. Al hacer los rellenos con muros de barro, la resistencia se incremento de $50 \mathrm{~K} \mathrm{~N}$ (11 kips) hasta cerca de $320 \mathrm{~K} \mathrm{~N}(72$ kips), que corresponde a más del $600 \%$.

Los resultados anteriores se obtuvieron con mu ros de relleno reforzados adecuadamente, y en especial marcos de concreto reforzado (con muros de relleno con diseño ingenieril). Si no se hubieran reforzado los rellenos, y los miem bros se hubleran reforzado mal, sobre todo para cortante, la resistencia máxima y la rigidez inicial del marco con estas caracteristicas, bajo carga monotónica, hubiera sido muy semejante a la obtenida con los rellenos refor zados. Esto se debe a que en este ultimo caso la falla empezó por aplastamiento ó por falla de cortante en los muros de relleno y como con secuencia la contribución del refuerzo fue des preciable. Sin embargo, el comportamiento pos terior a la resistencia máxima serla bastante diferente, sobre todo bajo acciones sismicas. 
Por consiguiente, la resistencia disminuirla bruscamente después de alcanzar su valor máximo, debido a la falla repentina por aplastamiento fráll o falla por cortante del relleno sin refuerzo; todas las fuerzas cortantes desa rrolladas en este instante, debido a las fuerzas de inercia, deberfan ser resistidas por las columnas o vigas de concreto reforzado. Si estos elementos no hubieran sido diseñados para soportar el cortante total (marcos con muros de relleno sin diseño ingenieril), tendrian una falla más o menos frágil, como se muestra en la fig 23.

Klingner y Bertero (ref 26) obtuvieron curvas carga lateral-deformación para dos especimenes ensayados bajo condiciones de acciones sismicas. La carga cíclica no afectó la resistencia máxima. Bajo cargas de servicio las estruc turas con relleno actuan como vigas monoliticas de gran peralte. Al incrementar la carga, los tableros se separaron de la estructura menos en las dos diagonales opuestas en compresión y por consiguiente la subestructura ya no tuvo un comportamiento de marco contraventeado. Mayores incrementos de carga causaron el aplas tamiento de algunas de las diagonales en compresión, lo que indica que se habla llegado a la resistencia máxima. El inicio de una degra dación importante del panel fue indicado por el aplastamiento de la diagonal en compresión equivalente (por lo general la del tablero más débil). A partir de este instante, los espect menes respondían como estructuras contraventea das por diagonales en compresión que iban fa1 lando gradualmente en uno o más tableros.

La magnitud. relativa de los daños en cada table ro determinó la posición de las zonas de articu laciones desarrolladas posteriormente cerca de las uniones viga-columna. El número de articulaciones aumento hasta formar un mecanismo de falla total, al mismo tiempo que la resistencia de los elementos de relleno disminuía hasta llegar a una carga de colapso rígido-plástico de segundo orden, correspondiente al mecanismo propio del marco sin muros de relleno. La pre sencia, comportamientos y falla de los tableros de relleno no redujeron de manera significativa la ductilidad rotacional de los miembros del marco.

A partir del analisis de los resultados obteni dos en las investigaciones anteriores, as $f$ como de las de otros investigadores y de observa ciones en campo de estructuras dañadas por sís mos, resulta obvia la precaución que el proyec tista debe tener para distinguir entre la respuesta sismica inelástica de las estructuras dúctiles convencionales y las estructuras con muros de relleno, ya sean con diseño ingenieril o no.

Por su superioridad respecto a los marcos sin muros de relleno, bajo cualquier estado de respuesta, es aconsejable que los diseñadores tomen seriamente en consideración la ventaja de emplear muros de relleno, siguiendo en el diseño los lineamientos ya mencionados. Por lo tanto, no es conveniente emplear materiales frágiles o paneles arquitectónicos para hacer los rellenos. Si se pretende tener eficiencia en el diseño, debe eliminarse cuando sea posi ble, el uso de elementos relativamente pesados tales como particiones que no contribuyan directamente a la resistencia estructural total durante sismos fuertes. Los elementos con función exclusivamente arquitectónica deben reemplazarse por elementos estructurales eficientes tales como muros de relleno con diseño ingenieril, los cuales también pueden tener funciones arquitectónicas. El diseño del edificio debería realizarse considerando las diferentes contribuciones de rigidez y resistencia de todos los mecanismos resistentes disponibles (por ejemplo, marcos dúctiles y 
marcos con muros de relleno con diseño ingenie ril) a la respuesta estructural del conjunto bajo todos los estados límite de excitación sismica. Se tiene la convicción de que los gas tos adicionales debidos al diseño y construcción propios de este criterio, se justifican al obtenerse una mayor seguridad por la hiperestaticidad y también por la disminución del costo debido al uso eficiente de los elementos divisorios y de relleno.

Selección del sistema estructural

Por tradición, la principal preocupación del Ingeniero Estructurista ha sido el dotar al edificio de capacidad de resistencia ante cargas varticales. Con el incremento de la altura de los edificios, el efecto de las fuerzas laterales debido a viento y sismo se ha conver tido en una mayor preocupación. Los desplazamientos de una estructura por solicitaciones laterales aumentan al aumentar su esbeltez $y$ pueden producir molestias a los ocupantes. Como ya se dijo anteriormente, el desplazamiento lateral puede hacer peligrar la integridad de los elementos no estructurales y la estabilidad estructural total del edificio. El reto al Ingeniero Estructurista en el diseño de edi ficios esbeltos altos, es la selección de un sistema estructural que proporcione las fuerzas laterales necesarias de manera tal que requiera el mínimo gasto por unidad de altura, sobre el costo para resistir las fuerzas gravi tacionales.

La aplicación de este criterio ha llevado a re sultados eficientes y económicos, y se han desarrollado nuevos sistemas estructurales para edificlos de más de 100 pisos, diseñados para resistir acciones laterales, principalmente de bidas a viento (ref 18).

El comité ACl - 442 (ref 27) da algunos lineamientos para escoger un sistema adecuado. Hay que tener cuidado al emplear estos lineamientos en el diseño sismo-resistente, ya que para algunos de los sistemas (como el de vigas pared) no se tienen datos respecto al comportamiento bajo movimientos severos del terreno por la ac ción sismica. Hasta contar con mejor información del comportamiento sismico de sistemas nuevos, se recomienda a los diseñadores seguir usando sistemas que han demostrado su eficiencia sismo-resistente, ya sea durante sismos se veros o mediante estudios analiticos y experimentales realizados racionalmente.

Sistemas Estructurales básicos.

Los diversos sistemas resistentes a cargas laterales pueden clasificarse como uno de los dos siguientes sistemas básicos estructurales 6 su combinación:

1. Marco rigido.

2. Marco contraventeado o muros de rigidez, Los sistemas de concreto reforzado, resistentes a carga lateral, más usados en los Estados Unidos son:

(1) estructuras espaciales; (2) estructuras es paciales con muros de rigidez (3) marcos tipo tubo (4) estructuras tipo tubo en tubo (5) estructuras tipo sombrero o de plantas voladas.

En las refs. 18,27 y 28 , se estudian las ventajas de los primeros cuatro sistemas. Las ti po sombrero consisten de uno ó más núcleos cen trales de concreto reforzado y pisos suspendidos. En la fig. 26 se presenta un ejemplo, el edificio West Coast Building de Vancouver, British Columbia, el cual fue sujeto a estudios experimentales dinámicos por Bouwkamp (ref 29). Desde el punto de vista de costos de construcción este sistema es muy atractivo; sin embargo, tal como se diseña y construye actualmente, existen serlas dudas respecto a su eficiencia como un sistema sismo-resistente. Los principales inconvenientes son: falta de hiperestati 
cidad (columnas en voladizo) y la existencia de una carga axial grande en la parte superior, lo cual no solo reduce la ductilidad del nacleo, sino que tambien puede producir serios efectos $P-\Delta$. No se tienen datos de su respues ta bajo movimientos severos del terreno por sismo. Las ventajas y desventajas de los dos principales sistemas estructurales (marco y muros) se tratarán al estudiar el comportamien to sismico de edificios.

Predicción del comportamien to mecán ico de las estructuras.

Como se ve en el diagrama de flujo de la fig 7 . este aspecto del proceso del diseño normalmente involucra tres pasos fundamentales: (1) modelo de la estructura, (2) análisis estructural y de esfuerzos, y (3) dimensionamiento y detalla do. En esta sección se tratará la importancia del modelo estructural. Los pasos 2 y 3 se tratan en las referencias 13,30 y 31 .

Idealizaçiăn de la estructura

La idealización realista de caracteristicas es tructurales, es de fundamental importancia en el logro de un diseño sismo-resistente eficien te, y requiere la representación exacta del comportamiento del edificio construrdo, sobre todo sus masas, condiciones de apoyo, conexiones, rigideces y resistencia de los elementos y cimentaciones. También debe considerarse la posible interacción de los elementos no estruc turales con los estructurales. Para decidir cómo representar estas caracteristicas, se necesita un entendimiento claro del comportamien to esperado de la estructura, esto puede adqui rirse a traves de observar cómo se comportan las estructuras reales junto con estudios anaI ticos y experimentales.

Por tenerse incertidumbre respecto a los diferentes factores que se deben considerar al modelar las estructuras, el disefiador debe enten der, desde el principio, que el diseño no se puede basar en sollo un anălisis determinlsta de un modelo escogido. El diseñador debe considerar varios modelos con base en las posibles combinaciones de las fronteras de rangos en las cuales puedan variar los diversos parámetros que gobiernan el funcionamiento de una estructura real. Para ilustrar este punto, reexamine mos el caso aparentemente sencillo del pabellón de estacionamiento de ambulancias del edificio 01 ive View Medical Center (ref 32).

La estructura de este pabellón consistía de una losa de concreto relativamente pesada (433 kips), soportada por 12 columnas rígidas de concreto reforzado, con estribos, como se ve en la fig. 27. Las columnas del lado norte fallaron por cortante en la parte superior, quedando las partes inferiores prácticamente en po sición vertical. El desplazamiento permanente del techo, fig 28, se produjo después de la falla de todas las columnas del lado norte. Esta estructura se diseñó basándose en el modelo mos trado en la fig 29 o sea, suponiendo un apoyo articulado en la parte superior de la zapata. Basado en este modelo, los cortantes calculados para las columnas fueron tan pequeños ( $f$ ig 29) que no se requería refuerzo por cortante. Un análisis más cuidadoso de la estructura del edi ficio, habría llevado la consideración necesaria de la restricción impuesta por la losa de piso, la cual estaba dos pies arriba del nivel de los cimientos de las columnas. La forma en que se construyó esta losa restringió a la columna, causando una condición próxima al apoyo fijo para la porción de columna sobre la losa; asi se duplicó el valor del cortante último cal culado para la columna ( $f i g 30$ ). Este fue el factor más importante en la falla de la estructura, todo por una equivocación en la idealización que dió lugar a que se subestimara el refuerzo necesario por cortante. 
El considerar posibles limites en las restricciones ofrecidas por la cimentación y la losa de piso, podría también haber mostrado que los períodos naturales de esta estructura (la estimación de éstos es esencial en el diseño sismo-resistente) podría variar entre $0.09 \mathrm{seg}$. y $0.34 \mathrm{seg}$. Este margen tan amplio enfatiza la necesidad de emplear conceptos no deterministas para el diseño sismo-resistente de las estructü ras.

Análisis de la confiabilidad del diseño final

La naturaleza del diseño sismo-resistente es no determinista, debido a las incertidumbres que se han mencionado anteriormente respecto a las caracteristicas de sacudimientos del terreno por futuros sismos intensos, asi como al compor tamiento mecánico real del sistema suelo-estruc tura. Por ello, resulta necesario someter la estructura diseñada, a una serie de análisis con objeto de verificar su seguridad bajo los posibles limites de las excitaciones esperadas $y$ de los parámetros que controlan su comportamiento en los estados límite de servicio y resistencia última (ref 31 ). El siguiente tema se limitará a los problemas que se presentan al verificar la seguridad del diseño para los esta dos de resistencia última.

Como la respuesta dinámica no lineal de las estructuras es muy sensible a las variaciones de las características de los movimientos del suelo, debe verificarse la seguridad de un diseño contra una información de historia del movimien to del terreno. Estas historias deben escogerse de tal manera que puedan probar la respuesta inelástica de la estructura a través del posible intervalo de periodos críticos potenciales dentro de los cuales pueda responder debido a la degradación de su rigidez.

Resulta complejo tratar de describir cuantitati vamente el comportamiento histerético real de un miembro o de sus zonas críticas. La mayor parte de la información disponible se ha obteni do de pruebas de miembros sujetos a momentos, fuerzas axiales y cortantes que actúan en un solo plano. La idealización de los ciclos histeréticos reales aún para este caso simple de comportamiento en un plano, es aún demasiado compleja para ser incorporada a programas prácticos de computadora, para analizar las estructuras globalmente. Por ello es de desear el describir sus principales características mediante unos cuantos indices numéricos. Si este comportamiento se puede idealizar como perfecta mente elasto-plástico, se puede describir con precisión mediante la resistencia a la fluencia y la historia de un factor de ductilidad, el cual se define como la deformación del siste ma dividido entre su deformación de fluencia. Desafortunadamente, el comportamiento histeré tico de los sistemas reales difiere significa tivamente de esta simple idealización. Por 10 tanto, aunque los factores de ductilidad son atiles para diseñar las máximas deformaciones, por lo general no sirven para cuantificar la capacidad de disipación de energfa. Para una discusión detallada sobre el empleo de factores de ductilidad ver refs. 33 y 34 .

COMPORTAMIENTO SISMICO DE EDIFICIOS DE CONCRETO REFORZADO

En Berkeley se han realizado algunos estudios profundos acerca del daño provocado por sismos recientes de intensidad media y alta $(15,17$, 32-39). Estos y otros estudios similares hechos por otros investigadores han demostrado la importancia de seguir los conceptos básicos del diseño sismo-resistente y han conducido a mejoras en las disposiciones para el diseño $y$ la construcción sismo-resistente. Se tratarán brevemente ejemplos típicos del comportamiento observado en edificios de concreto reforzado pa ra ilustrar la importancia del diseño sismo-resistente. 
Comportamiento del Edificio Principal del Centro Médico Olive View durante el terrenoto de San Fernando de $1971(32,33,36$ - 38)

Este era un edificio de seis niveles. Al examinar el arreglo general del edificio, fig. 31 , se encontró masas grandes innecesarias. Así mismo, el sistema estructural presenta discontinuidades significativas. Mientras que los cuatro niveles superiores se componían de muros de rigidez combinados con marcos rígidos espaciales, los dos niveles inferiores se estructuraron con sólo un sistema de marcos rígi dos espaciales. El sistema de piso consistió básicamente de un sistema losa plana-columna, con ábacos en las columnas. Se emplearon columinas de concreto con refuerzo transversal de estribos en algunos casos y zunchos en otros. Como se puede apreciar en la fig. 31, la forma y refuerzo de estas columnas variaba de un nivel a otro.

La combinación de discontinuidades en rigideces, resistencia y ductilidades, y ei empleo de masas innecesarias, tuvieron un importante papel en el comportamiento del edificio durante el terremoto de San Fernando en febrero de 1971. Aunque el edificio principal no colapsó, por razones de funcionalidad era inservible $y$ tuvo que demolerse, aan cuando el coeficiente sismico se estimo en 0.30 y en 0.44 para la plata baja y para el primer nivel respectivamente; es decir, considerablemente mayores que los especificados por el reglamento. Las defor maciones permanentes de los dos primeros niveles fueron tan grandes (el segundo nivel tuvo un desplazamiento hasta de 30 pulgadas respecto al primer nivel, fig. 32), que la reparación de los daños estructurales y no estructurales era antieconómica (fig. 33).

Comportamiento de los edificios Banco de América y Banco Central durante el terremoto de Managua en $1972(15,17, \underline{33})$
Los estudios de daños producidos durante el sismo de Managua del 23 de diciembre de 1972, indicaron que si bien es cierto que los edificios estructurados con marcos rígidos, correctamente detallados y construídos, pueden resis tir grandes excitaciones sísmicas sin colapsar, varios sufrieron deformaciones que pusieron en peligro la vida de sus ocupantes. Sin embargo, los edificios con muros de rigidez que se dise ñaron y construyeron adecuadamente, se comportaron excepcionalmente bien. Mientras más simétrica es la planta del edificio y mayor es la relación de área de muro de rigidez a área gruesa del piso, mejor es el comportamiento del edificio. Un buen ejemplo de estas observaciones se encuentra al comparar el comportamiento de los edificlos de los dos bancos mos trados en la fig. 34. El edificlo del Banco de América se comportó muy bien, aunque sufrió al gunos daños estructurales y no estructurales, esto puede atribuirse a la simetria y uniformi dad en la distribución de masas y rigideces es tructurales en todo el edificio (fig. 35).

El sistema estructural, resultado de una combi nación de muros dúctiles acoplados a marcos $t i$ po tubo estructural, parece ser un excelente sistema para el diseño sismo-resistente, si se proporcionan varias líneas líneas de defensa (fig. 36), a través de las cuales el sistema en conjunto puede adaptarse a las demandas de diferentes tipos de movimientos sismicos severos del terreno. Para comprender en forma cuantitativa la contribución de cada elemento estructural a la resistencia de conjunto y a la rigidez del edificio, se investigó la respuesta elástica de varias idealizaciones estructurales. Estas idealizaciones se sometieron a (1) cargas laterales estáticas representativas de las esperadas durante un sismo real, y (2) a acelerogramas de movimientos sísmicos del terremoto. Para la zona de la torre del edificio se consideraron tantos los modelos bi dimensionales como tridimensionales, 
idealizados como se ilustra en la fig. 36. Los niveles correspondientes al sótano se incluyeron en estas idealizaciones como si fueran resortes rotacionales y de translación en la base, necesarios para considerar la flexibilidad del medio correspondiente a la cimentación.

Los diversos modelos empleados en el anfilisis se obtuvieron eliminando secuencialmente del sistema estructural en conjunto, los subsistemas que a través de anălisis elásticos, estimaciones de capacidad de resistencia y daños observa dos, podian haber sufrido daños importantes en su resistencia y/o rigidez. Se evaluaron las caracteristicas dinámicas de estos sistemas (ver tabla 5) y se calcularon sus respuestas bajo cargas estáticas y dinámicas.

Los resultados indicaron que las deformaciones de la cimentación tuvieron poco efecto en la respuesta sismica del edificio. Por lo tanto, en adelante sólo se tratarán casos con condiciones de apoyos fijos en la base.

De un análisis tridimensional de la torre se en contró que el quinto modo era predominantemente torsional. A pesar de esto, debido a la simetría del sistema estructural los modos de trans lación eran virtualmente desacoplados.

Como puede verse en la tabla 5, la falla de diferentes elementos estructurales habria tenido un efecto importante sobre las caracteristicas dinámicas del edificio, o sea: (1) incremento del periodo fundamental de menos de 1.0 segundo a $1.35 \mathrm{seg}$. si todas las columnas perimetrales se supusieran no efectivas; (2) un incremento similar si se eliminaran las trabes de acoplamiento de la idealización estructural; (3) un incremento del periodo fundamental hasta 3.3 seg. si se despreciaran tanto las columnas peri metrales, como las trabes de acoplamiento; y (4) un aumento del período hasta $2.4 \mathrm{seg} . \mathrm{si}$ las trabes de acoplamiento y sólo las columnas perimetrales localizadas en el marco de periferia fueran suprimidas (fig. 36). A partir de los resultados de estos análisis elásticos, la inspección de daños y los perfodos medidos en campo despues del terremoto, la condición final del edificio parecia estar cerca a la correspon diente al sistema estructural descrito en (4), con alguna reducción adicional en rigidez, provocada por la deteriorización de la conexión losa-columna perimetral en la estructura del mu ro de rigidez del núcleo (fig. 36).

Se hicieron los análisis elästicos de la respuesta en el tiempo de estas diferentes idealizaciones estructurales, que incluian el caso de movimientos biaxiales del terreno. Los limi tes de la respuesta real pueden ser estimados directamente usando el espectro de respuesta elástico mostrado en la fig. 37.

De acuerdo con el periodo correspondiente al estado inicial de la estructura $T \doteq 1$ seg., y suponiendo un comportamiento absolutamente elástico, las máximas fuerzas de inercia y desplazamientos que se habrian desarrollado corresponden a una seudo-aceleración espectral (Sa) de $0.34 \mathrm{~g}$ y un desplazamiento espectral (Sd) de 3.35 pulg. $(85 \mathrm{~mm})$. Sin embargo, estos valores no podrían haberse desarrollado, debido a que la capacidad en resistencia y ductilidad de muchos elementos estructurales se habrían excedido, provocando un serio deterioro en su contribución y un correspondiente aumento en el período del edificio. La resistencia elásti ca máxima probable de los muros del núcleo fue controlada por su capacidad a agrietamiento por cortante, que se habría alcanzado para un valor estimado de $\mathrm{Sa}=0.10 \mathrm{~g}$ para el sistema estructural elástico inicial. Para este valor de Sa, no obstante, la mayoria de las trabes de acopla mlento habrian fallado, incrementando el perfodo fundamental a un valor de $T=1.35 \mathrm{seg}$. , e incrementando significativamente las fuerzas so bre los marcos de la periferia. Bajo estas circunstancias, las conexiones entre las columnas perimetrales y la losa se habrlan tambien 
empezado a deteriorar (a fuerzas de inercia correspondientes a $S a=0.15 \mathrm{~g})$. Si la rigidez y capacidad de transmisión de momentos de estas conexiones hubieran desaparecido completamente, el perifodo hubiera aumentado a $T=2.4 \mathrm{seg}$. (tabla 5). Una estructura con es te periodo bajo el. movimiento del terreno ESSO, aun si se considera efectos de los modos superiores, no habria desarrollado fuerzas de inercia significativamente superiores a las co rrespondientes a $\mathrm{Sa}=0.14 \mathrm{~g}$, con un desplazamiento maximo de $S a=8.26 \mathrm{pulg}$. $(210 \mathrm{~mm})$. Por tanto, deioido a la falla de varios fusibles es tructurales, construrdos en el sistema estructural, fue posible una considerable disminución en las fuerzas efectivas de inercia, sin que el edificio alcanzara excesivas deformacio nes.

La torre de 15 pisos del edificio del Banco Central sufrio considerables daños estructurales y no estructurales, a pesar de que se dise no para cargas laterales muy por encima de los requerimientos de cualquier reglamento de los Estado Unidos en el tiempo de su diseño en 1961. El daño puede atributrse principalmente a la flexibilidad del sistema estructural. La acción de marco proporcionó la mayor parte de la resistencia lateral. Debido a la gran flexibilidad del sistema de piso, se tuvieron movimientos laterales relativamente grandes en los pisos, asf como movimientos verticales de los mismos. Los muros de concreto reforzado mas rigidos, de los cubos de elevadores, intro dujeron junto con el muro de relleno de mampos terfa del lado oeste (fig. 34), una excentrici dad por torsión extremadamente grande en el edificio, que contribuy $\delta$ a los daños observados. También deberla notarse que hay una discontinuidad del sistema estructural al nivel del cuarto piso donde las columnas menos separadas, terminaban en las trabes de transferencia, las que estaban apoyadas en sólo 10 colum nas. Siempre que sea posible, deberán evitarse las formas irregulares como las de este edificio.

Mientras que el terremoto dejo fuera de operación los elevadores del edificio del Banco de América, las escaleras permanecieron intactas. En el edificio del Banco Central, en contraste, no sólo quedaron inservibles los elevadores, sino que los derrumbes se acumularon de tal manera en el cubo de escaleras que se hizo dificil el tránsito por ellas y podría haber consti tuido un serio riesgo para la seguridad de la gente si hubiera estado ocupado en el momento del terremoto.

Comportamiento de la "Escuela de Niñeras" durante el terremoto de 1976 en Guatemala (39)

La "Escuela de Niñeras" es un edificio relativa mente moderno, construído en 1964, de tres nive les con un sotano parcial (fig. 38). Construrdo como una combinación de mamposterfa y concreto reforzado; durante el terremoto de 1976 sufrió daño estructural de importancia en las columnas del primer piso y muchos daños en las ventanas, puertas y muros de mampostería y canceles. El edificio es de planta rectangular, de $27.50 \mathrm{~m}$. $\times 11.50 \mathrm{~m}$., y el sistema estructural consiste de marcos rígidos espaciales con siete marcos transversales $y$ dos longitudinales (figs. 38 y 39). Los dos pisos superiores y azotea están volados sobre la planta baja, $2.50 \mathrm{~m}$ al sur y norte y $1.20 \mathrm{~m}$. al este $y$ oeste (fig. 40). Todos los volados cargaban muros pesados de mampostería, y adicionalmente, los volados del lado sur cargaban canceles de concreto reforzado. Las crujías de los marcos estaban Ilenas con un gran nưmero de muros de mam posterla, muchos sin llegar hasta arriba, y que tentan una distribución irregular tanto en plan ta como en elevación (figs. 40 y 41 ).

La mayor parte del daño a la construcción (fig. 41), fue en los elementos no estructurales, sobre todo en los muros de relleno. El 
daño a estos muros se caracterizó por grietas horizontales y diagonales, roturas y/o colapso total (explosion) (fig. 42). Estos muros se construyeron de tabique con refuerzo vertical en las esquinas y en ocasiones en el centro.

Los daños a los elementos estructurales se limi taron principalmente a las columnas del primer piso, sobre todo las de los marcos transversales 2 y 3 (fig. 43). Esto fue resultado de la resistencia presentada por los muros de relleno que dieron lugar a fallas de columna corta por cortante (fig.43). Aunque el mecanismo responsable del daño a los miembros (estructurales y no estructurales) fue evidente, el mecanismo de la respuesta global que provocó el tipo de daño observado no fue claro en el sentido cualitativo y tampoco en el cuantitativo. Para aclarar es tas dudas se lievaron a cabo una serie de analisis dinámicos tridimensionales del edificio como conjunto.

Se desarrollaron cuatro idealizaciones de elementos finitos elásticos del edificio, para estudiar la influencia del relleno de mampostería sobre, primero, las caracteristicas dinámicas del edificio, y segundo, la respuesta sísmica para registros seleccionados del movimiento del suelo, incluyendo el registro disponible de 4 de febrero de 1976, del temblor de Guatemala. Las cuatro idealizaciones incluían una idealiza ción del marco sin muros, una incluyendo la rigidez proporcionada por las losas de piso y dos idealizaciones del marco más losas con la rigidez debida a los rellenos de mampostería; (una idealización empleaba relleno "suave" y la otra relleno "rigido"). La distribución de masas empleada para todas las idealizaciones fue identica y representaba la distribución real en contrada en el edificio.

Las columnas y vigas fueron idealizadas con base en elementos vigas tridimensionales, las losas como elementos placas, y los rellenos me- diante elementos con 12 grados de libertad, es pecialmente desarrollados para este estudio. La fig. 44 ilustra el modelo de elemento finito.

Las caracterfsticas dinámicas de cada uno de las cuatro idealizaciones fueron evaluadas a traves de un analisis del sistema sin amorti guamiento. En las figs. 45-48 se presentan los perlodos y croquis de las perpectivas de los primeros cuatro modos.Del analisis de las formas modales, los valores calculados para los factores de participación, y la res puesta sismica a diferentes movimientos del terreno, se vis con claridad la tremenda influencia de los muros de relleno. Los rellenos acoplaron los modos de vibración transla cionales más bajos, introduciendo respuestas torsionales mas grandes y trasladando estos modos fundamentalmente a un rango de periodos considerablemente más bajos, con el efec to destructivo de sintonizar al edificio con un rango de periodo dominante, propio del movimiento del terreno registrado en la ciudad de Guatemala.

En la fig. 49 se muestran las envolventes del desplazamiento de la azotea, obtenidas de la respuesta al movimiento del terreno registrado en Guatemala; estas envolventes muestran el efecto rigidizante de los muros de relleno así como su contribución a la respuesta torsio nal. Como consecuencia de estos efectos, la intensidad de las fuerzas en los miembros y su distribución en el edificio cambiaron significativamente. Las máximas solicitaciones en las columnas del primer piso aumentaron considerablemente mientras que las de los pisos superiores disminuyeron y los cortantes máximos de piso se repartieron irregularmente en cada nivel. Los esfuerzos cortantes en el relleno y las fuerzas en los miembros de la columna resultaron ser los más críticos en las áreas del primer piso de los marcos transversales 2 y 3 , que es donde se observo el daño más dramático. 
La evidencia combinada del análisis y los daños observados sugieren un mecanismo de falla en el que un tablero completamente relleno y sujeto a esfuerzos muy altos, sufre una falla parclal repentina y se convierte en un tablero de altura parcial que entonces provoca que las columnas adyacentes trabajen como columnas cor tas, el cortante considerablemente incrementado que se transmlte en esta columna corta, pue de llevar a su rotura. Los resultados obtenidos de la inspección de daños como de los estu dios analfticos indican que los rellenos pueden tener una influencia significativa en la respuesta sismica de marcos rigidos, y no deben ser ignorados al diseñar y construir este tipo de edificios.

Comportamiento de los sistemas viga pared-columna corta (ref 40, 41)

Un arreglo arquitectónico que ha sido comúnmen te empleado en Estados Unidos, Japón y otros países para escuelas, hospitales, edificios de mediana altura para oficinas y estacionamientos, es el que emplea vigas de borde de gran peralte y columnas cortas, como se ilustra en la fig. 50. El hecho de que los edificios que emplearon este sistema estructural sufrieran fuertes daños durante los temblores de Alaska en 1964, Tockachi-Oki en 1968 ( $f i g .51$ ), San Fernando en 1971 y Managua en 1972, indica lo poco deseable de este tipo de estructuración. Debido a que la altura libre de las columnas es corta, se desarrollan fuerzas cortantes altas en estos elementos, dando lugar generalmen te a fracturas de tipo muy frágil. Por ello es necesario, o abandonar este tipo de construcción, o, por lo menos, investigar medios prácticos para incrementar la ductilidad de las co lumnas cortas resultantes. Esta Gltima alterna tiva se está actualmente llevando a cabo en la Universidad de California en Berkeley (ref 41). Los resultados obtenidos a la fecha, demuestran que aun las columnas muy cortas de concre to reforzado, si están detalladas en forma apropiada, pueden responder de manera ductil. Se desarrollaron ductilidades relativas a la rotación mayores de 4 , y se obtuvieron localmente ro taciones plásticas promedio mayores de 0.02 rad., en una longitud de $152 \mathrm{~mm}$. ( $6 \mathrm{in}$ ) aan en lugares donde el esfuerzo cortante alcanzó valores cer canos a $10.5 \sqrt{f^{\prime} c}$ psi $\left(0.87 \sqrt{f^{\prime} c} \mathrm{MPa}\right)$. Esto indica que puede tenerse compatibilidad de un funcionamiento dúctil moderado con esfuerzos cor tantes altos. Sin embargo, debe recalcarse que el comportamiento dúctil que se observó fue limi tado y no lo suficientemente grande para garanti zar la supervivencia de este tipo de sistema estructural en caso de sacudimientos sismicos seve ros del terreno. Existe el peligro de que para este sistema "trabe-columna débil", la deformación inelástica se concentrará en las columnas de un sólo nivel resultando en demandas de rota ciones inelásticas imposibles de satisfacer, tal como se trató con anterioridad y se ilustró en la fig. 12 .

Comportamiento de estructuras con muros de rigidez $y$ marcos rigidos espaciales.

Como se hizo ver, aún hay dos escuelas filosóficas acerca de cuál sistema básico es el más eficiente para el diseño sismo-résistente: mar co rigido espacial (flexible) o muros de rigidez (rígido). Hasta 1967, la mayoría de los ingenieros de Estados Unidos estaban a favor de los marcos rigidos espaciales dúctiles. Es to fue y sigue siendo aún hoy, claramente reflejado en los códigos sísmicos de Estados Uni dos. El daño a algunos edificios de marcos con muros de rigidez, durante el terremoto de Alaska en 1964, volvió escépticos a los ingenieros respecto al empleo de este tipo de sistema estructural: una estructura de marcos con muros se destruyó y algunas más sufrieron daños estructurales considerables. Sin embargo, estudios detallados de los daños a estas estructuras con base en muros, revelaron que en todos los casos la falla se debió a uno o varios de los siguientes factores: (1) pobreza conceptual de diseño del edificio como 
conjunto, as $f$ como del sistema estructural, o sea, mala distribución de masas y/o muros en el edificio; (2) mal diseño y detallado; (3L mala calidad de los materiales; y (42 mala calldad en la mano de obra, sobre todo en las Juntas constructivas.

Como consecuencia del excelente comportamiento de estructuras de marcos con muros durante el sismo de 1967 en Caracas, Venezuela, y durante otros sismos severos que ocurrieron en la altima década, se ha incrementado considerablemente la aceptación y el uso de sistemas estructurales de concreto reforzado de marcos con muros (ref. 42). A pesar de este comportamiento exce lente, $y$ de un entendimiento avanzado del comportamiento de estructuras con base en muros, logrado a traves de la investigación desarrolla da en Estados Unidos, Japón y Nueva Zelanda (ref 13), el diseño de muros y sistemas estructurales de marcos con muros está todavia penali zado por los reglamentos sismicos de Estados Unidos, comparado con los requisitos para los marcos rigidos espaciales dúctiles. El principal argumento para exigir coeficientes de dise ño sismico más altos, es que los muros son rigidos y carecen de la adecuada ductilidad. Los experimentos realizados en Berkeley (ref 43) han demostrado que no es posible diseñar y cons truir muros de rigidez que tengan ductilidad de desplazamiento y de rotación muy grandes en su región critica (fig 52), aún cuando los esfuerzos cortantes nominales alcancen el valor de $15 \sqrt{f c}$ (psi) el cual excede al valor maximo de $10 \sqrt{f c}$ (psi) permitido por el reglamento. El empleo de estos muros acoplados con trabes muy dúctiles puede llevar al mejor sistema "columna fuerte-trabe debil", que viene a ser el requisi to básico para diseñar sistemas estructurales formados por marcos espaciales (fig. 53).

PREDICCION ANALITICA DEL COMPORTAMIENTO SISMICO OBSERVADO EN ESTRUCTURAS DE CONCRETO REFORZADO
Debido a la complejidad del comportamiento inelástico de cualquier edificio tridimensional real, cuando está sometida a un movimiento seve ro del terreno la predicción numerica debe rea lizarse con programas de computadora. En estu dios en Berkeley acerca del comportamiento sismico de los edificios, se pudo justificar el da ño dservado por medio de análisis hechos con programas de computadora disponibles; sin embar go, esto requirio de un esfuerzo considerable. No se tiene actualmente un programa capaz de prever con precisión el comportamiento sismico inelastico tridimensional de un edificio real. Aun si fuera desarrollado tal programa de compu tación, es de dudarse que se pudiera usar en predicciones confiables del comportamiento histerético tridimensional de estructuras, debido a la falta de información de dicho comportamien to cuando se tienen deformaciones tridimensiona les. Existe una necesidad urgente de integrar los estudios analiticos y experimentales de tal comportamiento.

El análisis inelástico de los modelos de edificios pseudo-tridimensionales se puede hacer mediante el programa DRAIN-TABS (44). Se pueden usar algunos programas de tipo general para rea lizar el análisis tridimensional, de modelos no lineales con integración directa en el tiempo. Dentro de ellos están los programas NONSAP, ANSR-1, ADINA, Y NASTRAN que por lo general son convenientes de usar $(45,46)$. Son más convenientes los programas especiales como DRAIN-TABS, pero por otro lado requieren cierta especialidad y son costosos en aplicaciones prácticas grandes. Como consecuencia se han hecho pocos analisis tridimensionales de edificios reales. En la mayorla, estos programas no consideran el efecto de los elementos no estructurales; esto no es de sorprender, ya que se han formulado po cas, si no es que ninguna, idealizaciones realis tas (modelos matemáticos) del comportamiento no lineal de los elementos no estructurales comunes. 
La mayor parte de las predicciones acerca de la resistencia y capacidad de deformación de los edificios se basa actualmente en análisis inelásticos bidimensionales efectuados con idealizaciones de marcos planos y/o mu ros de cortante. Estas idealizaciones se pueden usar para idealizar exclusivamente edificios regulares con excentricidad por torsion despreciable o nula. Todos los marcos y muros de cortante en una dirección se tratan como sistemas en un plano ligados en cada nivel mediante uniones rigidas que representan el diafragma de piso. Por lo tanto estas idealizaciones suponen que los diafragmas de piso son rigidos esencialmente. Para idealizaciones de estructuras planas o muros de cortante, los diafragmas semirigidos de piso no pueden representarse de manera adecuada. Unicamente los diafragmas de piso que sean muy flexibles en relación al marco o muro de cortante se pue den idealizar desacoplando cada plano de mar$\cos 0$ muros y con soluciones independientes. La principal desventaja de este modelo es que desprecia el efecto de torsión; aún un edificio sin excentricidad entre masa y resistencia dentro del rango elástico podría tener torsión debido a la deformación inelástica inicial de una o más zonas construldas débilmente. Existe una necesidad urgente de estudiar el efecto de estas torsiones inelásticas sobre la resistencia y capacidad de deformación global de un edificio.

A pesar de estas desventajas, se han empleado las idealizaciones de marco bidimensional y el muro de cortante para aclarar algunos problemas en la predicción, la resistencia y capacidad de deformación de los edificios $(33,35$, 38).

El método más deseable y practico para evaluar el comportamiento sismico, deberla combinar la sencillez de ejecución con niveles aceptables de confiabilidad. No es de sorprender que en la práctica la predicción de la respuesta sísmica se basa en análisis de respuesta lineal. Se pueden usar interpretaciones apropiadas de los resultados de tales analisis para identifi car deficiencias $y$, tal vez, llegar a estimaciones aceptables de la resistencia de los edi ficios, particularmente los del tipo relativamente frágil, o aquéllos en que las deformaclones inelásticas se desarrollen simultáneamente en un número de zonas suficiente para convertir la estructura en un mecanismo con el suficiente endurecimiento por deformación como para compensar el efecto $P-\Delta$. No obstante, ta les tipos de comportamiento son la excepción $y$ no la regla en los edificios reales.

Si \& comparan los resultados obtenidos para el comportamiento de las estructuras como conjunto y sus subsistemas, por un lado a partir de experimentos de laboratorio y de campo, y por otro a partir de análisis en que se emplean mé todos elasticos lineales, esto oltimo por 10 general conduce a predicciones muy conservadoras de la resistencia. Los métodos elásticos lineales, siempre que no se trate de estructuras de tipo frágil, no son útiles cuando se de sea información adecuada para predecir la capa cidad de deformación. Los estudios realizados en las refs. $31,33,38$, prueban que la historia de las respuestas de desplazamientos no li neales calculados puede ser sustancialmente distinta de las predicciones elásticas. Debido a que los métodos elásticos lineales son re lativamente simples y no son costosos, se debe estudiar la correlación entre la respuesta elástica calculada y la inelástica real de estructuras de tipo normal. Se deberán formular los lineamientos para la interpretación de los resultados del análisis elástico para tener una idea de la resistencia real y la capacidad de deformación de tales estructuras. 
NECESIDADES DE EDUCACION, DE INVESTIGACION Y DE DESARROLLO

En este articulo se ha revisado el comportamiento observado de los edificios de concreto reforzado, durante sismos destructivos recientes, sus causas, y las dificultades para prede cir tal comportamiento. Es de esperarse realmente que esta revisión haya creado una mayor precaución respecto a una de las principales razones de la mayorla de los comportamientos mediocres que se observaron: la dificultad para predecir las caracteristicas dinámicas reales de (1) los movimientos del terreno bajo sismos; y (2) la estructura en el momento del sismo. Con objeto de disminuir los efectos destructivos de los temblores, es necesario no solamente mejorar el diseño, construcción y man tenimiento de las estructuras por hacer, sino además hay que desarrollar mejores metodos para reacondicionar las estructuras existentes. Estas mejoras se pueden llevar a cabo solamente a traves de esfuerzos integrando el aspecto educativo, la investigación y el desarrollo. Algunos de estos esfuerzos requeridos se resumen a continuación. En la ref. 13 se puede ver un estudio más detallado.

Necesidades de educación

Nuestros conocimientos han tenido importantes avances en las áltimas dos décadas, a pesar de muchos problemas sin resolver en la predicción del comportamiento de los edificios bajo los efectos combinados de las solicitaciones usuales y los movimientos del terreno por sismos de extrema intensidad. Se tiene un importante cúmulo de conocimientos respecto a los problemas causados por movimientos sismicos extremos. sin embargo, al comparar el estado del arte con el estado de la práctica se nota que tales conocimientos no se han incorporado a la práctica. Por ello es crucial impartir este conocimiento a los estudiantes de Ingenierra Es- tructural dentro de su programa de estudios un $\underline{i}$ verstarios y en escuelas profesionales, as $r$ co mo a los profesionistas en cursos de actualización que se pueden ofrecer en programas de educación continua. Dentro de los tópicos que deberlan ser incluidos tenemos:

1. orígenes y mecanismos de los temblores de gran intensidad. Debe incluirse el metodo apro piado para medir que tan intensas son las excitaciones provocadas por tales temblores.

2. comportamiento mecánico real de los suelos y materiales de construcción bajo condiciones impuestas por la combinación de excitaciones indu cidas por solicitaciones normales y temblores muy fuertes

3. comportamiento mecánico tridimensional de los sistemas reales suelo-estructura llevados al colapso por cargas o deformaciones produci das por la acción combinada de solicitaciones normales y sacudimientos por temblores severos. Se incluye el daño acumulado durante la vida de servicio de los edificios debido a la variación de cargas y solicitaciones. El conocer el daño acumulado permitira al diseñador determinar las condiciones del edificio (por ejemplo, los esfuerzos residuales, agrietamiento y deterioro de la resistencia y rigidez por la edad y la corrosión) en el momento que se presente un temblor fuerte.

4. los procedimientos y criterios para establecer las capacidades de resistencia y deformación de edificios existentes. Esto requerirra tener conocimiento del comportamiento histerético completo del edificio.

5. uso de cálculos probabilísticos y estadisticos para desarrollar métodos válidos para el di seño sismo-resistente de edificios.

6. aspectos socioeconómicos de los riesgos provocados por terremotos severos.

Neces idades de investigación y desarrollo

Las necesidades de investigación están 
relacionadas con las educativas ya que a través de la investigación se incrementa el conocimiento. Sin embargo, como hace ver Holley (ref 47), no es suficiente la pura investigación. Los estudios analfticos y experimentales deben incrementarse con el trabajo de desa rrollo. Dentro de las diferentes necesidades de investigación y desarrollo, debe insistirse an las sigulentes:

1. desarrollar metodos más precisos para prede cir las caracteristicas de los posibles sismos fuertes que puedan ocurrir en cualquier zona de construcción.

2. supervisar en forma racional estudios anal! ticos integrados con experimentos acerca del comportamiento mecánico de los materiales simples y compuestos, empleados en la construcción del sistema suelo-estructura (tanto elementos estructurales como no estructurales), bajo cargas $y / 0$ deformaciones provocadas por sismos severos.

3. realizar investigaciones de materiales nuevos que puedan influir en el comportamiento de los edificios bajo sismos extremos.

4. desarrollar métodos mas exactos para probar los materlales en el campo en forma no destruc tiva.

5. desarrollar procedimientos más confiables para determinar las capacidades de resistencia $y$ deformación de los sistemas suelo-estructura bajo condiciones de carga o deformación que pu dieran ser impuestas por los efectos combinados de las solicitaciones usuales con los sismos severos. Se requileren estudios integrales de campo, laboratorio y analfticos, y desarrollar (a) nuevas tócnicas para probar nuevos edificios llevandolos a la falla; y (b) programas de computadora para analisis no lineal tridimensional para predecir el colapso progesivo de los edificios.
CONCLUSIONES

Se ha hecho un intento para crear un mejor conocimiento de las incertidumbres y dificultades involucradas para lograr una construcción de concreto sismo-resistente eficiente, revisando: (1) los diferentes aspectos involucrados en el diseño, construcción y mantenimiento de los edificios; (2) el comportamiento de edi ficios existentes durante sismos recientes;

(3) las dificultades para predecir tal comportamiento.

La construcción sismo-resistente eficiente requiere integrar el conocimiento de muchas disciplinas distintas: Sismología, Geologra, Geofisica e Ingenierfa sismica. Se requiere una colaboración estrecha entre los investigadores, profesionales, fabricantes y empleados del gobierno. Se espera realmente que la discusión general aqui expuesta haya dejado en claro la necesidad de integrar el conocimiento con la cooperación de los esfuerzos, para disminuir los efectos destructivos de los sismos.

\section{RECONOCIMIENTOS}

Se expresa el reconocimiento a la National Science Foundation por su apoyo financiero para algunos de los estudios mencionados en este trabajo. Aprecio grandemente la colaboración de J. Axley en la preparación de este articulo. El autor también quisiera reconocer la ayuda de M. C. Randall, D. Parodi y C. Jones en la preparación de este articulo.

\section{REFERENCIAS}

1. Bresier, B., "Behavior of Structural Elements, a Review," Building Practices for Disaster Mitigation, National Bureau of Stan dards Building Science Series 46, Washington, D.C., 1973. 
2. Sawyer, H, A., Jr., "Comprehensive Design of Reinforced Concrete Frames by Plasticity Factors." 9th Planning Session of CED Sympo sium,: Hyperstatique, Ankara, Septiembre, 1964.

3. Bertero, V. V., y Bresler, B., "Design and Engineering Decisions: Failure Criteria (Limit States)," Proceedings of 6th WCEE, New Delhi, India, Enero, 1977.

4. Seismology Committee, Structural Engineer Association of California, Recommended Lateral force Requirements and Commentary," cuarta edición, San Francisco, 1975.

5. Bresler, B., y Bertero, V. V., "Olive View Medical Center Material Studies, Phase 1," Report No. EERC 73-19, Earthquake Engineering Research Center, Universidad de California, Berkeley, 1973.

6. Bertero, V. V., "State-of-the-Art in Establishing Design Earthquakes," Proceedings of a Workshop on Earthquake-Res istant Reinforced Concrete Building Construction, Vol. 11. pp. 315-345, Berkeley, 1977.

7. Bertero, V. V., Mahin, S. A., y Herrera, R. A., "Problems in Prescribing Reliable Design Earthquakes," Proceedings of the 6th WCEE, Vol. 11, New Delhi, India, Enero, 1977.

8. Bertero, V. V., Herrera, R. A., y Mahin, S.A., "Establishment of Design EarthquakesEvaluation of Present Methods." Proceedings of the Int'l Symposium on Earthquake Engineering, St. Louis, Agosto, 1976.

9. Bertero, V.V., "Strength and Deformation Capacities of Buildings under Extreme Environments," Symposium sobre Ingenierla Estructural y Mecánica Estructural, en honor del Profesor E. Popov, Berkeley, 1977 (sera publicado por Prentice Halll

10. Drenik, R. F., Wang, P. C., y Wang., W., "Case Study of Critical Excitation and Response Structures," Report No. POLY EE[EP-75D1D. Polytechnic Institute of New York, Noviembre, 1975.
11. AIA Research Corporation, "Architects and Earthquakes," Informe preparado para Natio nal Sclence Foundation, Washington, D.C., octubre, 1975.

12. Dowrlck, D. J., Earthquake Res istant Desing. A. Manual for Engineers and Architects, John Wiley $\varepsilon$ Sons, 1977.

13. Bertero, V. V., organizador, Proceedings of a Workshop on Earthquake-Res istant Reinforced Concrete Building Construction, en tres volúmenes, Berkeley, 1977.

14. Pari, R., "Ductility of Reinforced Concrete Frames under Seismic Loading," New Zealand Engineering, Vol. 23, No. 11, pp. 429-435, Noviembre, 1968.

15. Bertero, V. V., Mahin, S. A., y Hollings, J., "Response of a Reinforced Concrete Shear Wall Structure During the 1972 Managua Earthquake," Bulletin of N. Z. National Society for Earthquake Engineering, Vol. 7, No. 3, Septiembre, 1974.

16. Paulay, T., "Design Aspects of Shear Walls for Seismic Areas," Research Report 74-1.1, Dept. de Ingenierra Civil, Univ. de Canter bury, Chrischurch, Nueva Zelanda, Octubre, 1974.

17. Mahin, S. A. y Bertero, V.V., "Nonlinear Seismic Response of a Coupled Wall System," Journal of the Structural Div., ASCE, Vol. 102, ST9, PP. 1759-1780, Septiembre, 1976.

18. Fintel, M. y Ghosh, S. K., "Structural Sys tems for Earthquake Resistant Reinforced Concrete Buildings," Proceedings of a Workshop on Earthquake-Resistant Re inforced Concrete Bullding Construction, Vol. 11, Pp. 707-741, Berkeley, 1977.

19. Bertero, V. V. y Popov, E. P., ISeismic Behavior of Ductile Moment-Resisting Reinforced Concrete Frames," Reinforced Concrete structures In Selsmic Zones, Publication SP-53, American Concrete Institute, Detrolt, 1977. 
20. Popov, E. P., Bertero, V. V., Galunic, B., $y$ Lantoff, G., "On Seismic Design of $R / C$ Interior Joints of Frames," Proceedings of 6th WCEE, Vol. 11, PP. 5.191-5.196, New Delht, India, Enero, 1977.

21. Galunic, B., Bertero, V. V., y Popov, E. P., "An Approach for Improving Seismic-Resistant Behavior of Reinforced Concrete In terior Joints," Report No. UCB/EERC-77/30, Earthquake Engineering Research Center, Universidad de California, Berkeley, 1977.

22. Mahin, S., Bertero, V. V., Rea, D., y Atalay, M., 'Rate of Loading Effects on Uncracked and Repaired Reinforced Concrete. Members," Report №. EERC-72/9, Earthquake Engineering Research Center, Universidad de California, Berkeley, 1972.

23. Bresler, B. y Bertero, V. V., "Influence of High Strain Rate and Cyclic Loading on Behavior of Unconfined Concrete in Compression," Proceedings of the Second Canadian Conference on Earthquake Engineering, McMaster University, pp. 64, Hamilton, Ontario, Junio, 1975.

24. Vallenas, J., Bertero, V. V., y Popov, E. P., "Concrete Confined by Rectangular Hoops and Subjected to Axial Loads," Report No. UCB/EERC-77/13, Earthquake Engineering Research Center, Universidad de California, Berkeley, 1977.

25. Bertero, V. y Vallenas, J., "Confined Concrete: Research and Development Needs," Proceedings of a Workshop on Earthquake-Resistant Reinforced Concrete Building Construction, Vol. 11, pp.594-610, Berkeley, 1977:

26. Klingner, R. E. y Bertero, V. V., "Infilled Frames in Earthquake-Resistant Construction," Report No. EERC 76/32, Earthquake Engineering Research Center, Universidad de California, Berkeley, 1976.

27. ACl Committee 442, "Response of Buildings to Lateral Porce," ACl Joupnal Proceedings,
Vol. 68, No. 11, pp. 81-106, Febrero, 1971.

28. Roy, H. E. H., "Designing for Lateral

Load," Proceedings of the Structural Concrete sympos Ium, Pp. 146-175, Toronto, Canada.

29. Bouwkamp, J. G., "Dynamic Studies of a 16Story Office Building with Cable-Suspended Floors," Proceedings of the 6th WCEE, Vol. 111, pp. 11-18, Dubrovnik, Yugoslavia, Sep tiembre, 1978.

30. Bercero, V. V., "Identification of Research Needs for Improving Aseismic Design of Euilding Structures," Report No. EERC 75-27, Earthquake Engineering Research Center, Uni versidad de California, Berkeley, 1975.

31. Zagajeski, S. W. y Bertero, V. V., "Computer-Aided Optimum Design of Ductile Reinforced Concrete Moment-Resisting Frames," Report №. UCB/EERC-77/16, Earthquake Engineering Research Center, Universidad de California, Berkeley, 1977.

32. Bertero, V. V., et.al., "Design Implication of Damage Observed in the Olive View Medical Center Buildings," Proceedings of the 5th WCEE, Vol. I, PP. 51-59, Roma, Junio, 1973.

33. Mahin, S. A. y Bertero, V. V., "An Evaluation of Some Methods for Predicting Seismic Behavior of Reinforced Concrete Buildings," Report №. EERC 75-5, Earthquake Engineering Research Center, Universidad de California, Berkeley, 1975.

34. Mahin, S. A. y Bertero, V. V., 'Problems in Establishing and Predicting Ductility in Aseismic Design," Proceedings, International Sympos lum on Earthquake Structural Engineering, Pp. 613-628, Universidad de Missouri, Rolla, Missouri, Agosto, 1976.

35. Subcommittee of the SEAONC Research Committee, "Seismic Analysis of the Charaima Building, Caraballeda, Venezuela, " Report No. EERC 70-4, Earthquake Engineering Research Center, Universidad de California, 
Berkeley. 1970.

36. Bertero, V. V. y Collins, R. G., "Investigation of the failures of the 01 ive View Stalrtowers during the San Fernando Earthquake and their Impilcations in Seismic Design," Report No. EERC 73-26, Earthquake Engineering Research Center, Universidad de Callfornia, Berkeley, 1973.

37. Chopra, A. K., Bertero, V. V. Y Mahin; S. A., "Response of the Olive View Medical Center Main Building during the San Fernan do Earthquake," Proceedings, 5th WCEE, Paper No. 5, Roma, 1973.

38. Mahin, S. A., Bertero, V. V., Chopra, A. K., y Collins, R. G., "Response of the Ollve View Hospital Main Building during the San Fernando Earthquake," Report No. EERC 76-22, Earthquake Engineering Research Center, Universidad de California, Berkeley, 1976.

39. Axley, J., "Infill Panels: Their Influence on Seismic Response of Buildings," Ph.D. Dissertation, Civil Engineering Dept., Uni versidad de California, Berkeley (en prepa ración).

40. Aoyama, H., et al, "A study of Damage to the Hachinohe Technical College Due to 1968 Tokachi-Oki Earthquake (Part 1)," Proceedings of the U.S. Japan Seminar on Earthquake Engineering with Empahs is on the Safety of School Buildings, Pp. 199-213, Sendal, Japón, Septiembre, 1970.

41. Zagajeski, S. W., Bertero, V. V. y Popov, E. P., 'Hysteretic Behavior of Reinforced Concrete Columns Subjected to High Axial and Cyclic shear forces," Report No. UCB/ EERC-78/05, Earthquake Engineering Research Center, Universidad de California, Berke ley, 1978.

42. Finte1, M., "Ductile Shear Walls in Earthquake-Resistant Multistory Buildings," ACl Publication SP-53, PP. 117-126, 1977.
43. Bertero, V. V., Popov, E. P., Wang, T. Y., y Vallenas, J., "Seismic Design Implications of Hysteretic Behavior of Reinforced Concrete Structural Walls," Proceedings of the 6th WCEE, PP. 5.159-5.165, New Delhi, India, Enero, 1977.

44. Guendelman, I. R. Y Powell, G. H., "DRAINTABS, A Computer Program for Inelastic Earthquake Response for Three-Dimensional Buildings Systems," Report No. EERC 77-08, Earthquake Engineering Research Center: Universidad de California, Berkeley, 1977.

45. Powel, G. H., "Computer Programs for Analysis of Seismic Response of Reinforced Concrete Buildings," Proceedings of the Workshop on Earthquake-Res istant Re inforced Concrete Building Construction, Vol. II, pp. 969-980, Berkeley, Julio, 1977.

46. Gates, W., "The Art of Modeling Buildings for Dynamic Seismic Analysis," Proceedings of the Workshop on Earthquake-Resistant Reinforced Concrete Building Construction, Vol. 11, pp. 857-885, Berkeley, Julio, 1977.

47. Holley, M. J., 'Not Research Alone, but Re search and Development," Proceedings, Workshop on Simulation of Earthquake Effects on Structures, National Academy of Engineering, Washington, D. C., San Francisco, Septiembre, 1973. 
TABLA 1 RESUMEN DE LA EVALUACION ESTADISTICA DE DATOS DE ENSAYES (EN FABRICA) DE ACERO DE REFUERZO

\begin{tabular}{|c|c|c|c|c|c|}
\hline .. & $\begin{array}{c}\text { Valor } \\
\text { promedio } \\
\bar{x}\end{array}$ & $\begin{array}{l}\text { Desviación } \\
\text { estandar }\end{array}$ & $\begin{array}{c}\text { Especificación } \\
\text { ASTM miñịa } \\
x_{\min }\end{array}$ & $\begin{array}{c}\text { Relación } \\
\text { de exceso } \\
t_{1}\end{array}$ & $\begin{array}{l}\% \text { por debajo del } \\
\text { minimo especifi- } \\
\text { cado (estimado) }\end{array}$ \\
\hline Grado A-15 & & & & & \\
\hline $\begin{array}{l}\text { Esfuerzo de fluen } \\
\text { cia, ksi }\end{array}$ & 52.7 & 3.2 & 40 & 3.97 & $<0.5$ \\
\hline $\begin{array}{l}\text { Resistencia en } \\
\text { tensión, ksi }\end{array}$ & 80.1 & 4.5 & 60 & 4.5 & 0.75 \\
\hline $\begin{array}{l}\text { \% Alargamiento } \\
\text { Grado } A-432\end{array}$ & 19.4 & 3.3 & Varios & 1.8 a 3.8 & $2.5 a<0.5$ \\
\hline $\begin{array}{l}\text { Esfuerzo de fluen } \\
\text { cia, ksi }\end{array}$ & 71.1 & 6.7 & 60 & 1.7 & 4 \\
\hline $\begin{array}{l}\text { Resistencia en } \\
\text { tensión, ksi }\end{array}$ & 112.5 & 8.8 & 90 & 2.6 & 0.5 \\
\hline$\%$ Alargamiento & 12.4 & 2.8 & Varios & 0.9 a 6.4 & $19 a<0.75$ \\
\hline
\end{tabular}

(1) $t_{j}=\left(\bar{x}-x_{\min }\right) / \sigma$

TABLA 2 COMPARACION DE VALORES OBSERVADOS Y CALCULADOS DEL MODULO DE ELASTICIDAD PARA CONCRETO EN COMPRESION

\begin{tabular}{|c|c|c|c|c|c|c|c|c|}
\hline \multirow{2}{*}{$\begin{array}{l}\text { Grupo } \\
\text { Espécimen }\end{array}$} & \multirow{2}{*}{$\begin{array}{c}\text { Resistencia } \\
\text { Especificada } \\
\text { fi } \\
\text { psi }\end{array}$} & \multicolumn{3}{|c|}{ Observado-Valores Promedios } & \multicolumn{4}{|c|}{ Valores Calculados } \\
\hline & & $\begin{array}{c}\text { Resistencia } \\
\text { f c prom. } \\
\text { psi }\end{array}$ & $\begin{array}{c}\text { Peso } \\
\text { Unitario } \\
w \\
\text { pef }\end{array}$ & $\begin{array}{l}\text { Eobs } \\
\text { ksi }\end{array}$ & $\begin{array}{l}\mathrm{E}_{\mathrm{c}}(1) \\
\mathrm{ksi}\end{array}$ & $E_{\text {obs }} / E_{c}(1)$ & $\begin{array}{l}E_{c}(2) \\
k s i\end{array}$ & $E_{\text {obs }} / E_{c}$ (2) \\
\hline $\begin{array}{ll}\text { MTF } & 1 \\
\text { MTF } & 111 \\
\text { MTF } & 111 \\
\text { PDC } & \\
\text { ST } & \\
\text { AC } & \end{array}$ & $\begin{array}{l}5000 \\
5000 \\
3000 \\
3000 \\
5000 \\
3000\end{array}$ & $\begin{array}{l}6700 \\
9340 \\
5690 \\
4830 \\
7410 \\
4280\end{array}$ & $\begin{array}{l}144 \\
148 \\
147 \\
113 \\
146 \\
145\end{array}$ & $\begin{array}{l}3420 \\
3880 \\
3110 \\
2040 \\
3410 \\
2720\end{array}$ & $\begin{array}{l}4030 \\
4200 \\
4160 \\
2170 \\
4140 \\
3110\end{array}$ & $\begin{array}{l}0.85 \\
0.92 \\
0.75 \\
0.94 \\
0.82 \\
0.88\end{array}$ & $\begin{array}{l}4660 \\
5740 \\
4440 \\
2750 \\
5040 \\
3710\end{array}$ & $\begin{array}{l}0.73 \\
0.68 \\
0.70 \\
0.74 \\
0.67 \\
0.73\end{array}$ \\
\hline Promedio & & & & & & 0.86 & & 0.71 \\
\hline
\end{tabular}

(1) $E_{c}$ calculada con base en la resistencia especificada

(2) $E_{c}$ calculada con base en la resistencia observada 
TABLA 3 APLICABILIDAD DE MATERIALES ESTRUCTURALES A DIFERENTES TIPOS DE EDIFICIOS SISMO RESISTENTE (Ref 12)

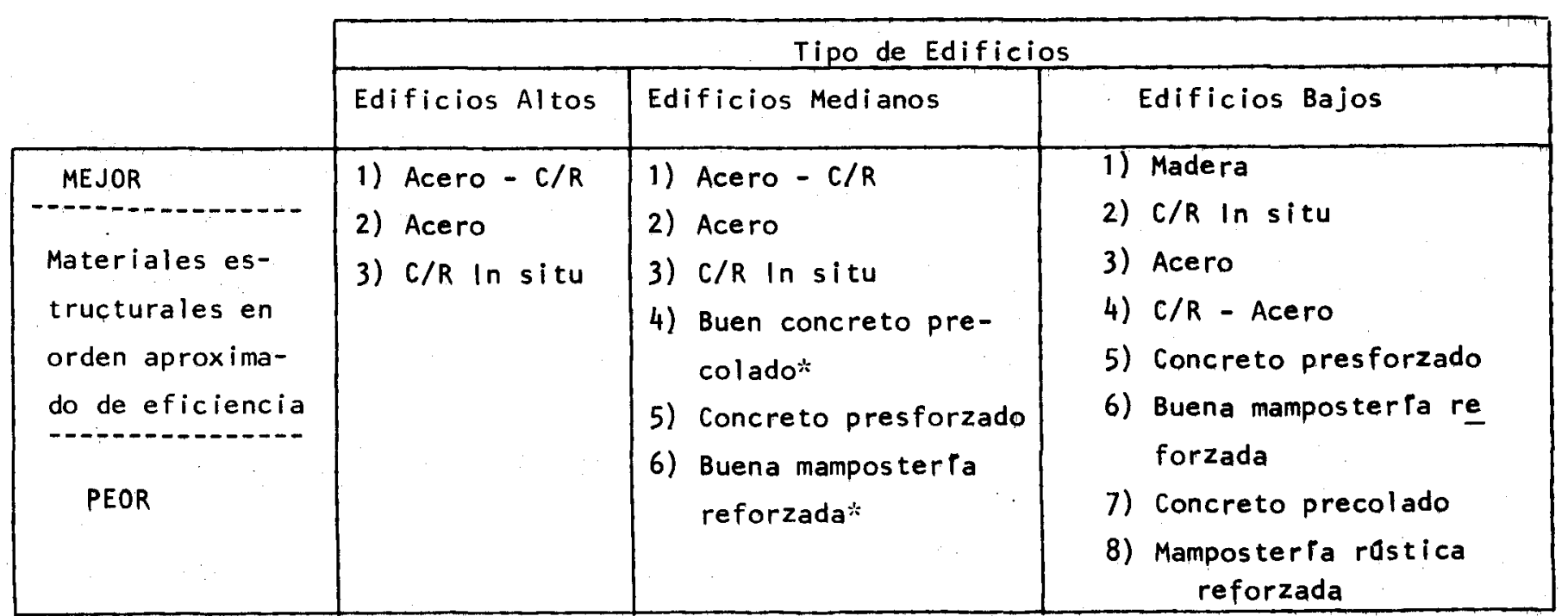

*Estos dos materiales apenas reunen los requisitos para incluirlos en el grupo de edificios altos. En realidad muchos diseñadores sismicos no usan ninguno de estos materiales. En el Japón la mamposterla no es permitida para edificios de más de tres niveles.

TABLA 4 EFECTO DEL CONFINAMIENTO EN LA RESISTENCIA A COMPRESION Y DEFORMACION DEL CONCRETO

\begin{tabular}{|c|c|c|c|c|c|}
\hline \multirow{3}{*}{$\begin{array}{l}\text { Tipo de } \\
\text { concreto }\end{array}$} & \multirow{3}{*}{$\begin{array}{l}\text { Relación de } \\
\text { esfuerzo de } \\
\text { confinamiento } \\
\left(f_{r} / f_{c}^{\prime}\right)\end{array}$} & \multicolumn{2}{|c|}{ Compresión Máxima } & \multicolumn{2}{|c|}{ Compresión última } \\
\hline & & $\begin{array}{c}\text { Relación de } \\
\text { deformaciones }\end{array}$ & $\begin{array}{l}\text { Efectividad del } \\
\text { confinamiento }\end{array}$ & $\begin{array}{l}\text { Relación de } \\
\text { deformaciones }\end{array}$ & $\begin{array}{l}\text { Efectividad del } \\
\text { confinamiento }\end{array}$ \\
\hline & & $\left(\varepsilon_{0}^{*} / \varepsilon_{0}\right)$ & $k_{0}$ & $\left(\varepsilon_{0}^{*} / \varepsilon_{0}\right)$ & $k_{u}$ \\
\hline Normal & 0.13 & 2.8 & 7.0 & 11.5 & 0 \\
\hline$E-5$ & 0.32 & 7.8 & 5.0 & 11.5 & 3.1 \\
\hline$\frac{\text { Concreto }}{\text { Iigero }}$ & 0.13 & 1.9 & 4.4 & 8.7 & -0.5 \\
\hline$R-5$ & 0.32 & 4.0 & 2.0 & 6.7 & 2.0 \\
\hline \multirow{2}{*}{$B-5$} & 0.13 & 1.35 & 3.9 & 10.6 & 0 \\
\hline & 0.32 & 1.85 & 1.0 & 8.6 & 0.9 \\
\hline \multirow{2}{*}{$R-3$} & 0.11 & 1.8 & 2.7 & 8.9 & -1.0 \\
\hline & 0.24 & 5.9 & 2.5 & 8.9 & 2.0 \\
\hline \multirow{2}{*}{ B-3 } & 0.11 & 1.7 & 1.35 & 11.6 & 0 \\
\hline & 0.24 & 8.0 & 2.1 & 9.0 & 2.1 \\
\hline
\end{tabular}


TABLA 5 PERIODOS NATURALES PARA DIFERENTES IDEALIZACIONES ESTRUCTURALES DEL EDIFICIO DEL BANCO DE AMERICA.

\begin{tabular}{|c|c|c|c|c|c|c|c|c|c|}
\hline \multirow{4}{*}{ Modo } & \multicolumn{9}{|c|}{ Valor del periodo en segundos para } \\
\hline & \multicolumn{3}{|c|}{$\begin{array}{l}\text { Estructura completa con } \\
\text { cimentación }\end{array}$} & \multicolumn{4}{|c|}{$\begin{array}{l}\text { Modelo bidimensional. (cimentación rigida). } \\
\text { Movimiento E-0 despreciando la acción de }\end{array}$} & & \\
\hline & \multicolumn{2}{|c|}{ Rigida } & \multirow{2}{*}{$\frac{\text { Flexible }}{3 \text { DIM }}$} & \multirow{2}{*}{$\begin{array}{l}\text { Columnas } \\
\text { en caras. } \\
\text { Ny } \mathbf{S}\end{array}$} & \multirow{2}{*}{$\begin{array}{l}\text { Todas las } \\
\text { columnas } \\
\text { de la pe- } \\
\text { fería }\end{array}$} & \multirow{2}{*}{$\begin{array}{l}\text { VIgas de } \\
\text { acopla- } \\
\text { miento }\end{array}$} & \multirow{2}{*}{$\begin{array}{l}\text { Vigas de acopla } \\
\text { miento y todas } \\
\text { las columnas }\end{array}$} & \multirow{2}{*}{$\begin{array}{l}\text { Vigas de acopla } \\
\text { miento y colum= } \\
\text { nas en las caras } \\
\mathrm{N} \text { y } \mathrm{S}\end{array}$} & \multirow{2}{*}{$\begin{array}{l}\text { Vigas de acopla } \\
\text { miento y losa a } \\
\text { lo largo de las } \\
\text { caras N-S }\end{array}$} \\
\hline & 3 DIM & 2 DIM & & & & & & & \\
\hline 1 & 3.984 & 0.983 & 1.161 & 1.220 & 1.350 & 1.347 & 3.300 & 2.400 & 2.340 \\
\hline 2 & 0.256 & 0.252 & 0.269 & 0.277 & 0.285 & 0.364 & 0.582 & 0.484 & 0.474 \\
\hline 3 & 0.128 & 0.125 & 0.134 & 0.132 & 0.134 & 0.167 & 0.228 & 0.194 & 0.190 \\
\hline 4 & 0.083 & 0.031 & 0.086 & 0.085 & 0.085 & 0.097 & 0.126 & 0.107 & 0.105 \\
\hline 5 & 0.046 & 0.059 & 0.063 & 0.061 & 0.062 & 0.066 & 0.082 & 0.071 & 0.069 \\
\hline
\end{tabular}




\section{Frecuencia}

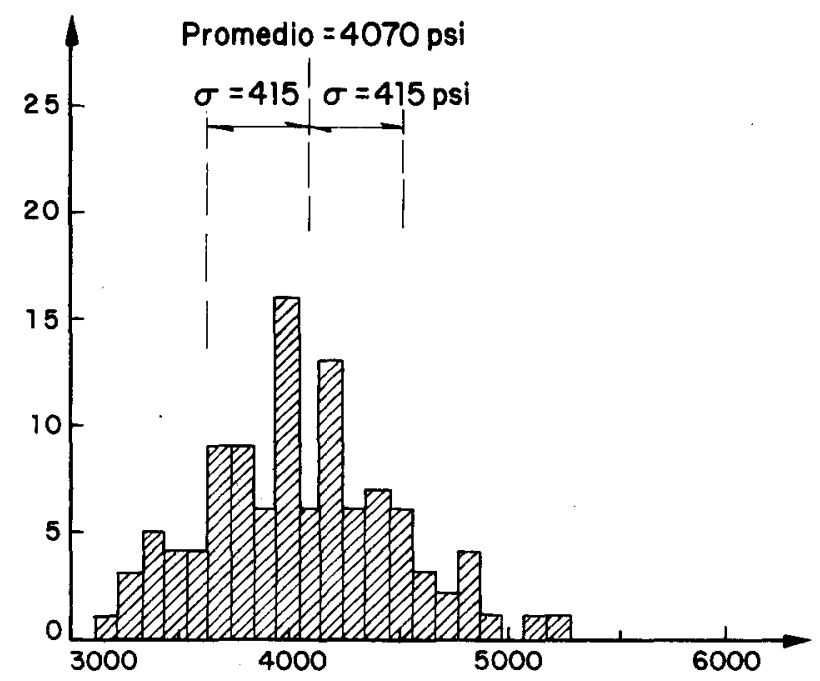

Resistencia en compresión, psi

Fig 1. Histograma de las resistencias en compresión del concreto. Edificio de Servicios principal. Pruebas de control de campo. Concreto de 3000 psi

Frecuencia

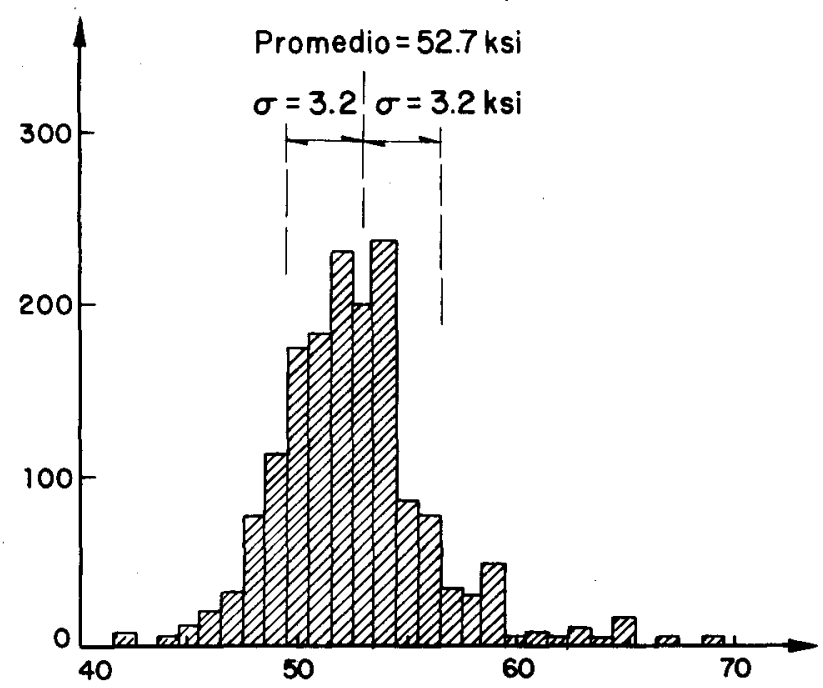

Esfuerzo de fluencia, ksi

Fig 3. Histograma de esfuerzos de fluencia de aceros de refuerzo grado A-15. Ensayes en fábrica

\section{Frecuencia}

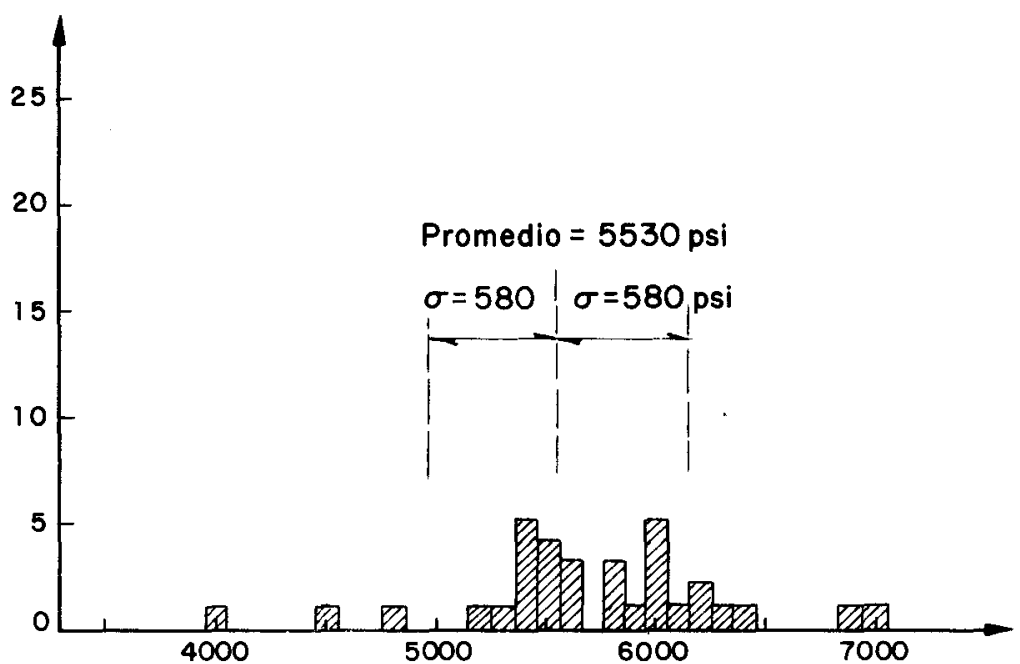

Resistencia en compresión , psi

Fig 2. Histograma de las resistencias en campresión del concreto. Edificio de Servicios principal. Pruebas de control de campo. Concreto de 5000 psi

Frecuencia

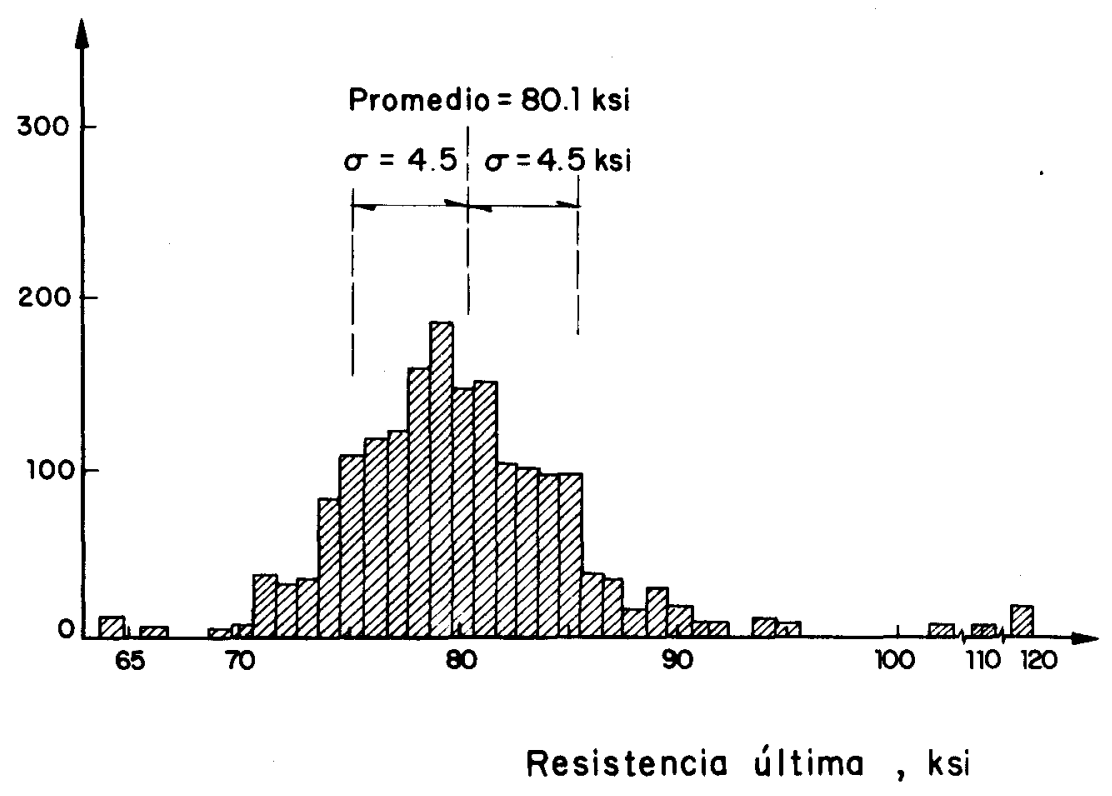

Fig 4. Histograma de resistencia en tension de acero de refuerzo grado A-15. Ensayes en fábrica

(N. del T. : $\left.1 \mathrm{psi}=0.07 \mathrm{~kg} / \mathrm{cm}^{2} ; 1 \mathrm{ksi}=70 \mathrm{~kg} / \mathrm{cm}^{2}\right)$ 

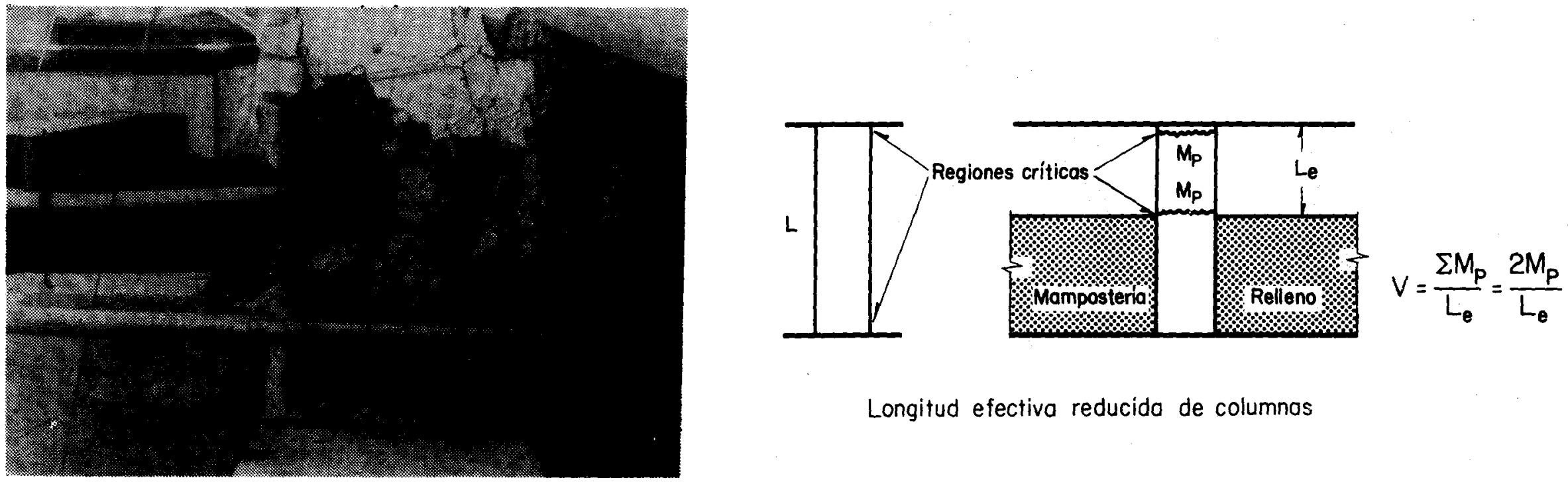

Longitud efectiva reducida de columnas
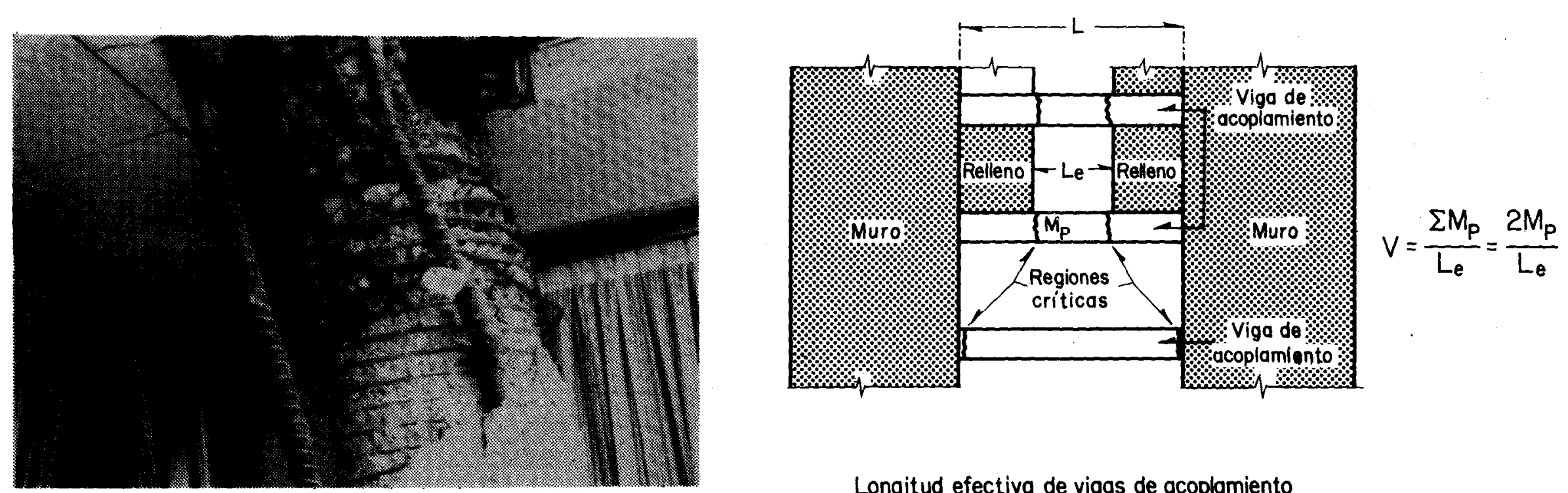

Longitud efectiva de vigas de acoplamiento reducida por muros de relleno

Fig 5. Falla de columna debida a que el esfuerzo en espiral termina debajo del paño inferior de la trabe que

Fig 6. Efectos de la adición de muros de relleno en el comportamiento de vigas $y$ columnas 
- ESTABLECIMIENTO DE LAS ACCIONES Y CRITERIOS DE DISEÑO

- REQUISITOS DE SEGURIOAD, SERVICIO Y MINIMIZACION DE DANOS

- plan estructural

- PREdicción del COMPCRTAMIENTO MECANICO DE LA ESTRUCTURA

1. Modoto estructural

2. Análisis estructural y de esfuerzos

3. Detallado y propor cionomiento
- analisis de CONFIABILIDAD
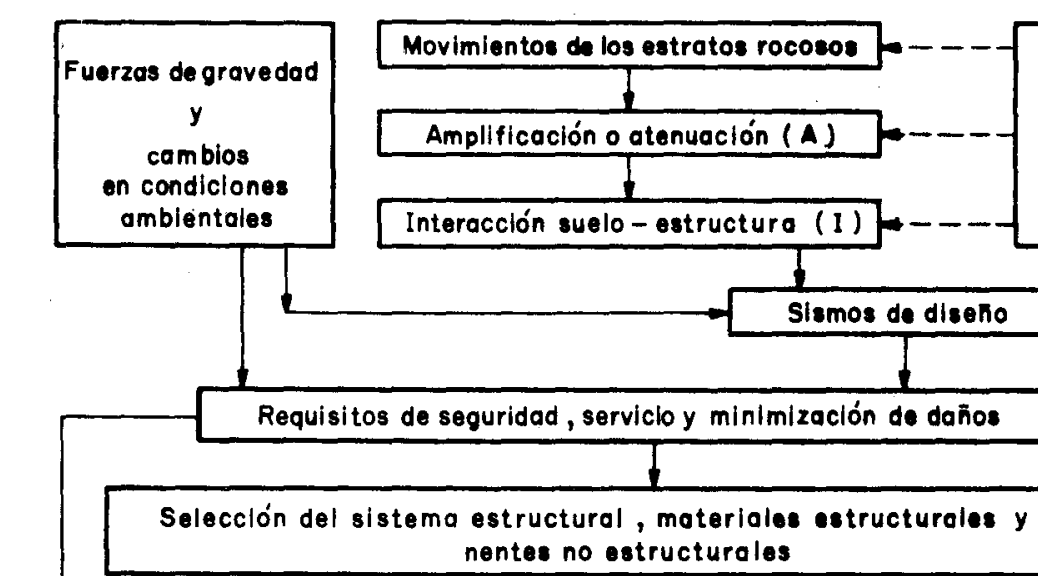

Registros existentes do movimientos del terreno

suelo - estructura (1) ---7
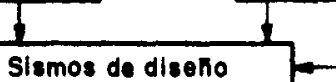

Requisitos de seguridad, serviclo y minimización de daños

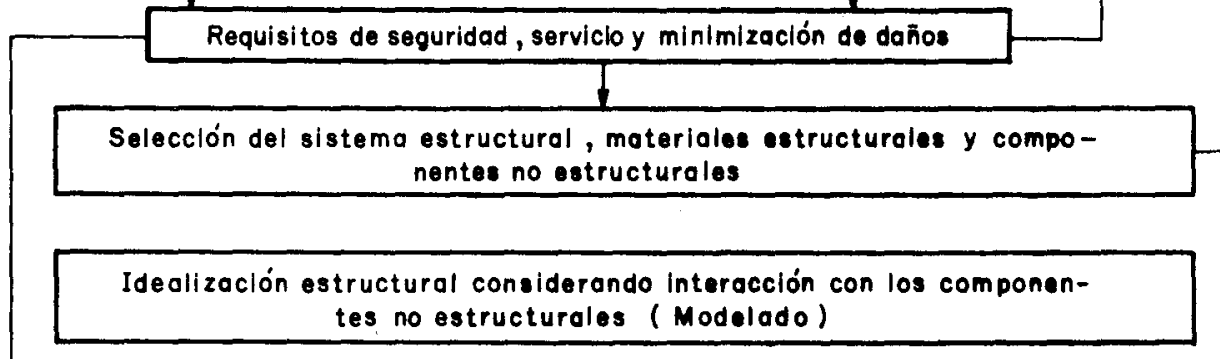

Selección de resistencia sísmica y de coeficlentes de desplazamientos de entrepiso aceptables, y de principales carocterísticas

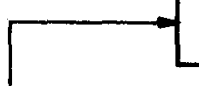
dinómicos
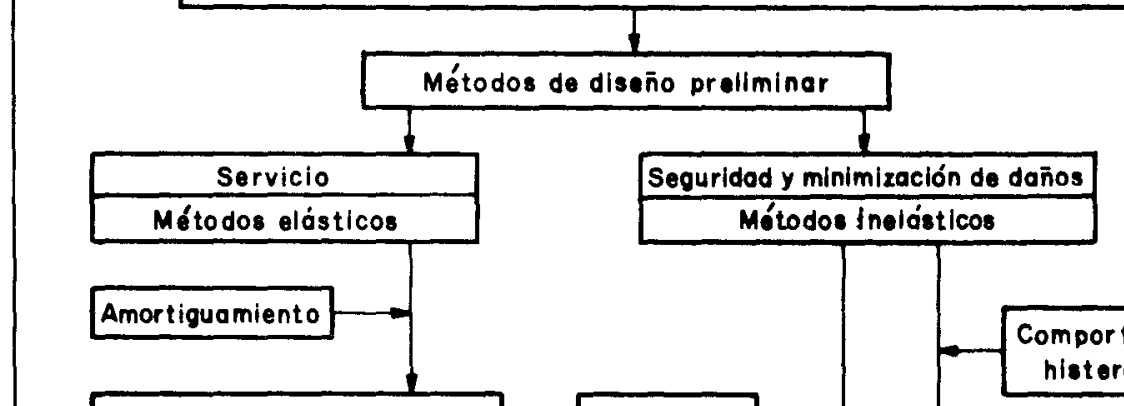

\{
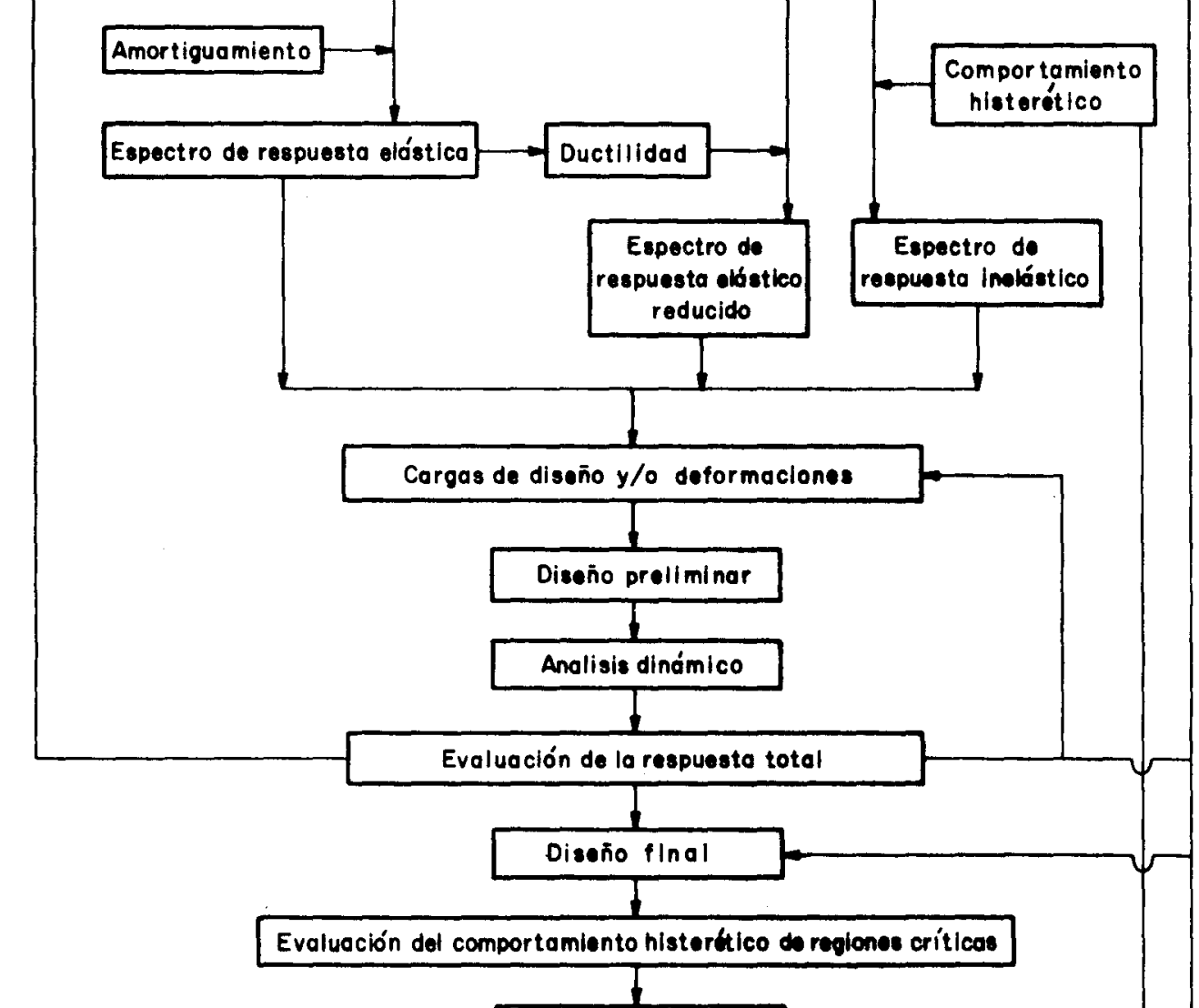

Analisis dinámico

Evaluación de la respuesto total

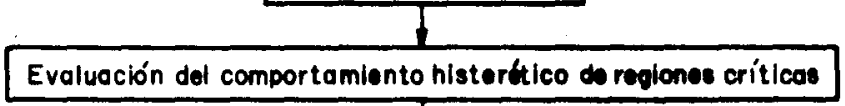

Evaluación del comportamiento histerítico de regiones críticas

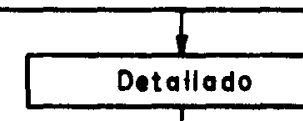

Analisis de contiabilidad (criterio)

Fig 7. Diagrama de flujo de pasos y aspectos generales del diseño sismo-resistente 


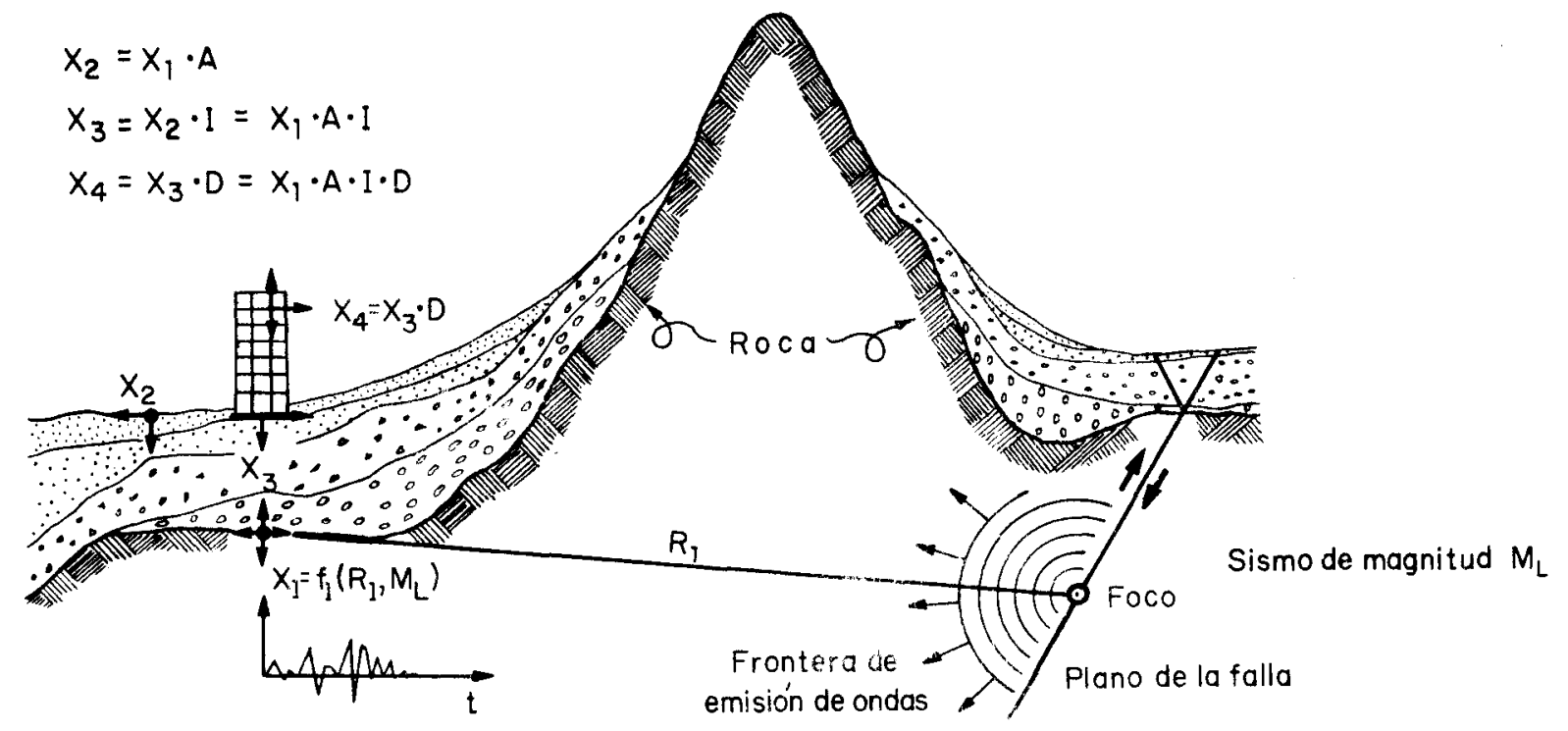

Fig 8 Factores que intervienen en la predicción de $l$ a respuesta sismica

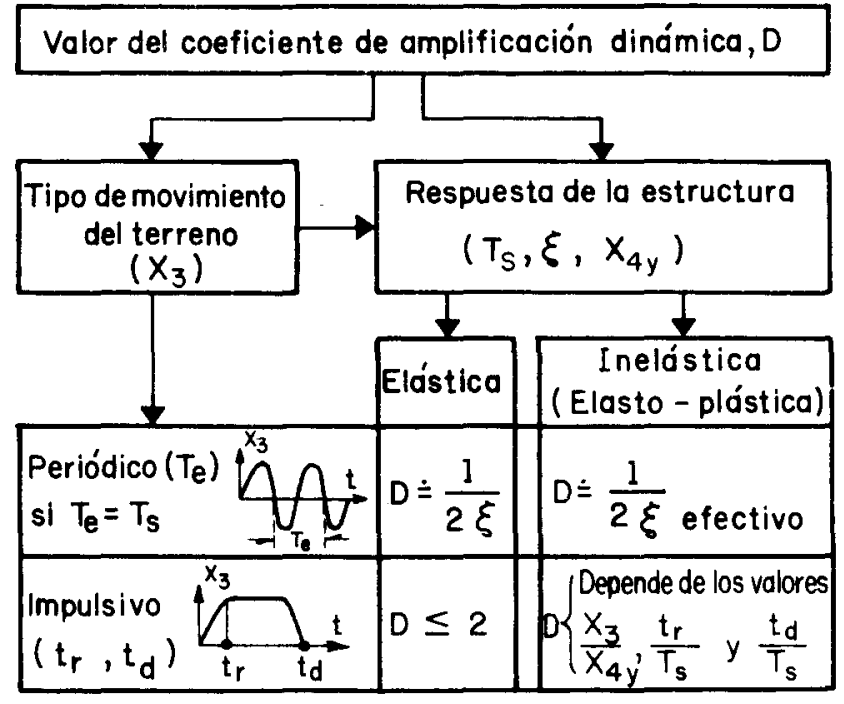

Fig 9. Evaluación del factor de amplificación dinámico para diferentes tipos de movimientos del terreno $y$ respuestas de estructuras

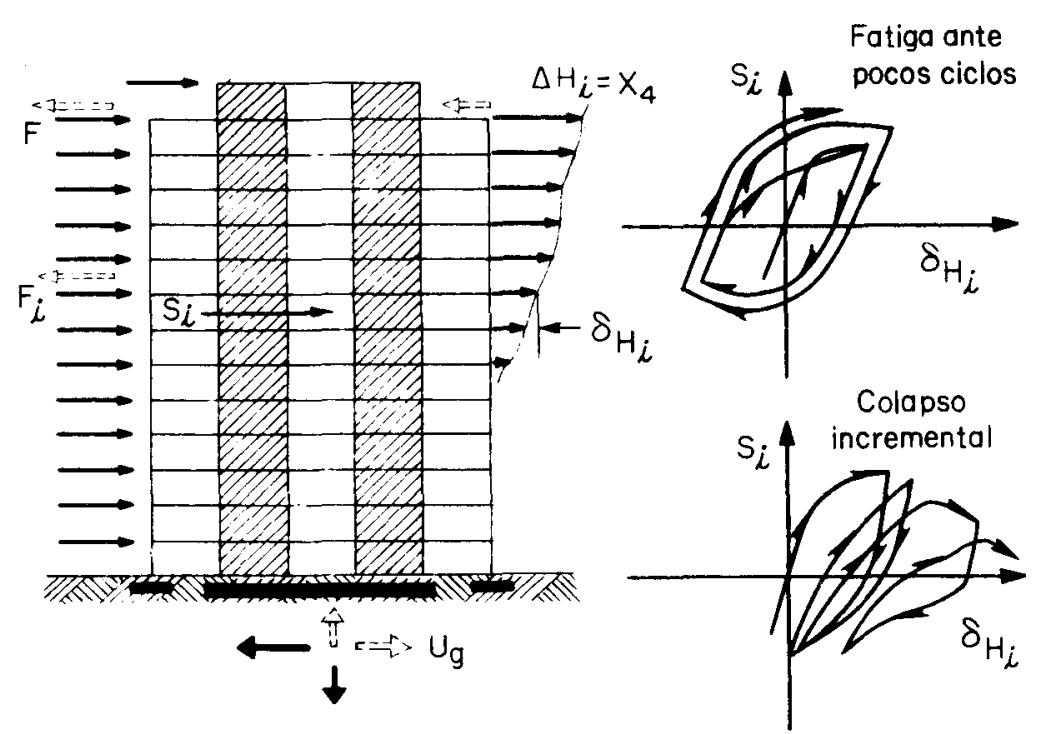

Fig 10. Posibles tipos de fallas ante movimientos severos del terreno

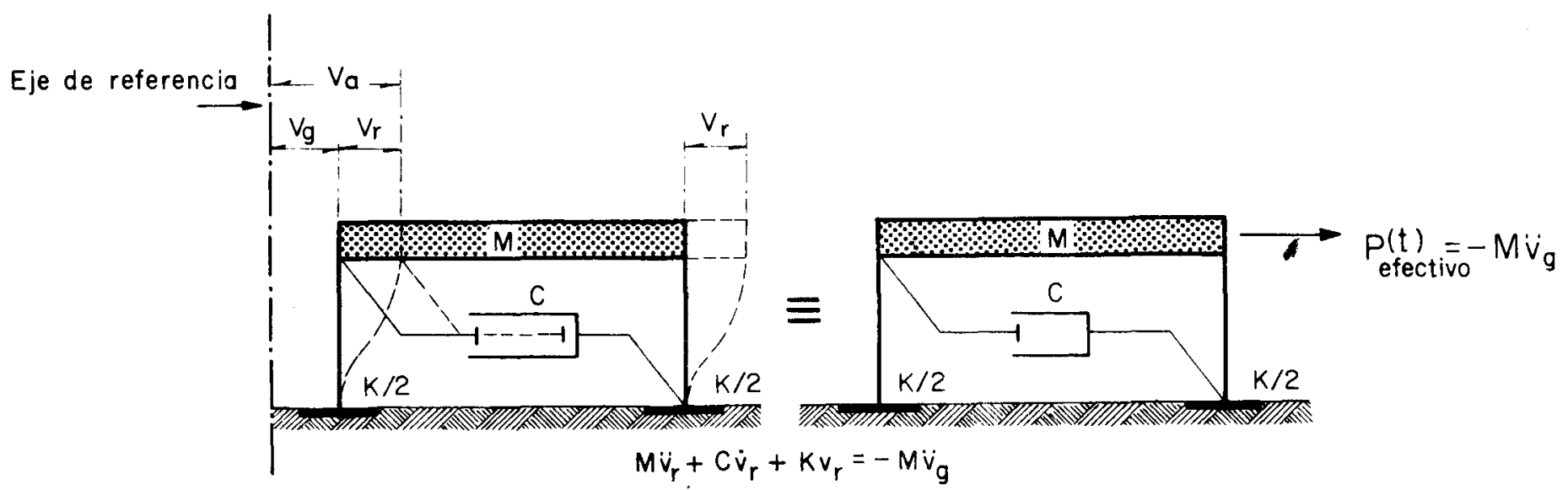

Fig 11. Sistema de un grado de libertad sujeto a movimiento horizontal del terre:o 

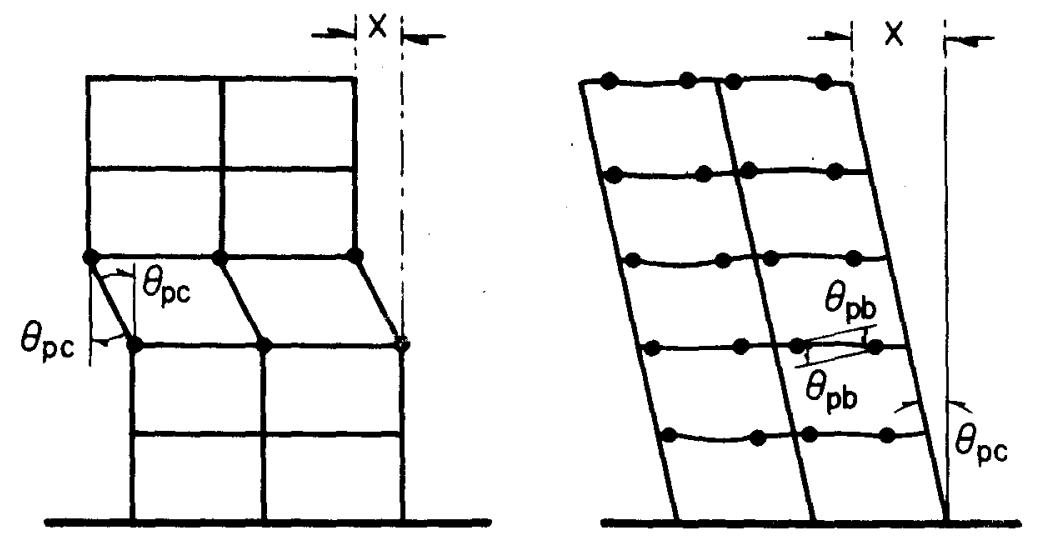

$$
\begin{aligned}
\mu_{\delta r} & =\frac{x_{u}}{x_{y}} \\
x_{u} & =\text { Desplazamiento último } \\
x_{y} & =\begin{array}{l}
\text { Desplazamiento en la } \\
\text { primera fluencia }
\end{array}
\end{aligned}
$$

Fig 12. Mecanismos alternativas de articulaciones plasticas para un marco típico de varios niveles

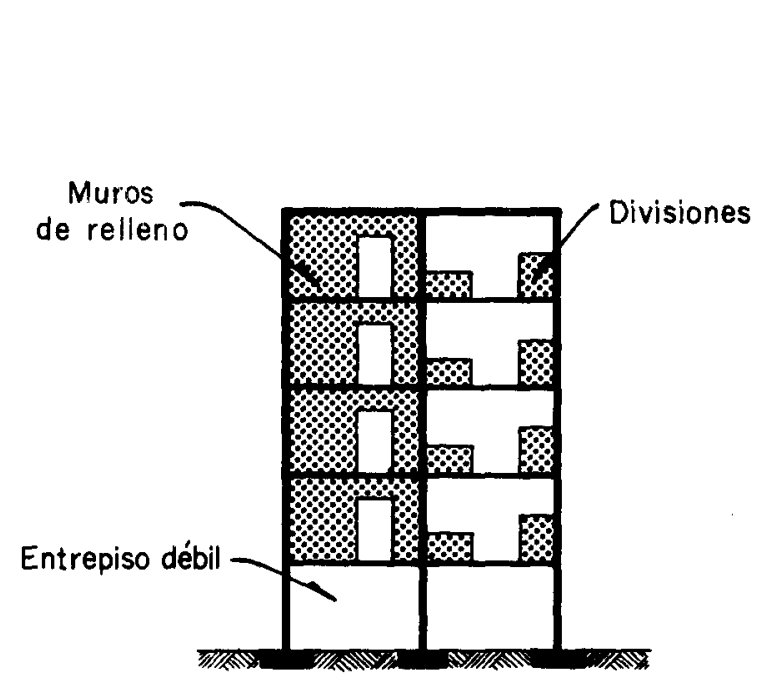

Fig 13. Creación de un entrepiso debil debido a la adición de elementos no estructurales

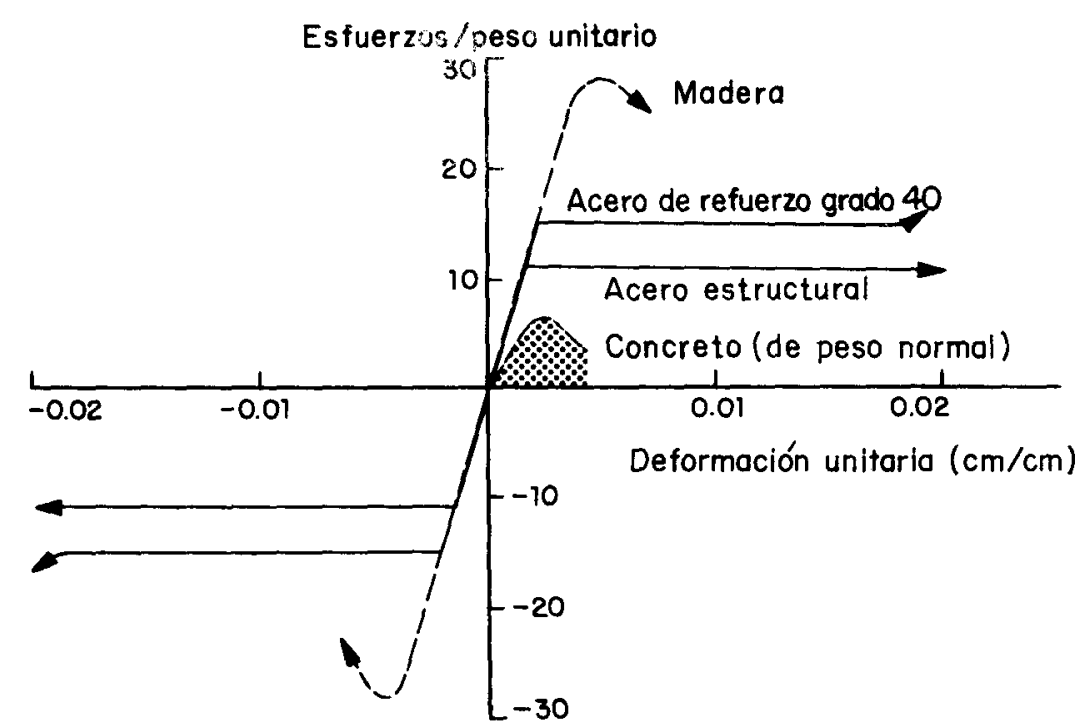

Fig 14. Diagramas esfuerzo por peso unitario vs deformación para diferentes materiales estructurales

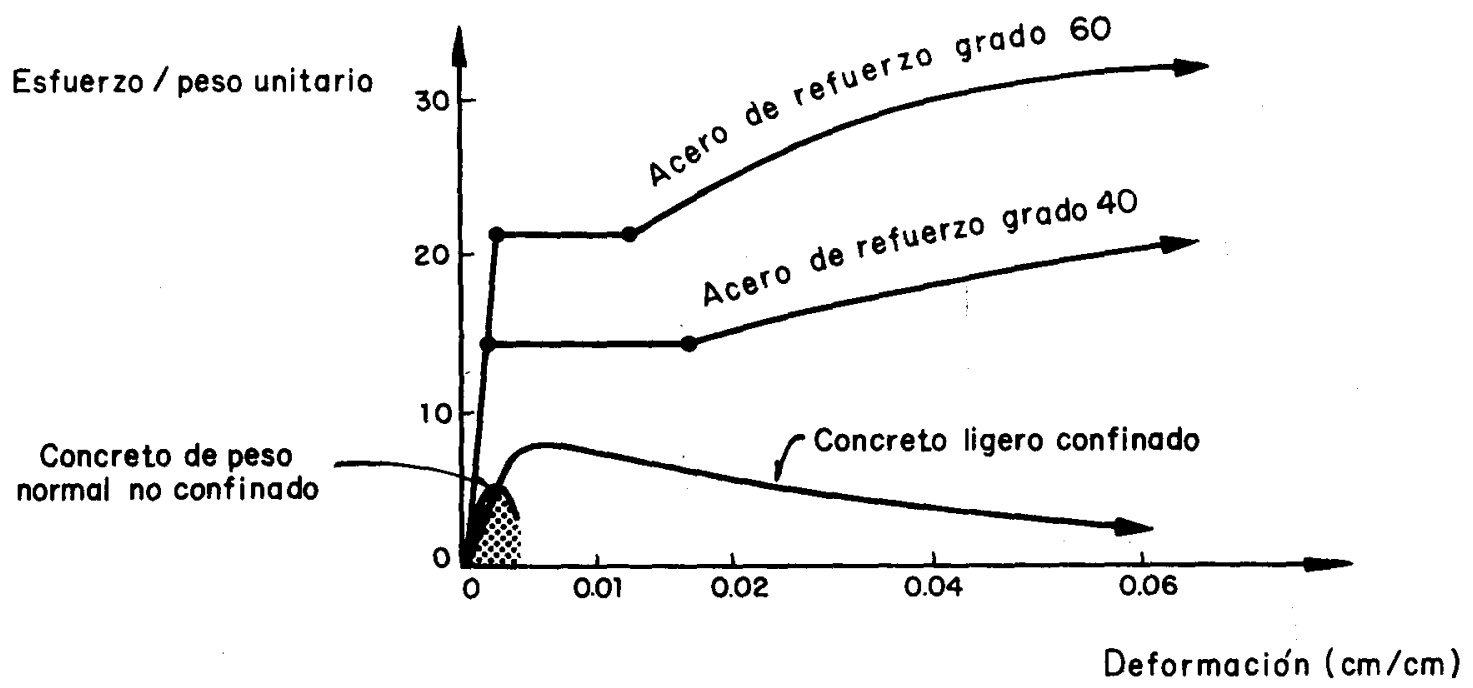

Fig 15. Diagramas esfuerzo por peso unitario vs deformación para concreto y acero de refuerzo 

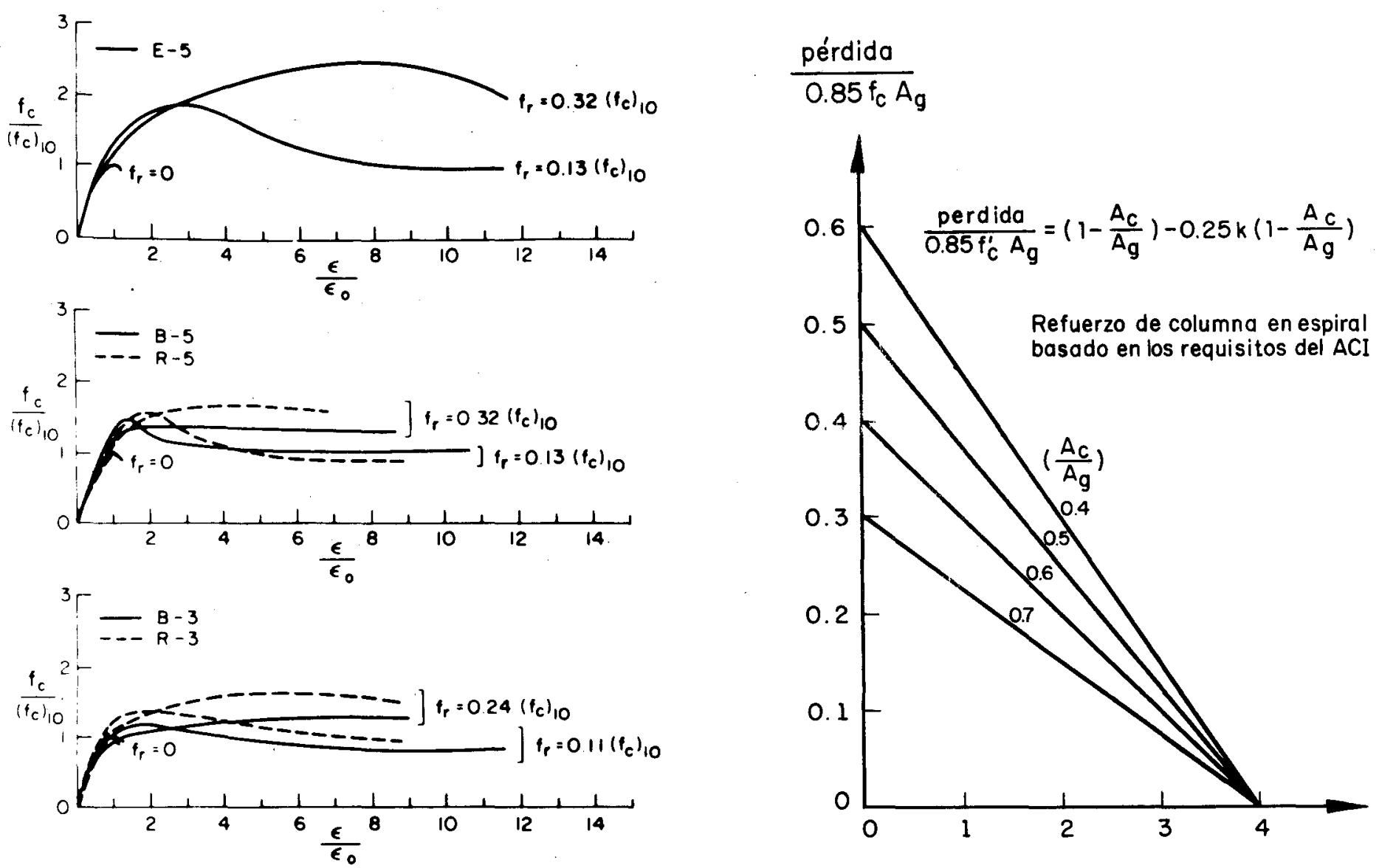

Coeficiente de efectividad de confinamiento, $k$

Fig 16. Efecto de la presión de confinamiento en la resistencia a compresión y ductilidad del concreto confinado

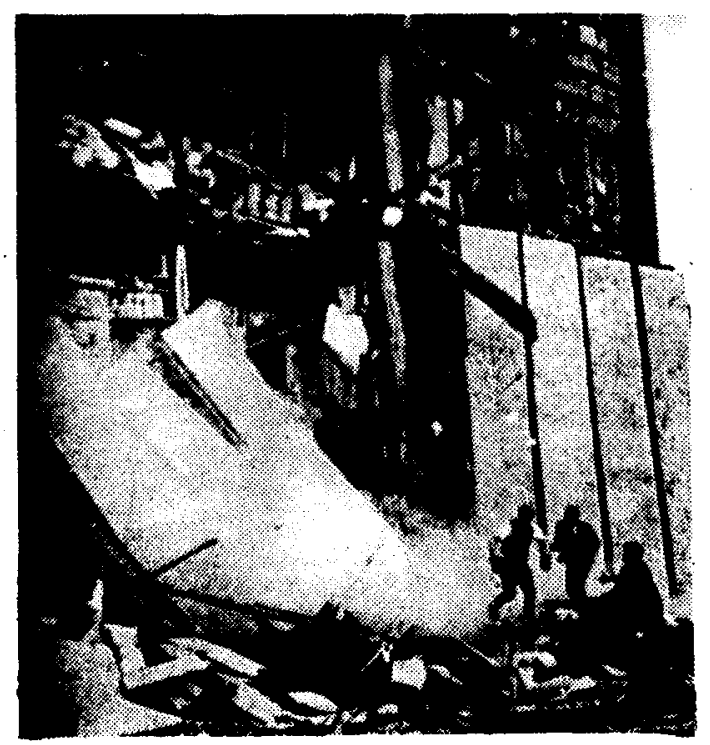

Sismo de Alaska 1964

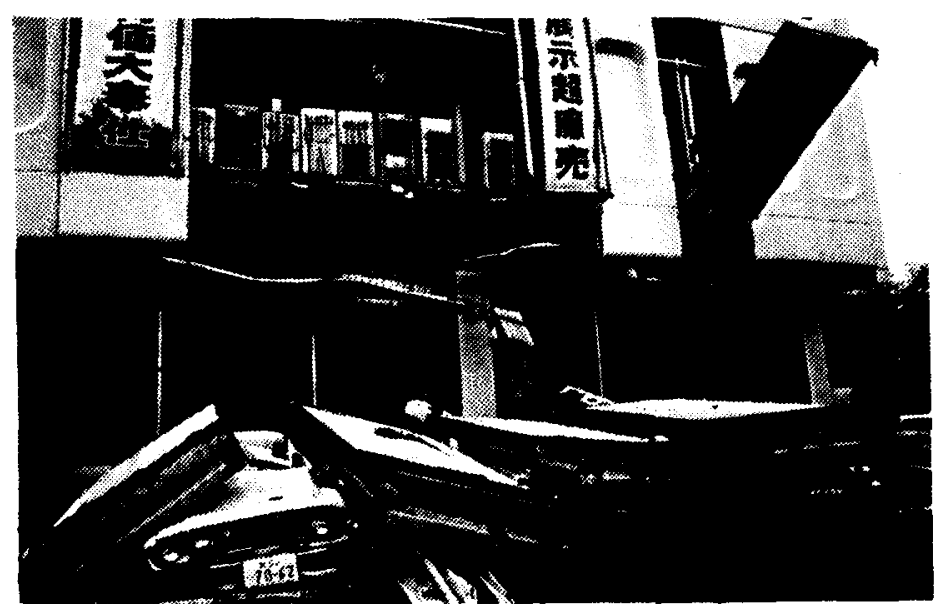

Sismo de Sendai 1978

Fig 18. Colapso de elementos no estructurales 


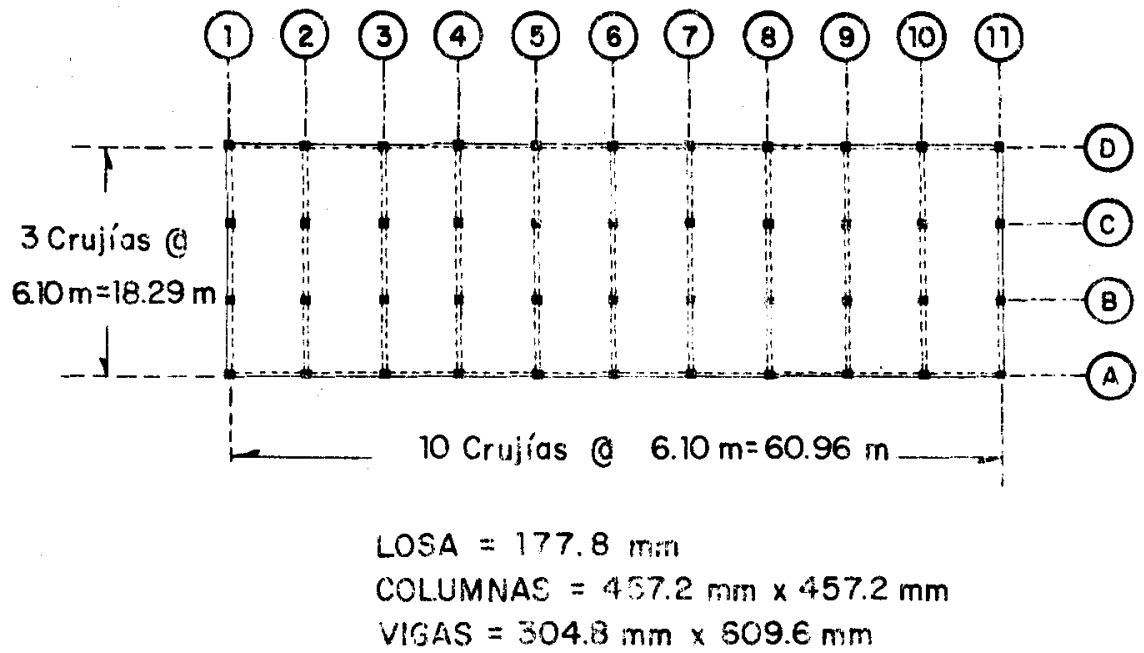

a) PLANTA

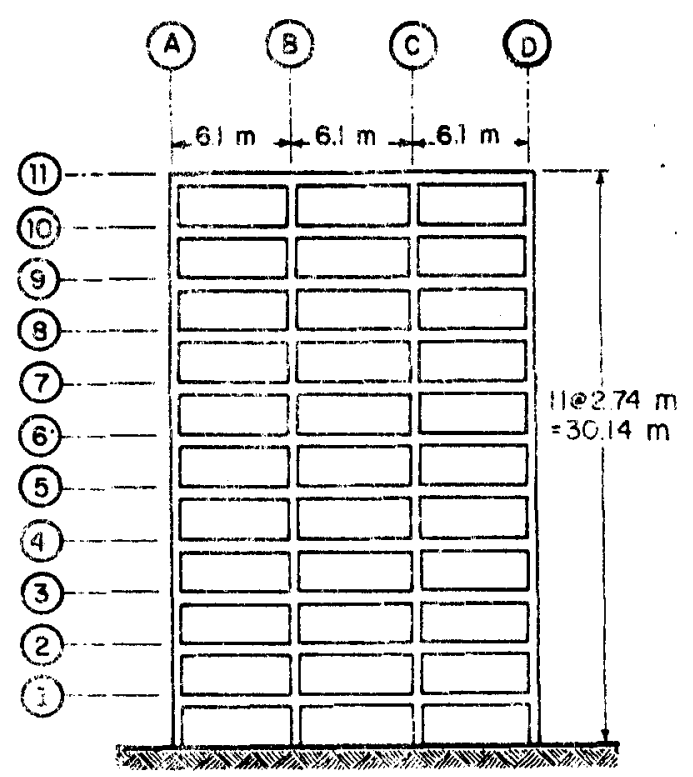

b) ELEVACION

Fig 19. Edificio prototipo

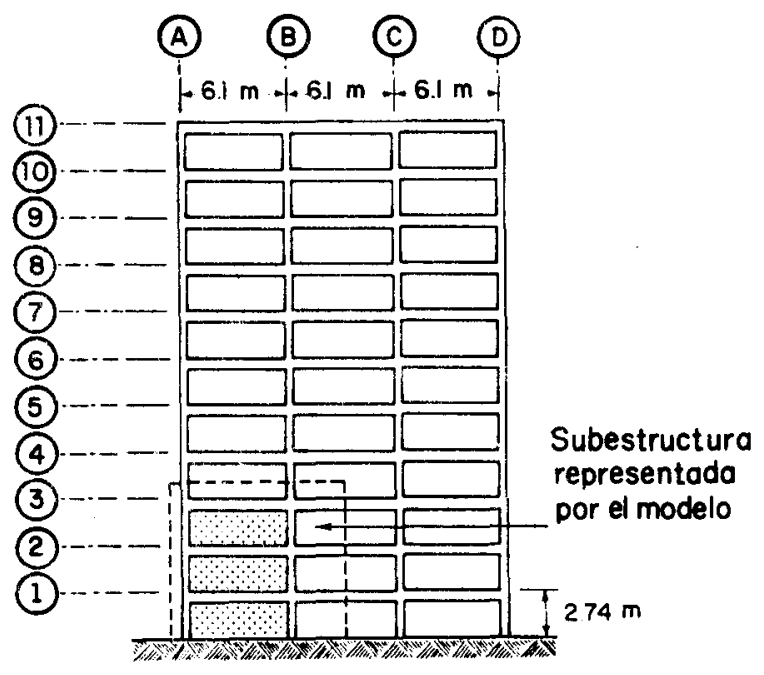

Elevación del marco extremo-prototipo

Fig 20. Subestructura representada por el modelo ensayado

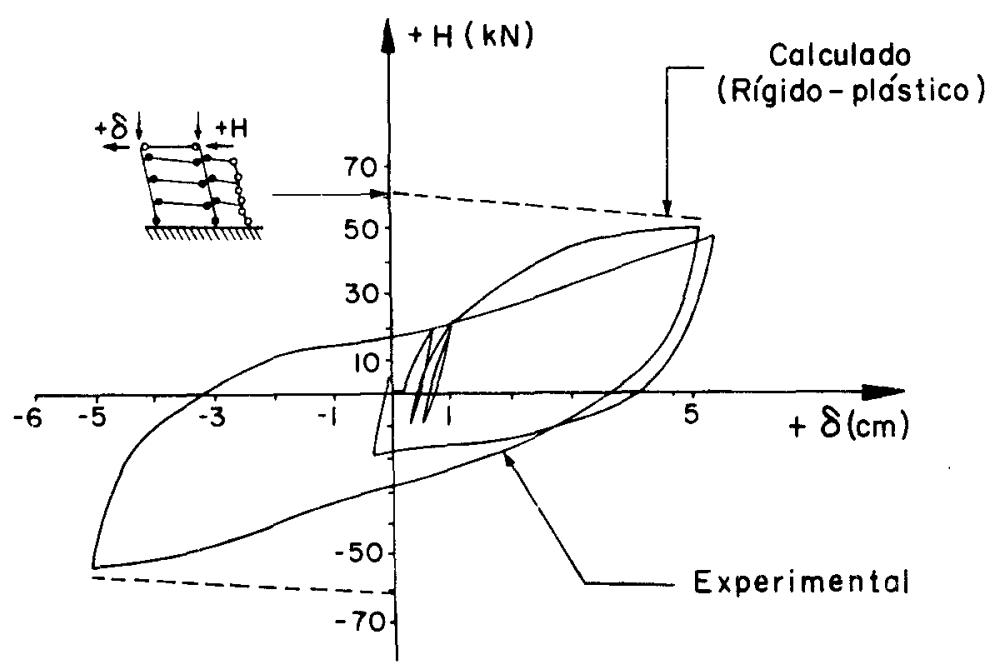

Fig 21. Marco sin muros de relleno. Relación carga lateral-desplazamiento

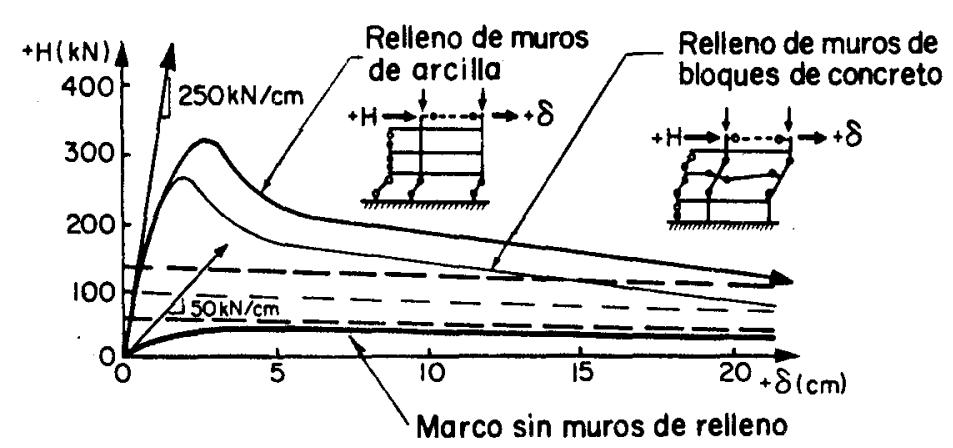

Fig 22. Comparación del comportamiento de marcos con muros de relleno $y \sin$ ellos

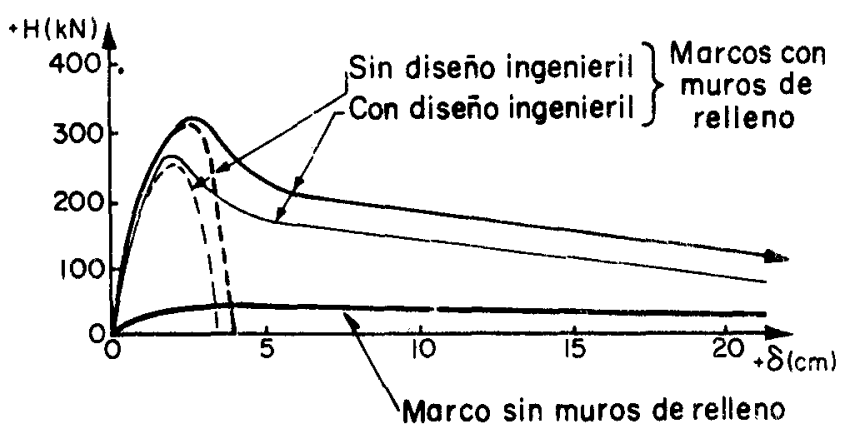

Fig 23. Comparación del comportamiento de marcos con muros de relleno con $y$ sin diseño ingenieril 


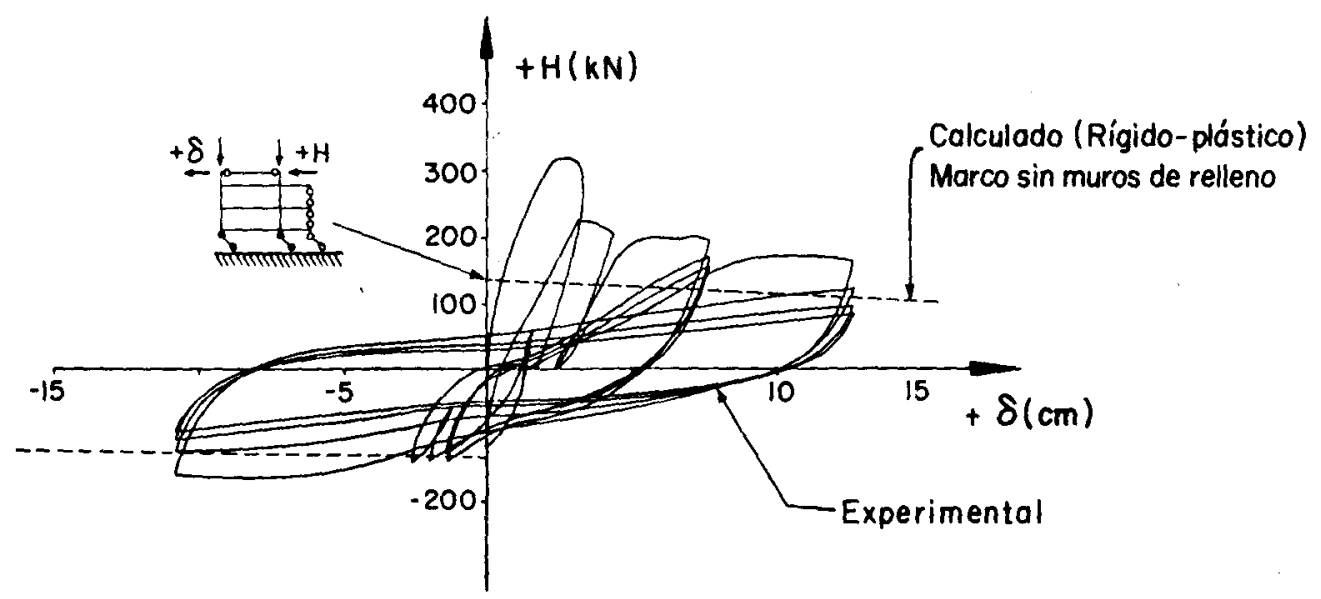

Fig 24. Comportamiento histeretico de un marco relleno con mampostería de arcilla

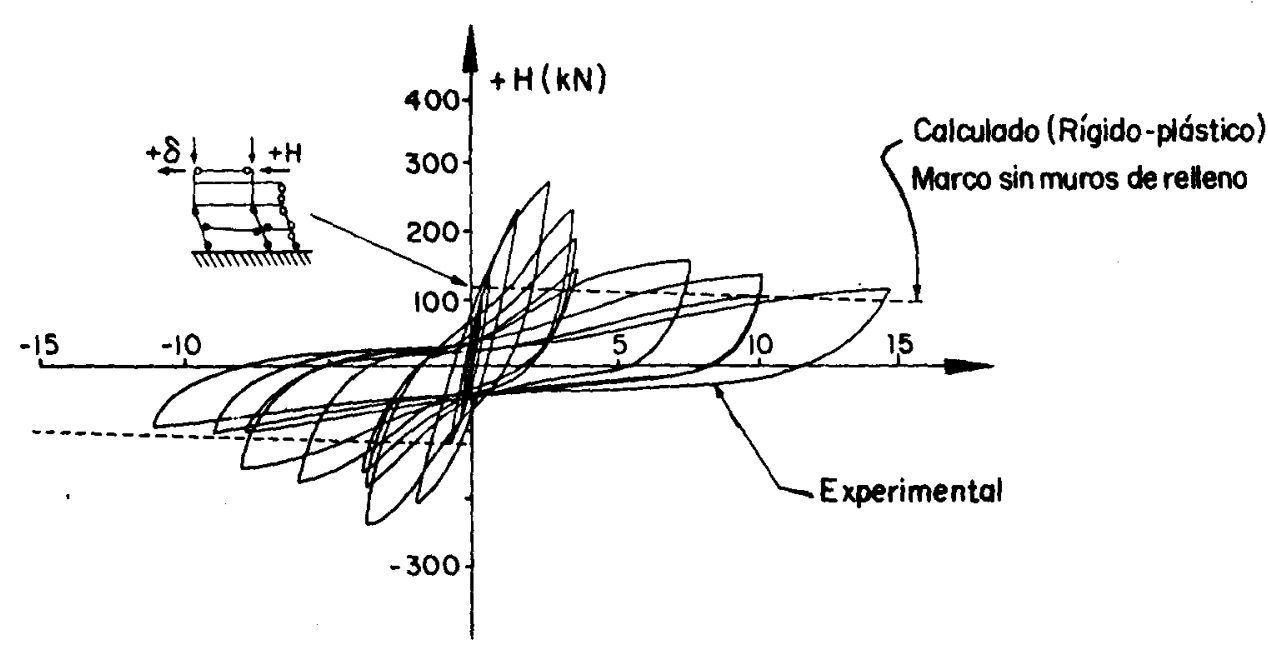

Fig 25. Comportamiento histeretico de un marco relleno con mampostería de arcilla

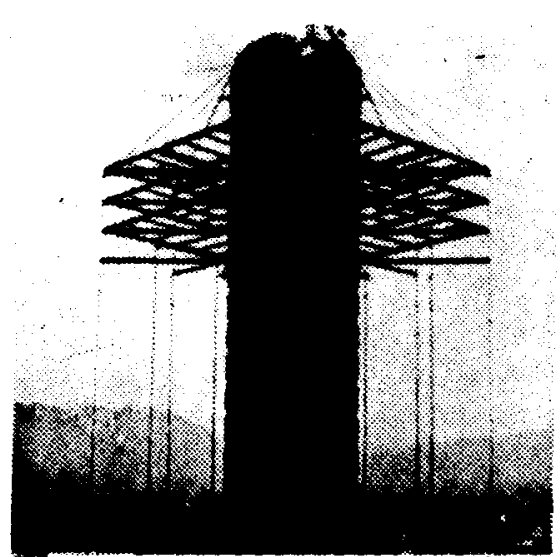

Procedimiento constructivo

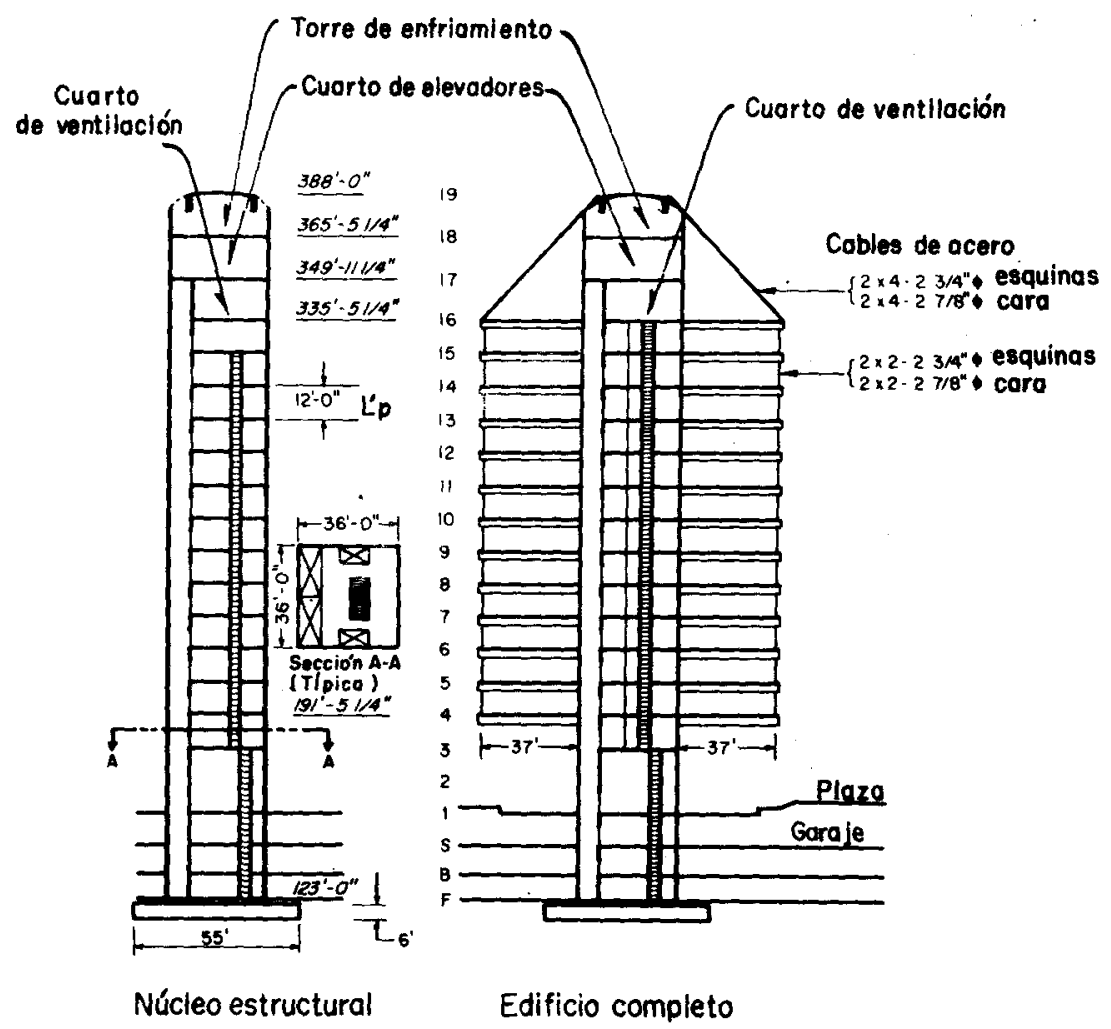

Fig 26. Ejemplo de estructura tipo sombrero 
113

\section{6}

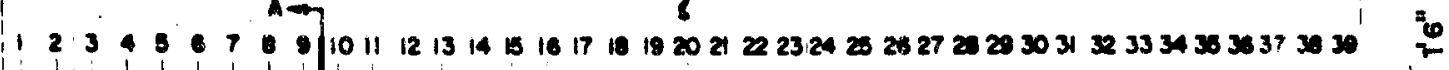
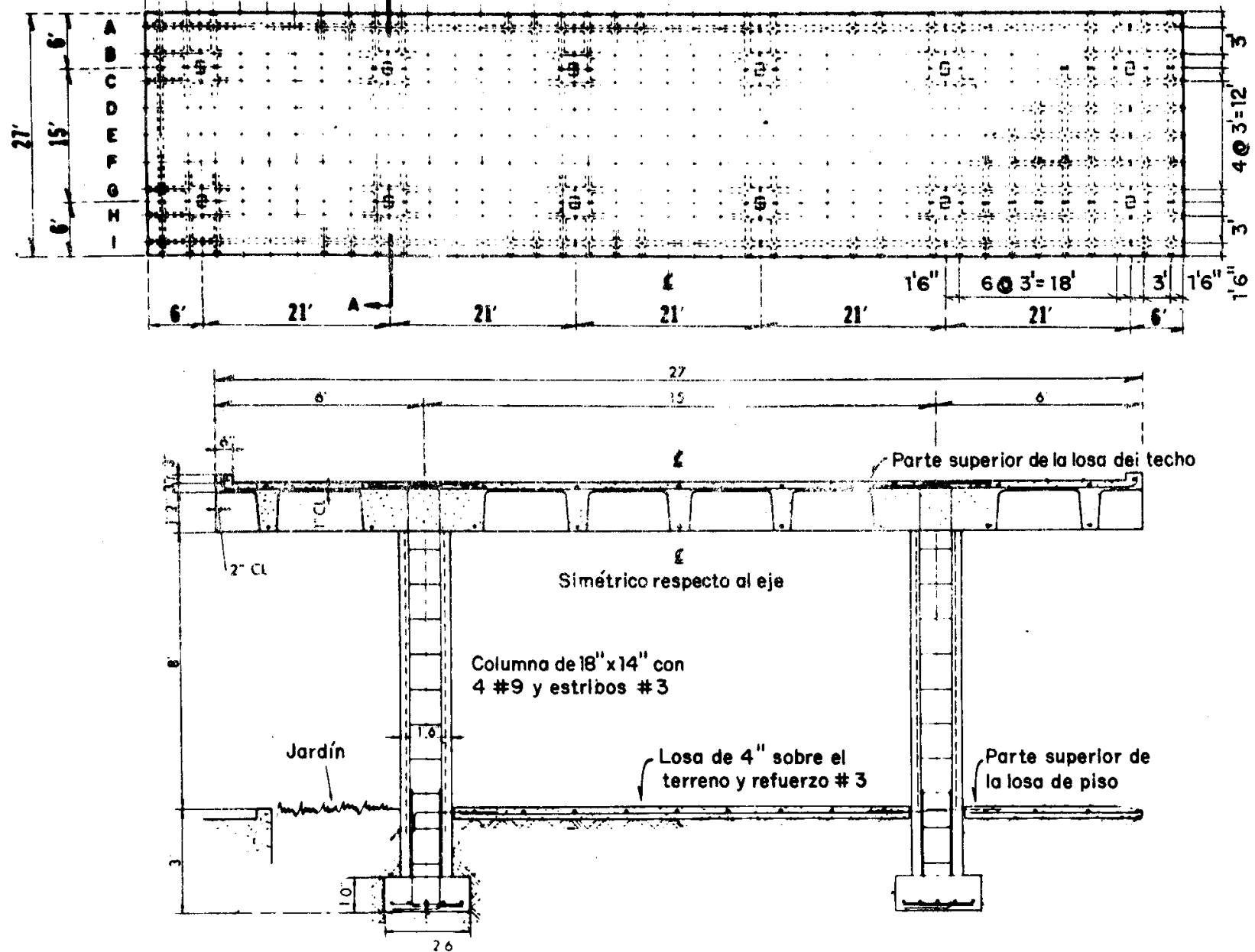

Fig 27. Planta del entrepiso y sección A-A del pabellón para estacionamiento de ambulancias

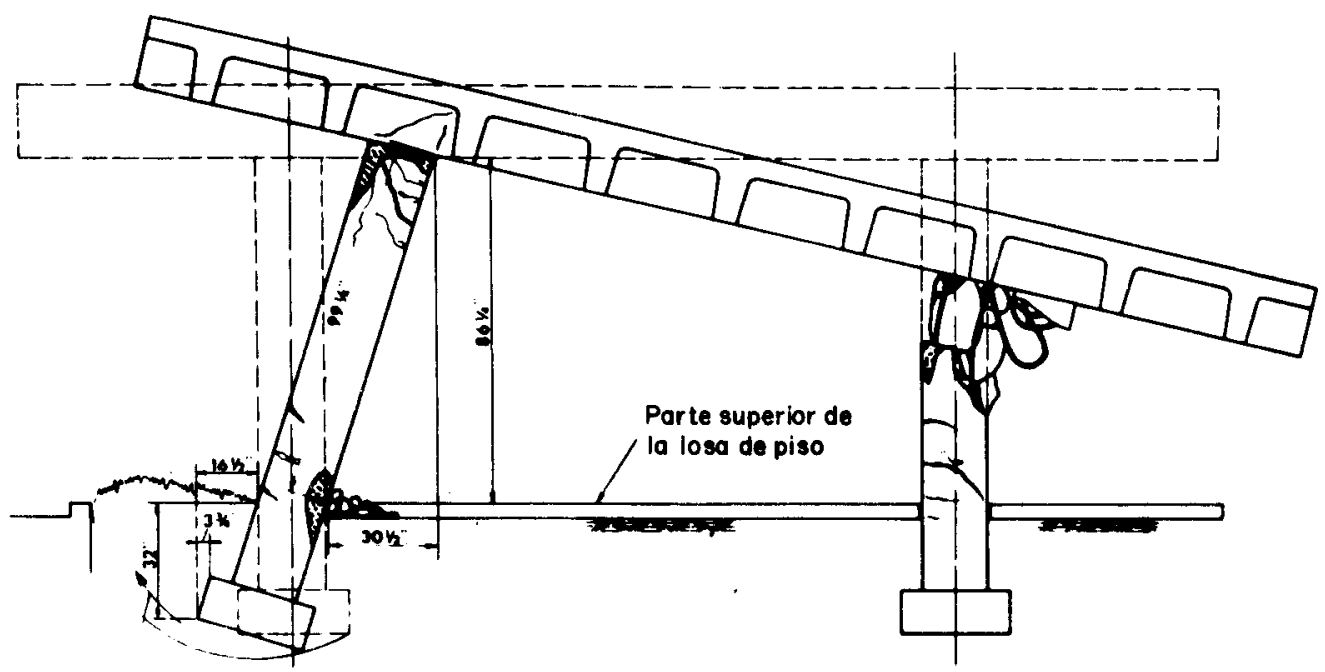

Folla del suelo

Columas del lado norte

Fig 28. Tlustración esquematica de la falla del pabellón para estacionamiento de ambulancias 


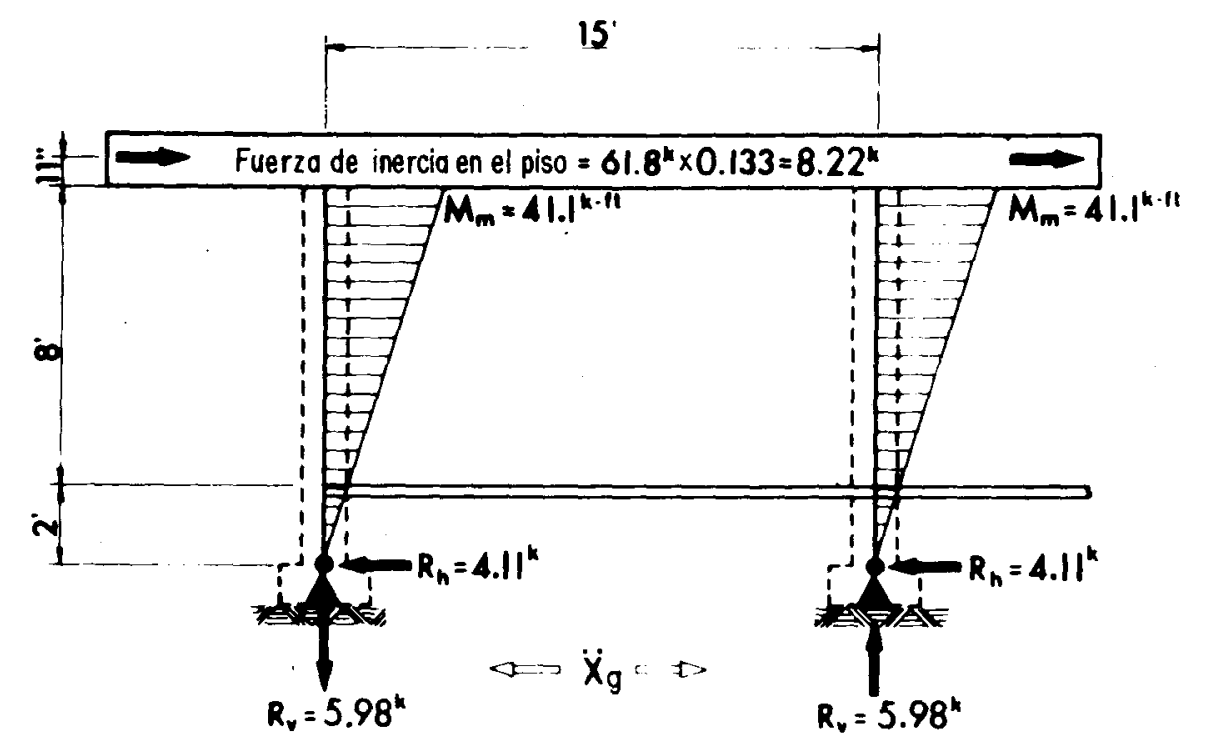

Fig 29. Fuerzas y momentos sismicos de diseño

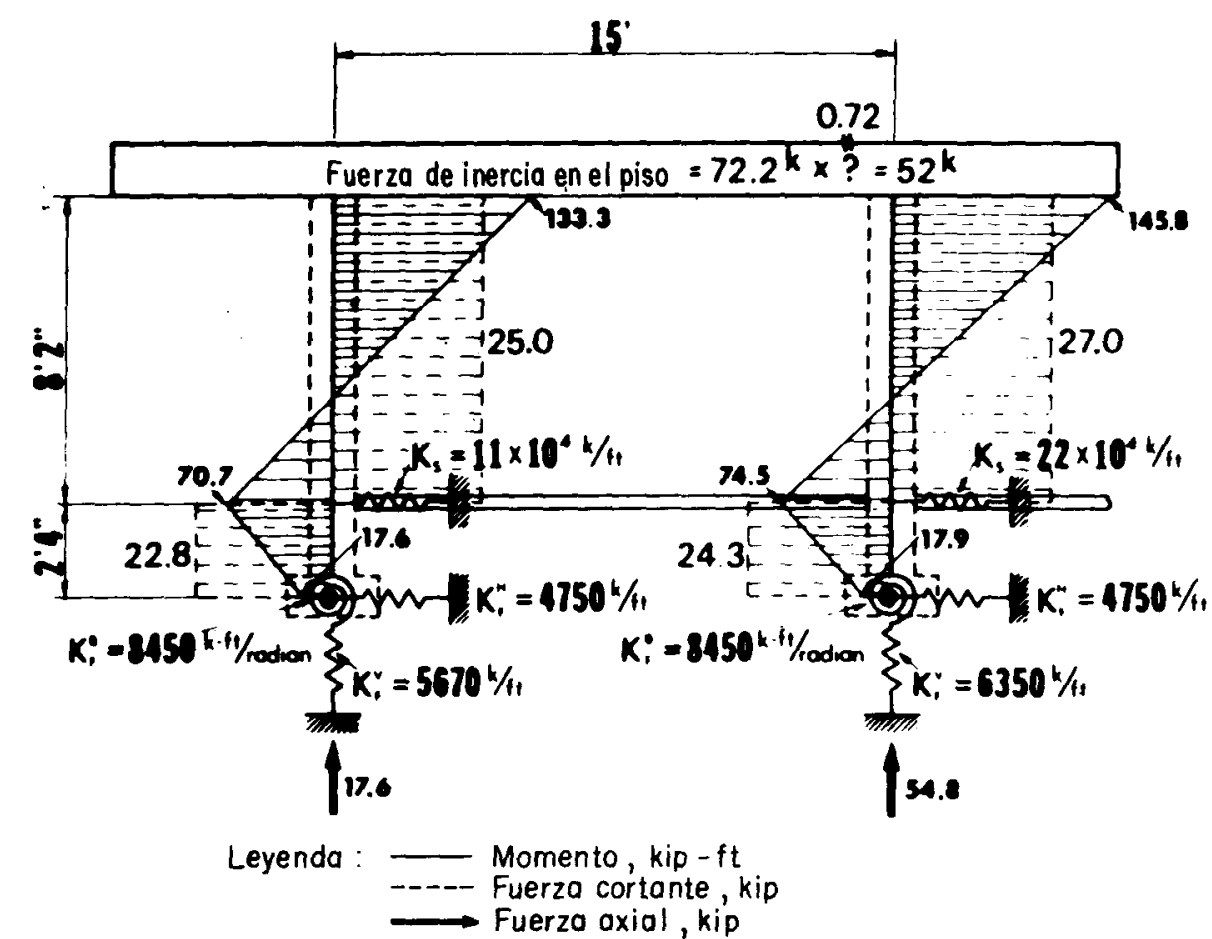

Fig 30. Fuerzas cortantes, axiales y momentos basados en un modelo estructural realista

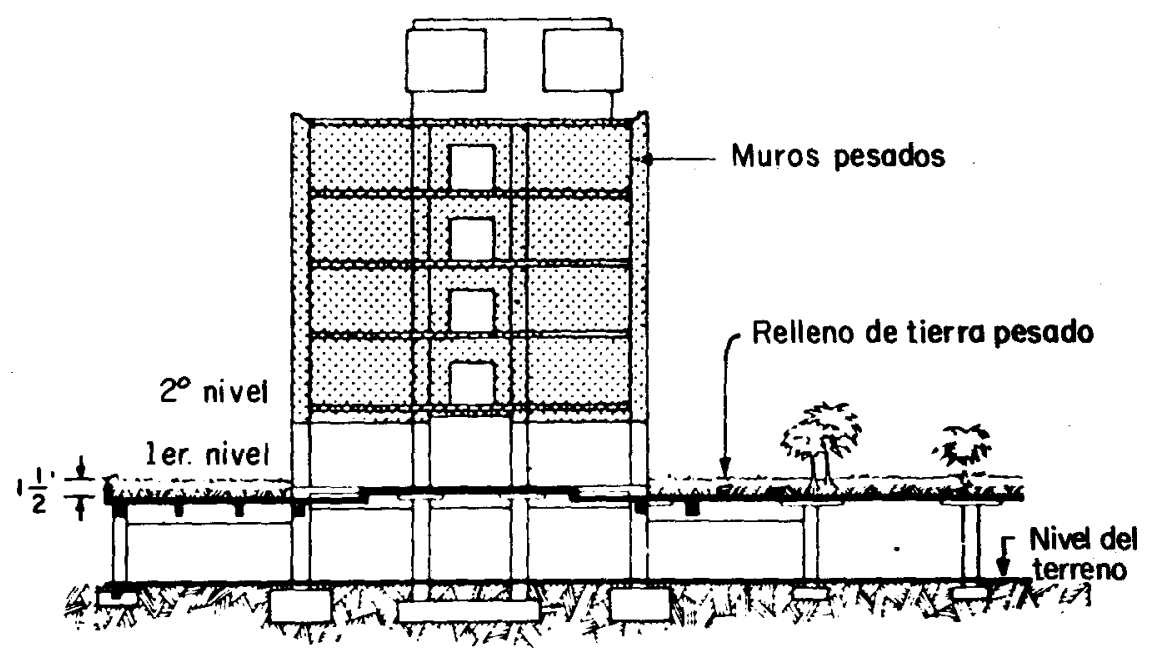

a) Elevación mostrando la presencia de masas innecesarias

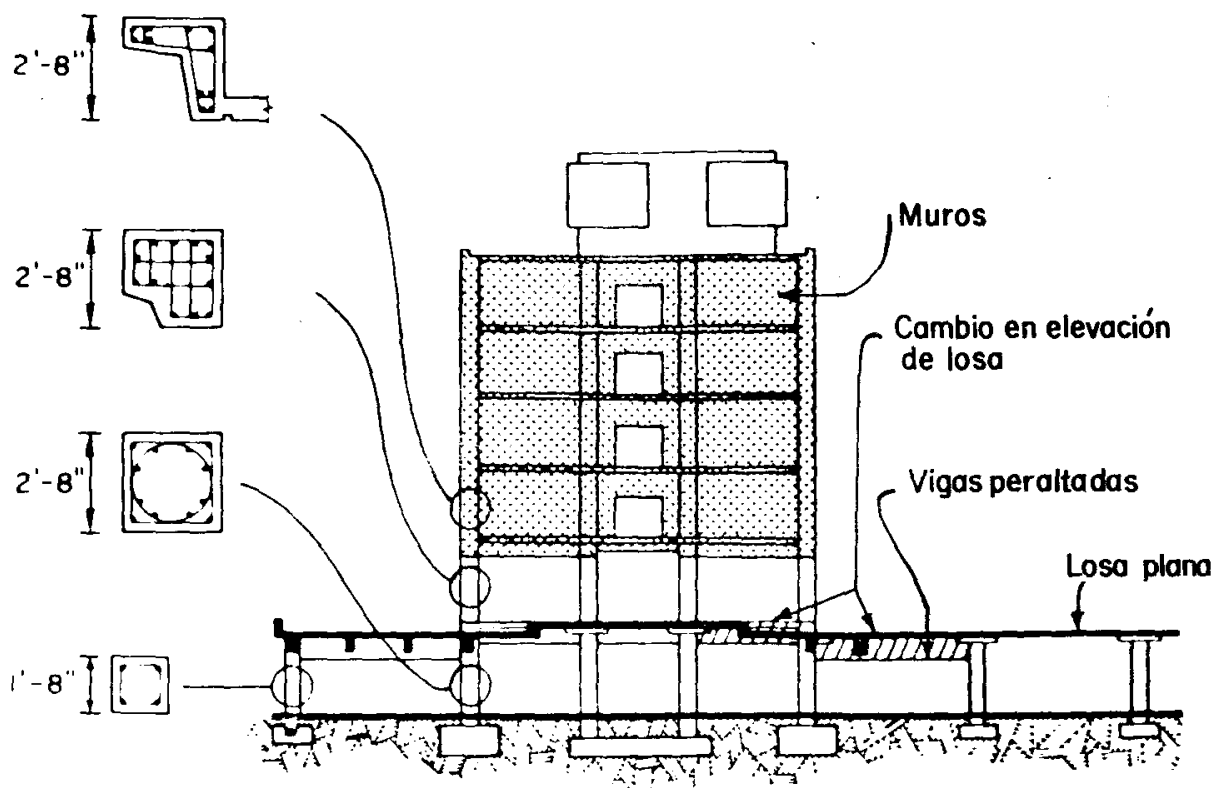

b) Elevación mostrando las discontinuidades en rigidéz, resistencia y ductilidad

Fig 31. Elevaciones del edificio principal del 01 ive View Medical Center 


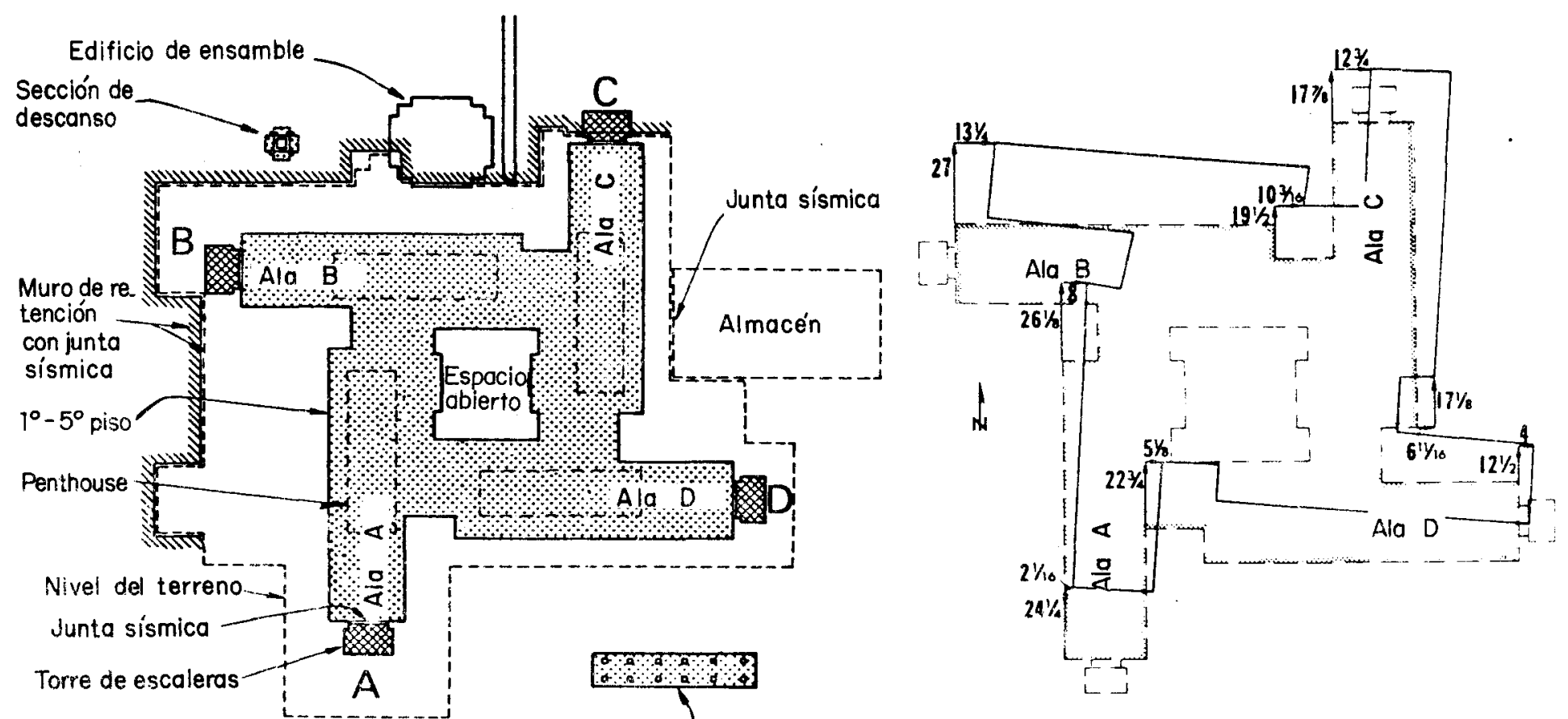

Planta

Nota: Todos los desplazamientos en pulgadas

Fig 32. Desplazamientos permanentes del entrepiso en el primer nivel

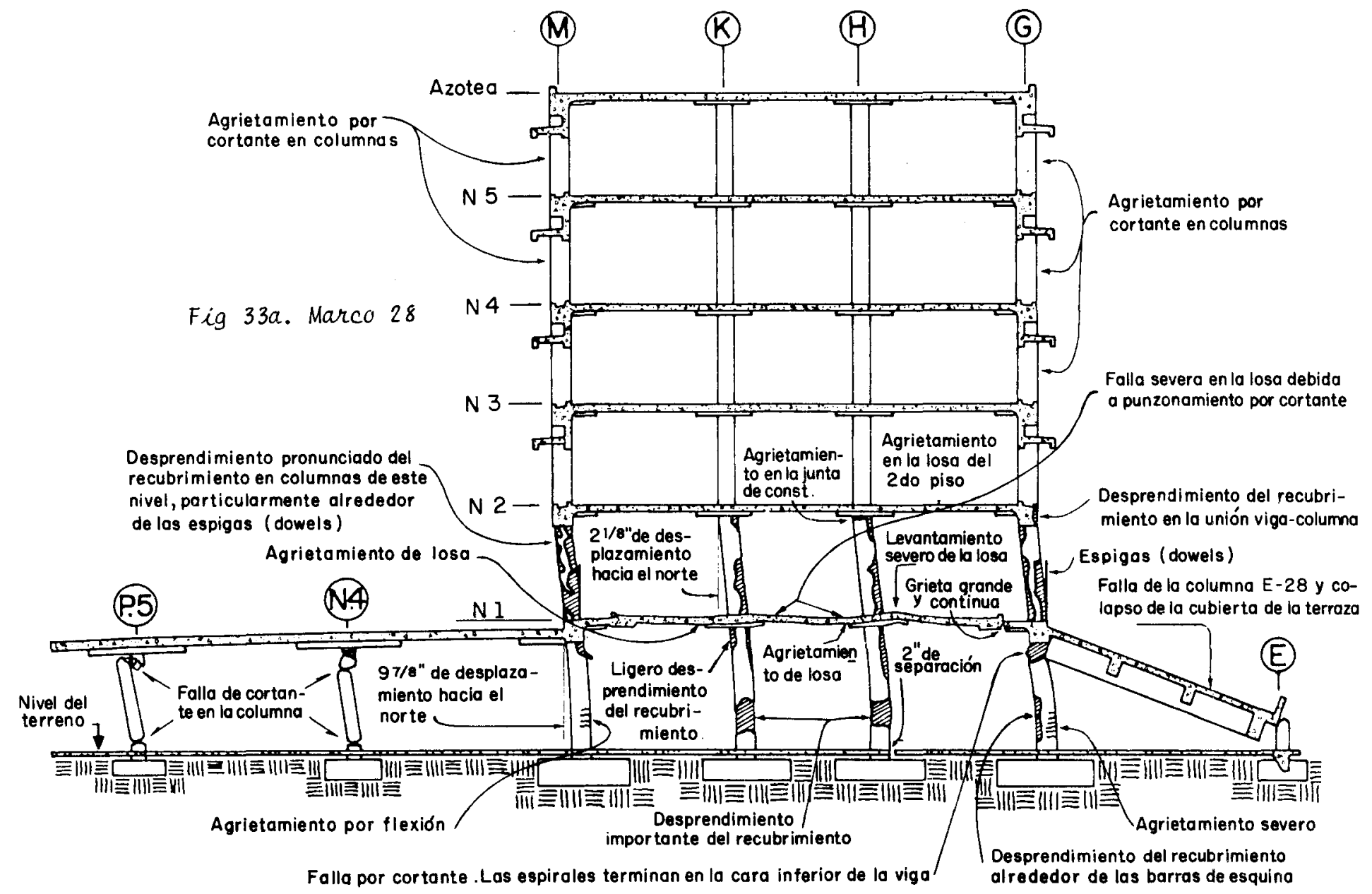




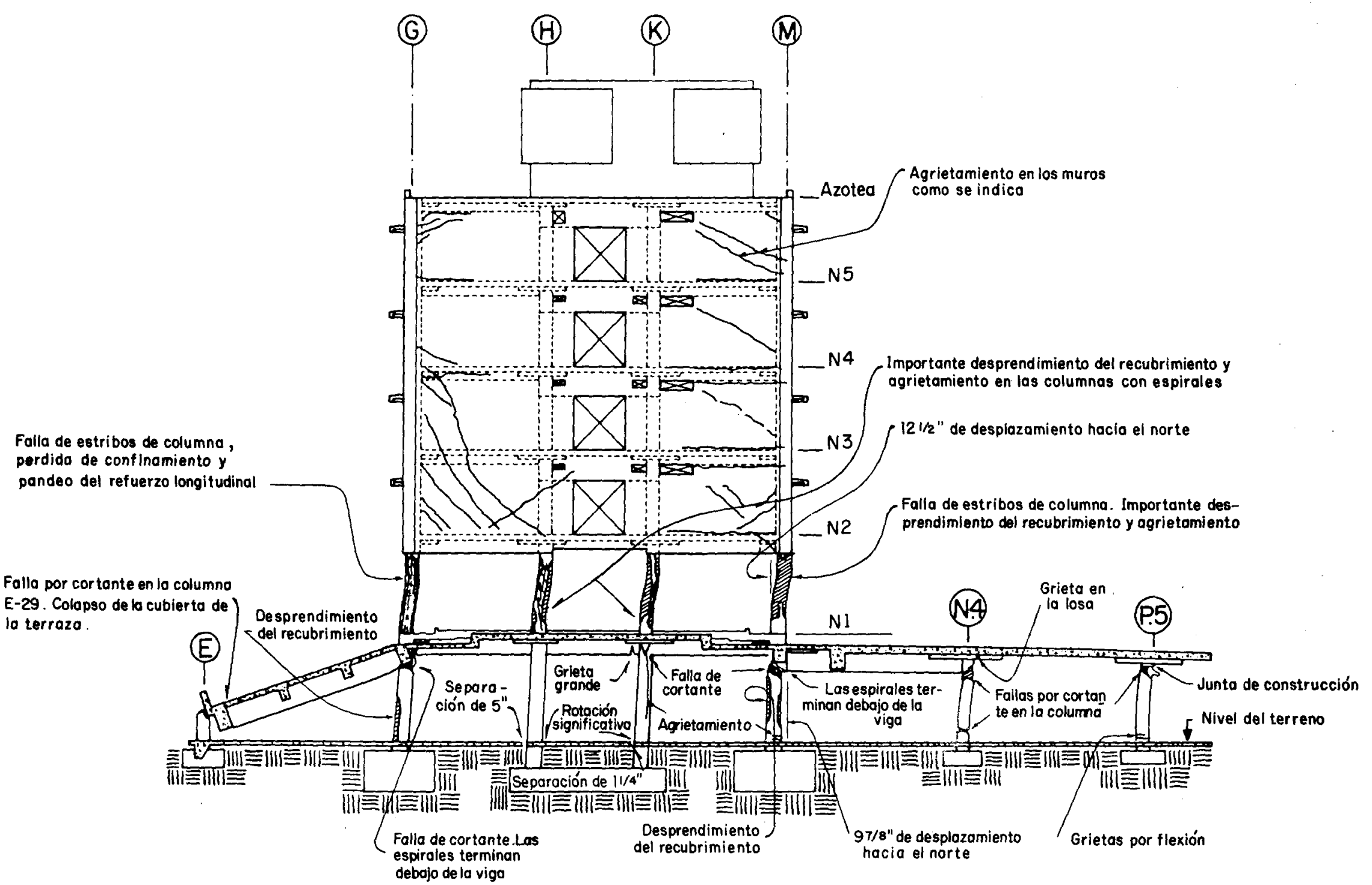

Fig 33b. Marco 29

Fig 33. Diagramas esquematicos de los daños en el edificio principal del $0 l$ ive View Medical Center 


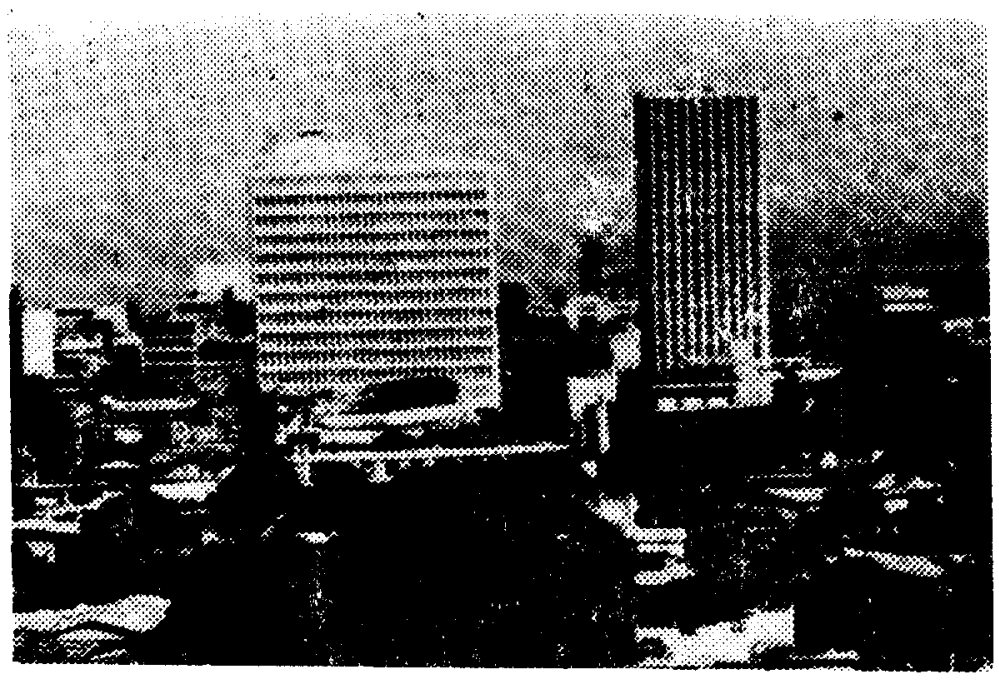

a) Vista de las fachadas sur

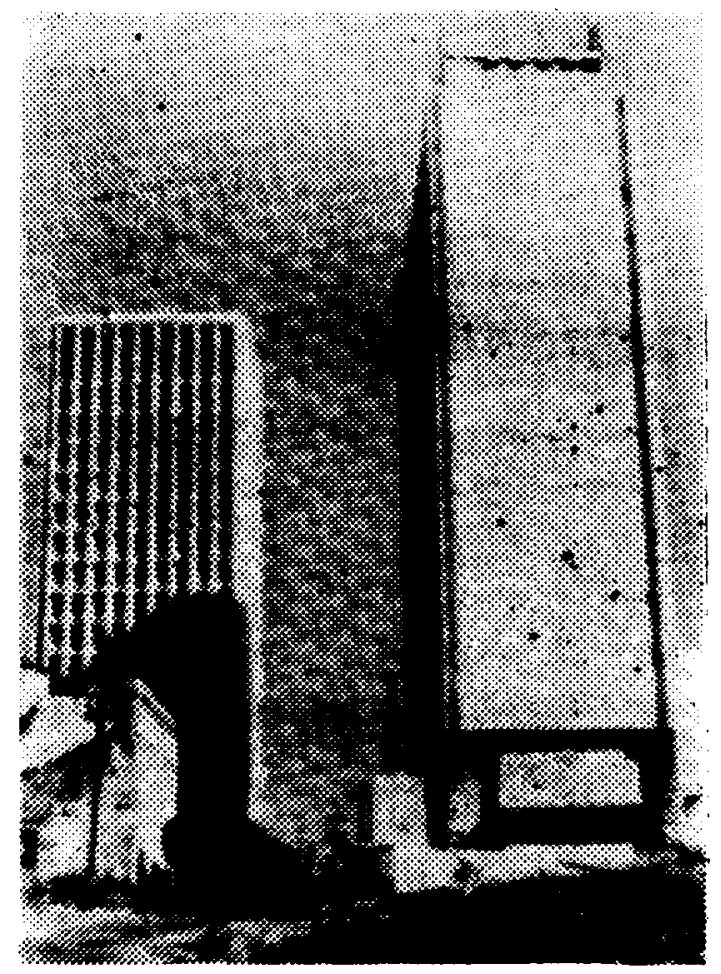

b) Vista de las fachadas oeste

Fig 34. Vistas de los edificios del Banco de America y del Banco Central de Managua

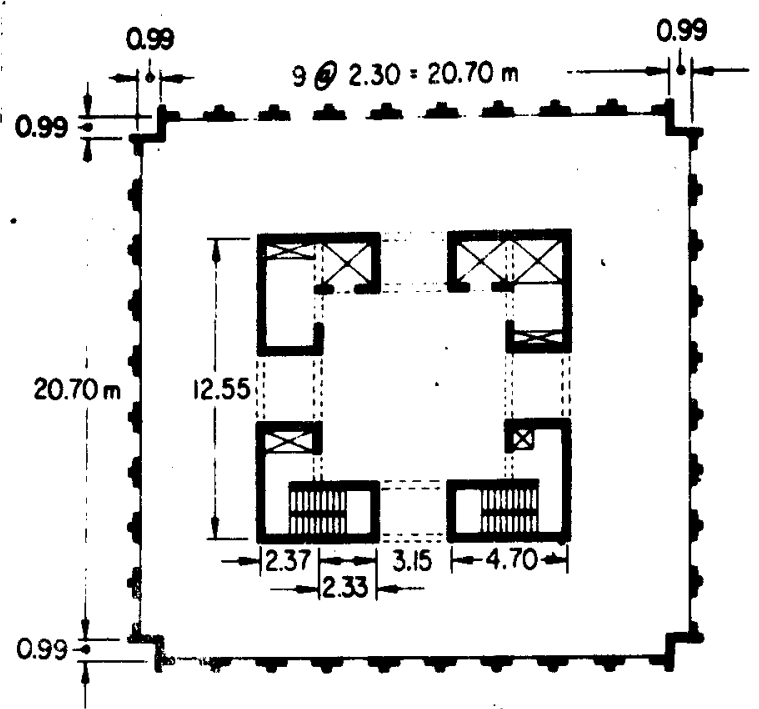

a) Planta

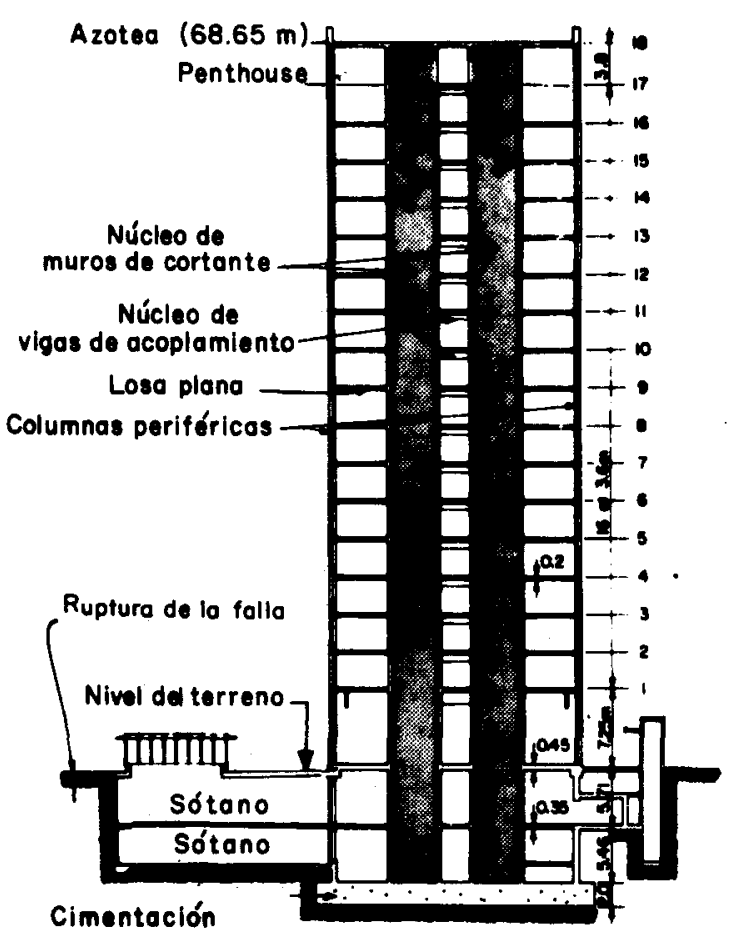

b) Elevación

Fig 35. Planta y elevación del edificio del Banco de America 


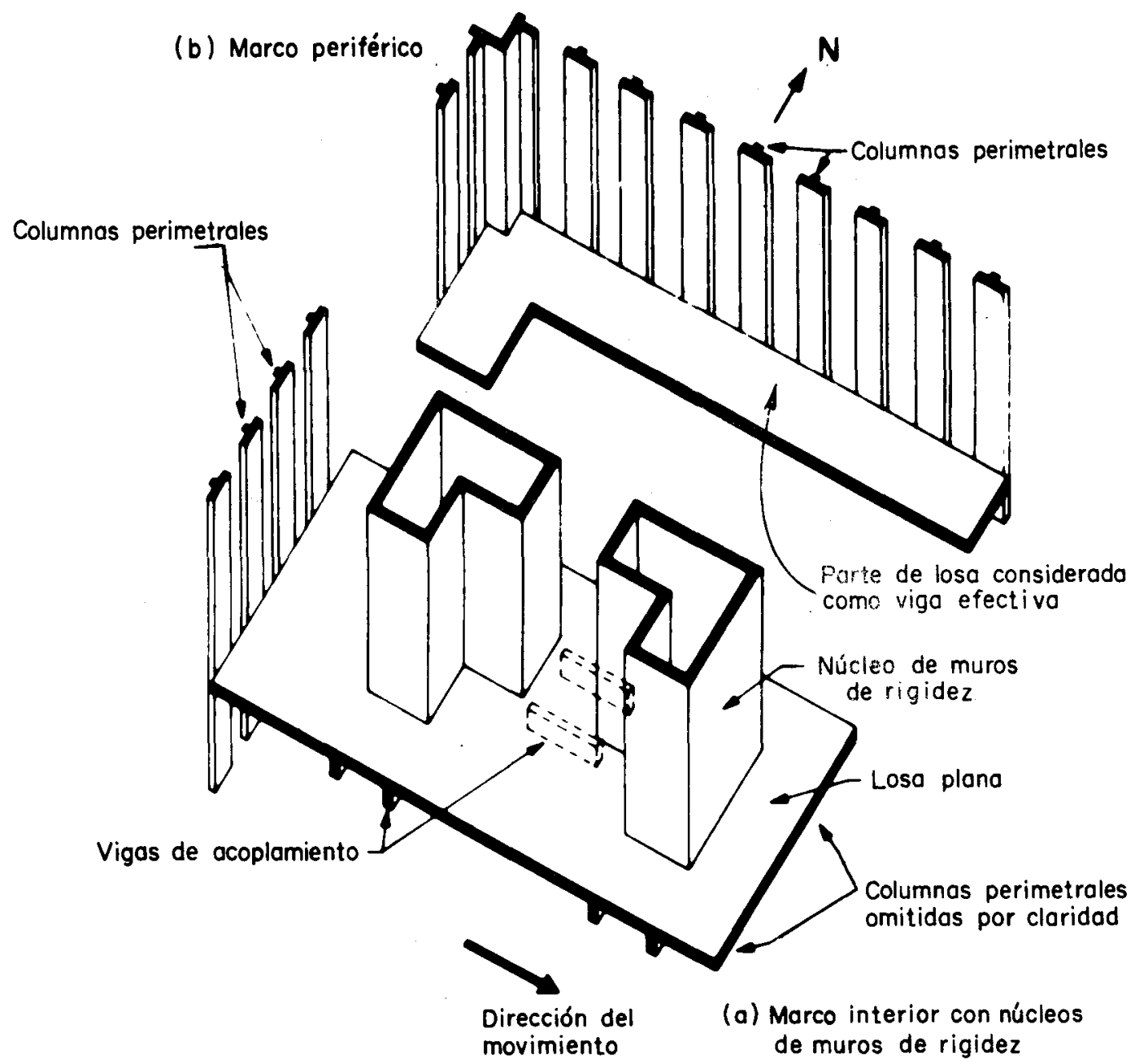

Fig 36. Banco de America. Esquema del sistema estructural

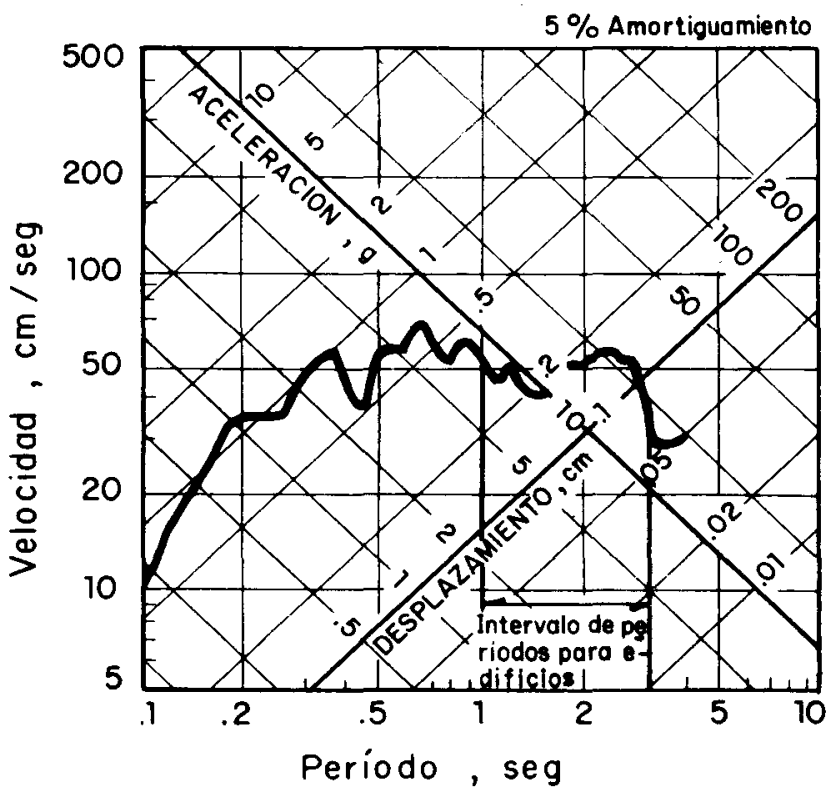

Fig 37. Espectro de respuesta para el acelerograma ESSO: componente Este 


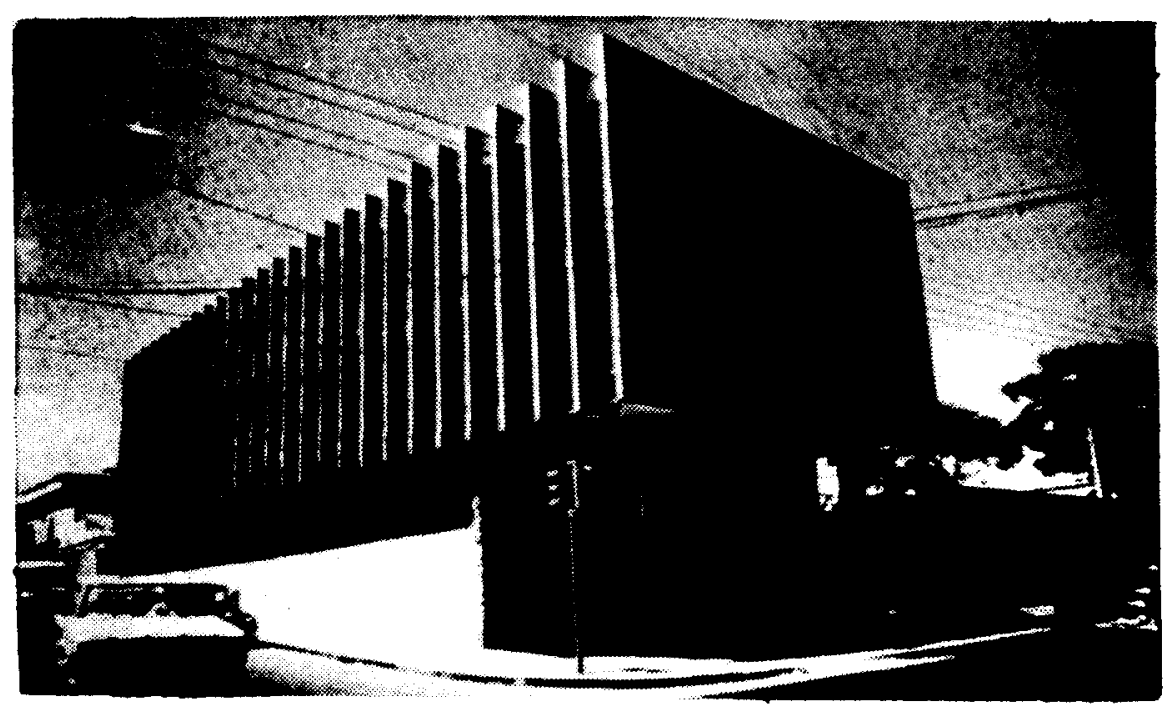

Fig 38. Escuela de Niñeras. Vista sur-este

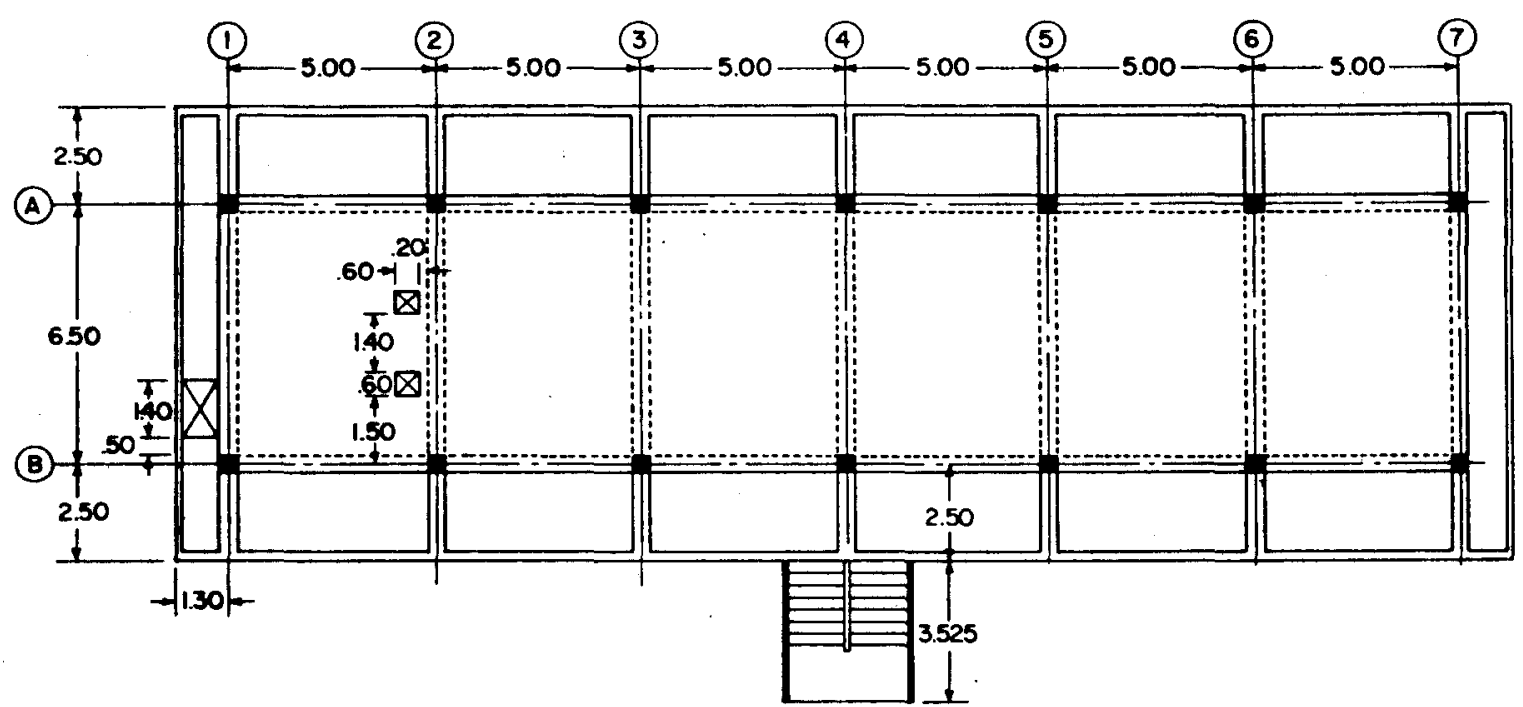

Planta del segundo y tercer niveles

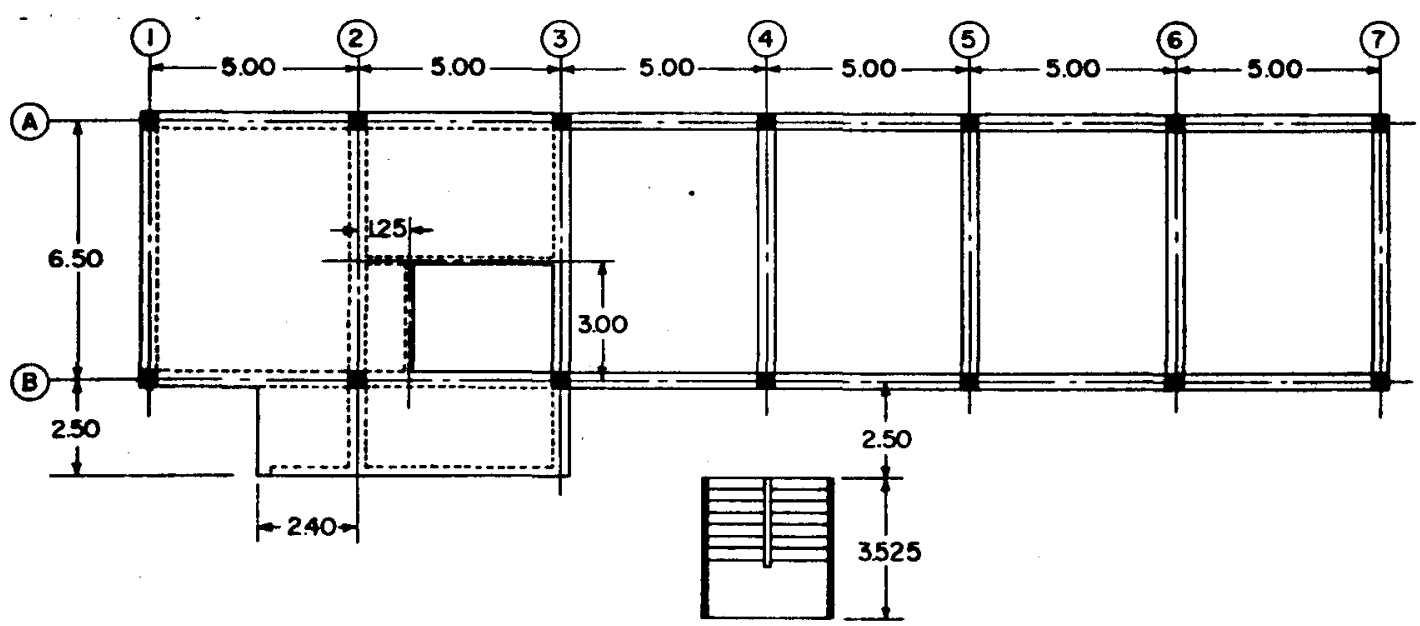

Planta principal (nivel del terreno)

Fig 39. Escuela de Niñeras. Plantas 


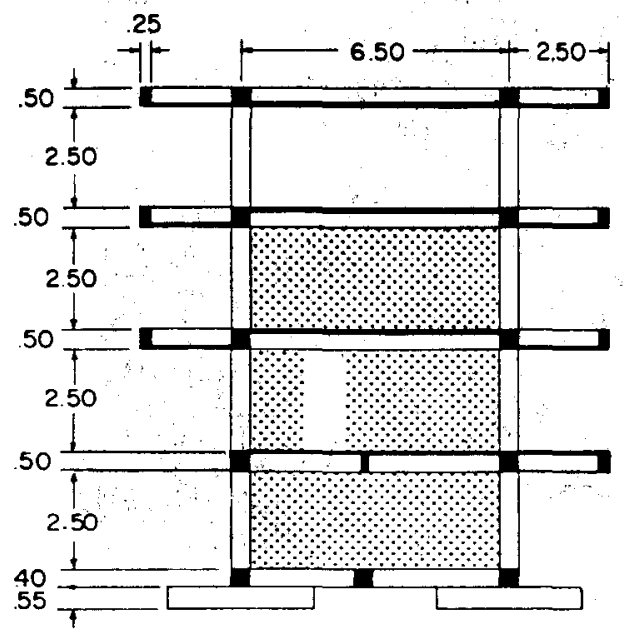

Marco 3

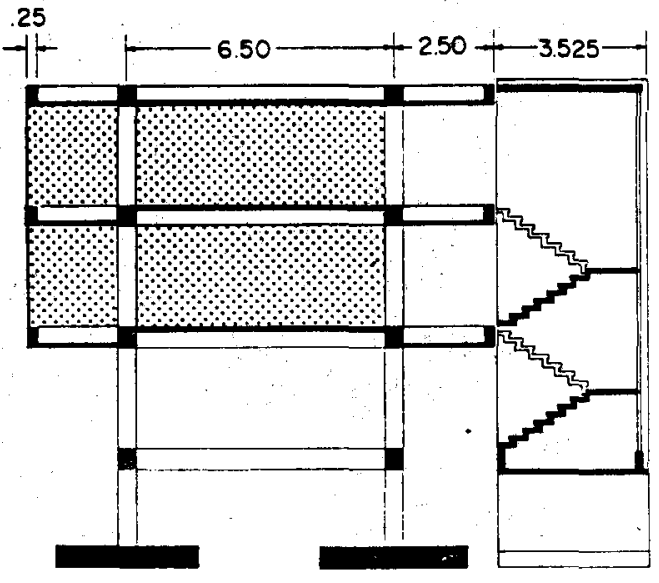

Marco 4

a) Secciones transversales

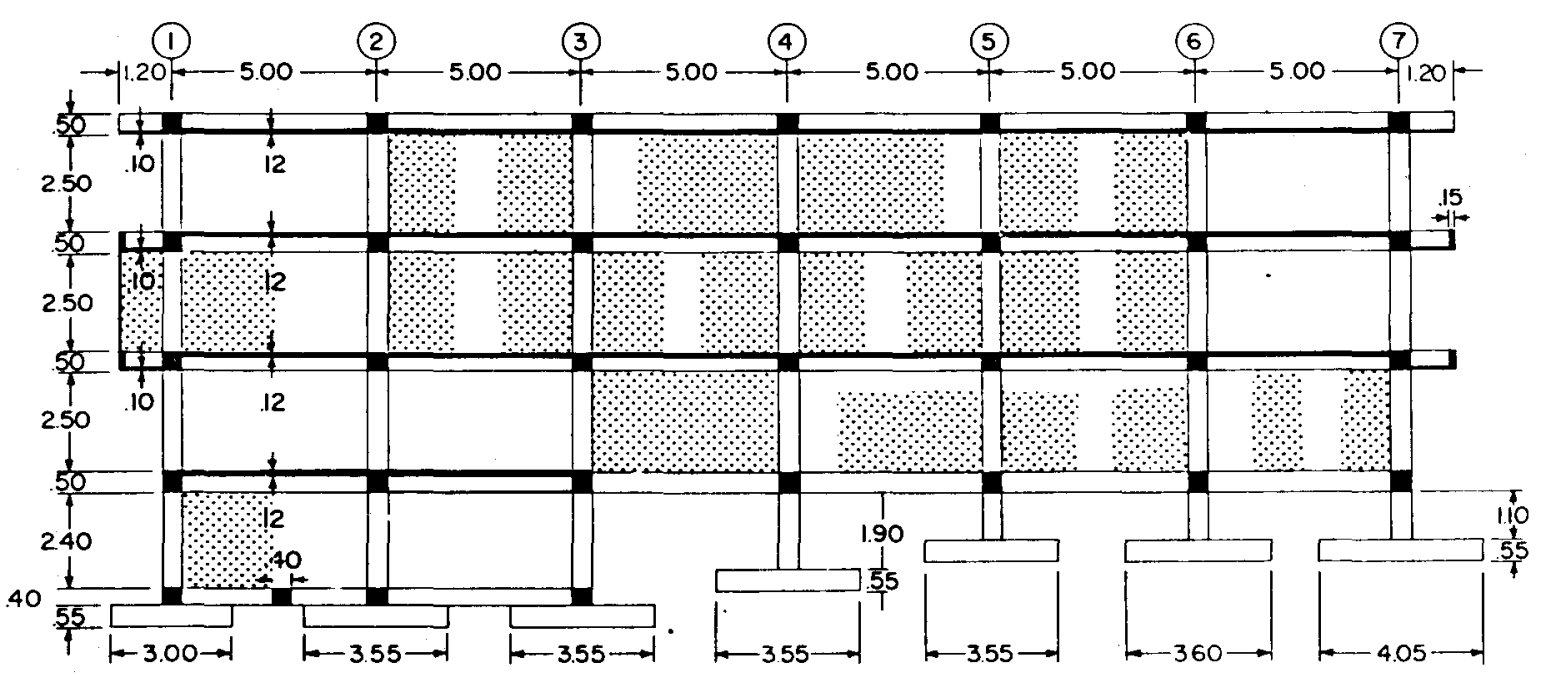

Marco B

b) Sección longitudinal

Fig 40. Secciones del edificio de la Escuela de Niñeras 

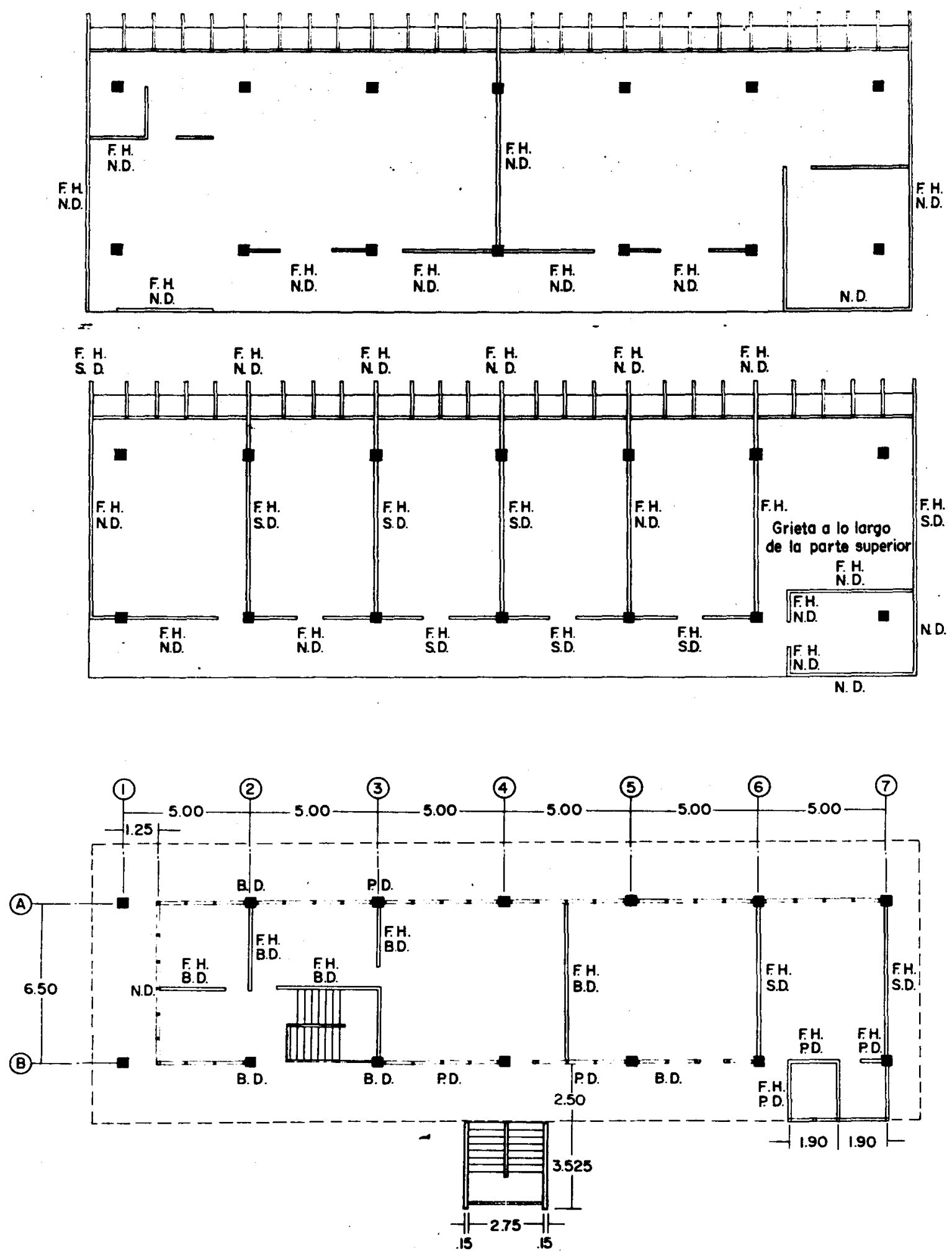

F.H. = (Altura total)

N.D. $=(\sin$ daños $)$

S.D. = (Daños ligeros )

P.D. = (Daño parcial $)$

B.D. = (Dahos pronunciodos)

Fig 41. Escuela de Niñeras. Levantamiento de daños 


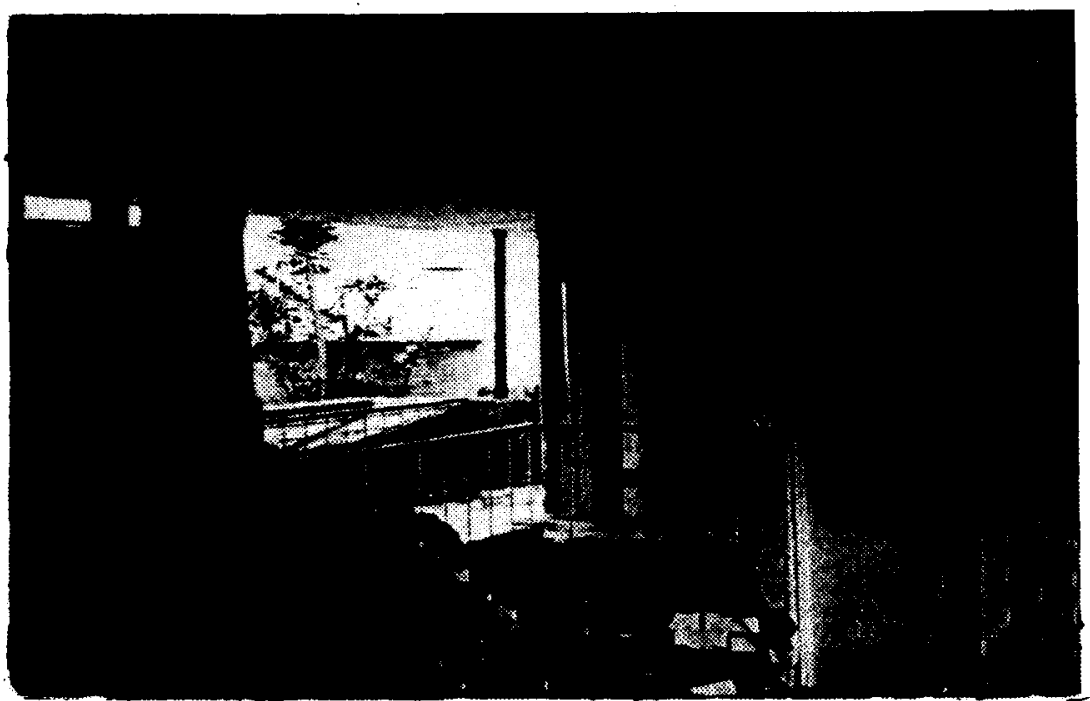

Fig 42. Escuela de Niñeras. Daños en los muros del marco trasversal No 3

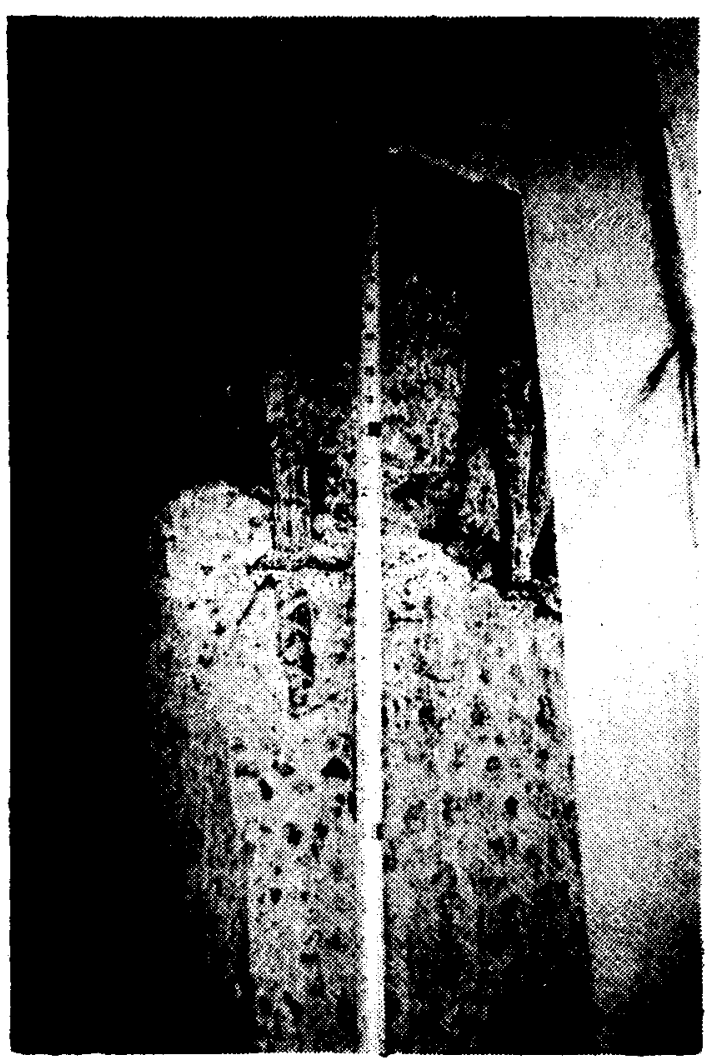

Fig 43. Escuela de Niñeras. Falla por cortante en la columna: marco trasversal No 2 y marco longitudinal $B$ 


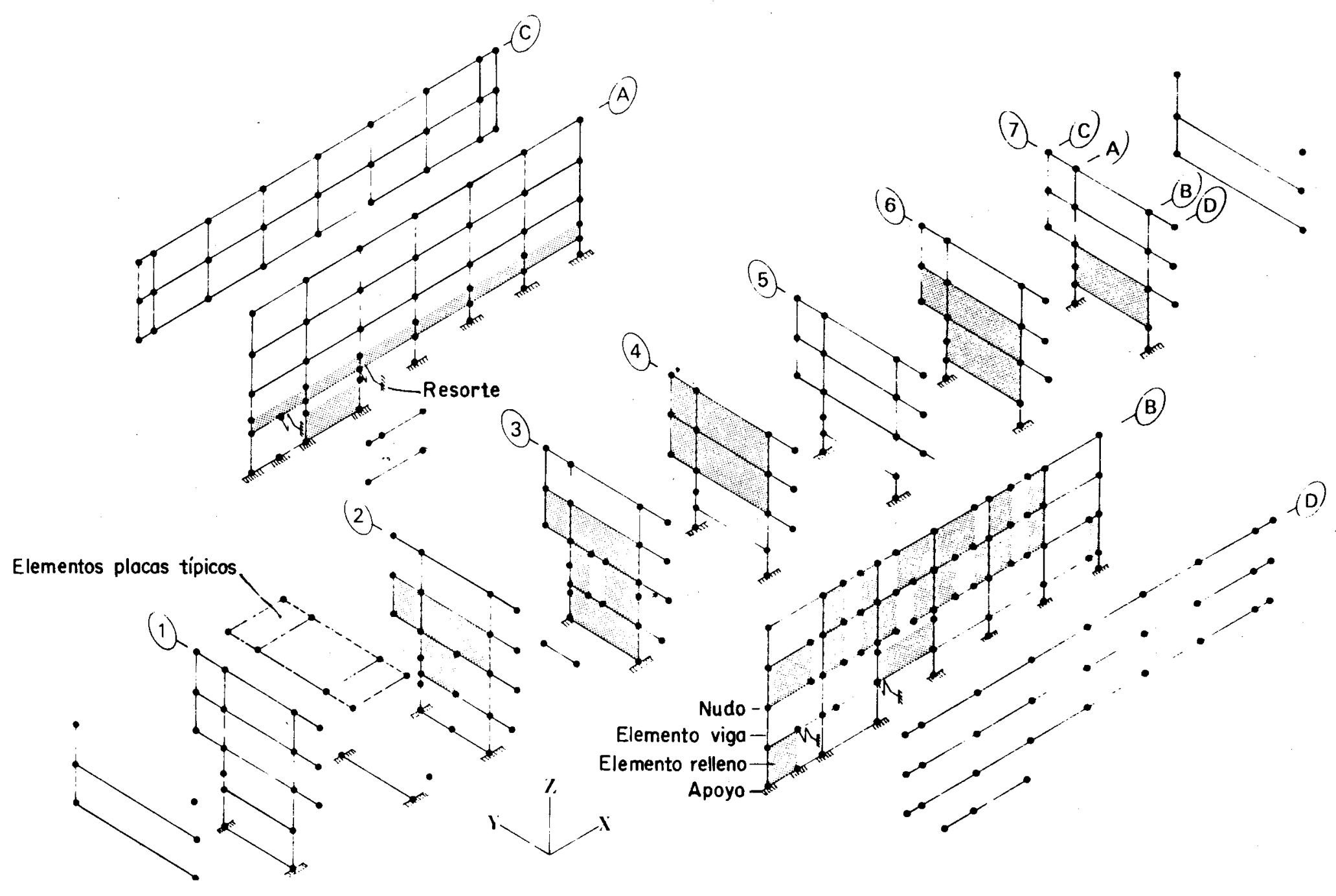

PROYECCION ISOMETRICA

Fig. 44 Modelo de elemento finito de la Escuela de Niñeras 


\section{Marco}

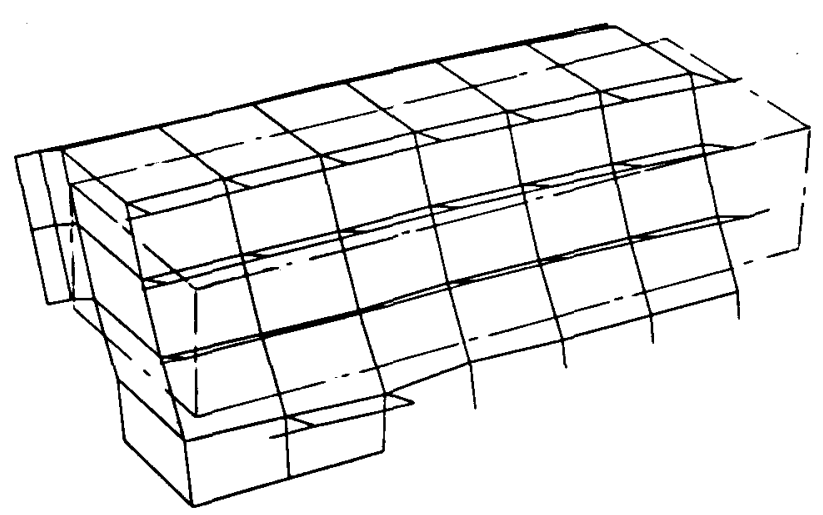

ESCUELA DE NINERAS

EICZ MOOE 1 (TI=0.650 SEC.)

Marco + losas + muros de relleno blando

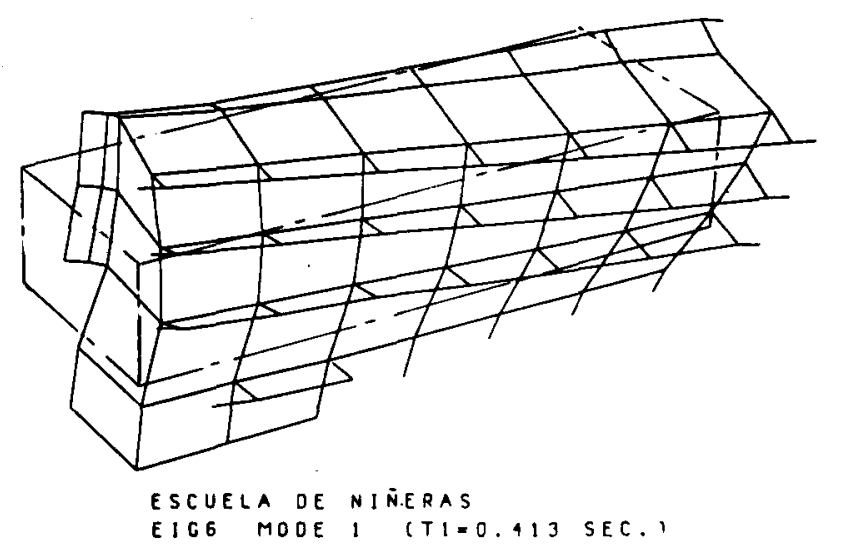

Marco + losas

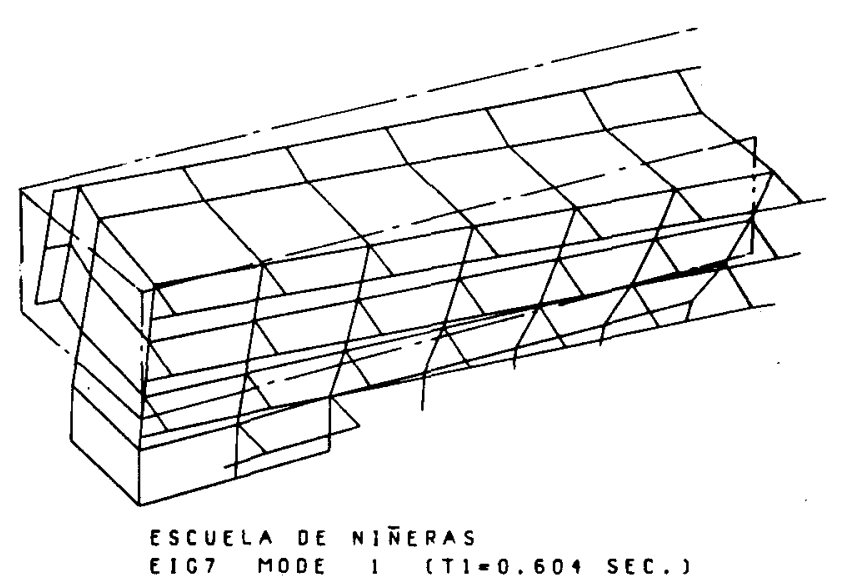

MODO 1

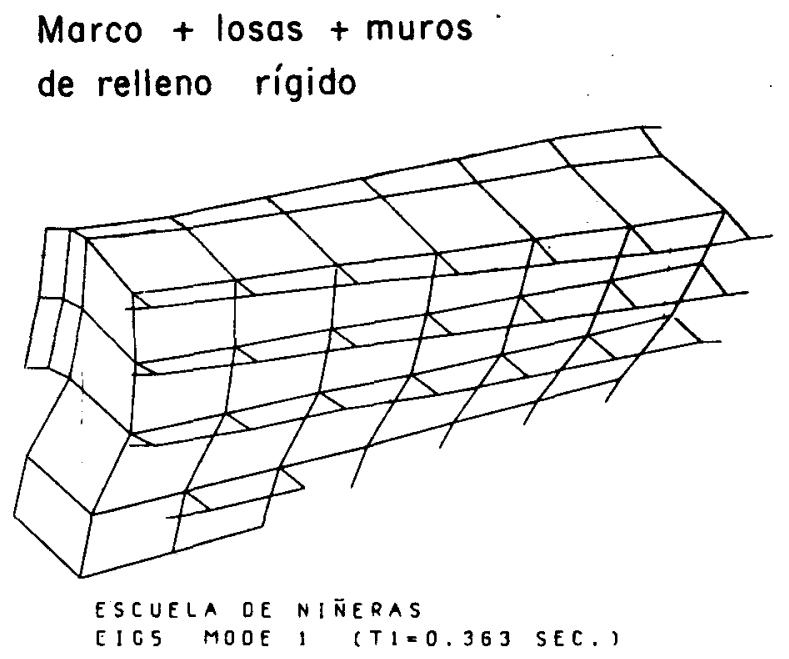

Fig 45. Escuela de Niñeras. Formas modales y periodos naturales 

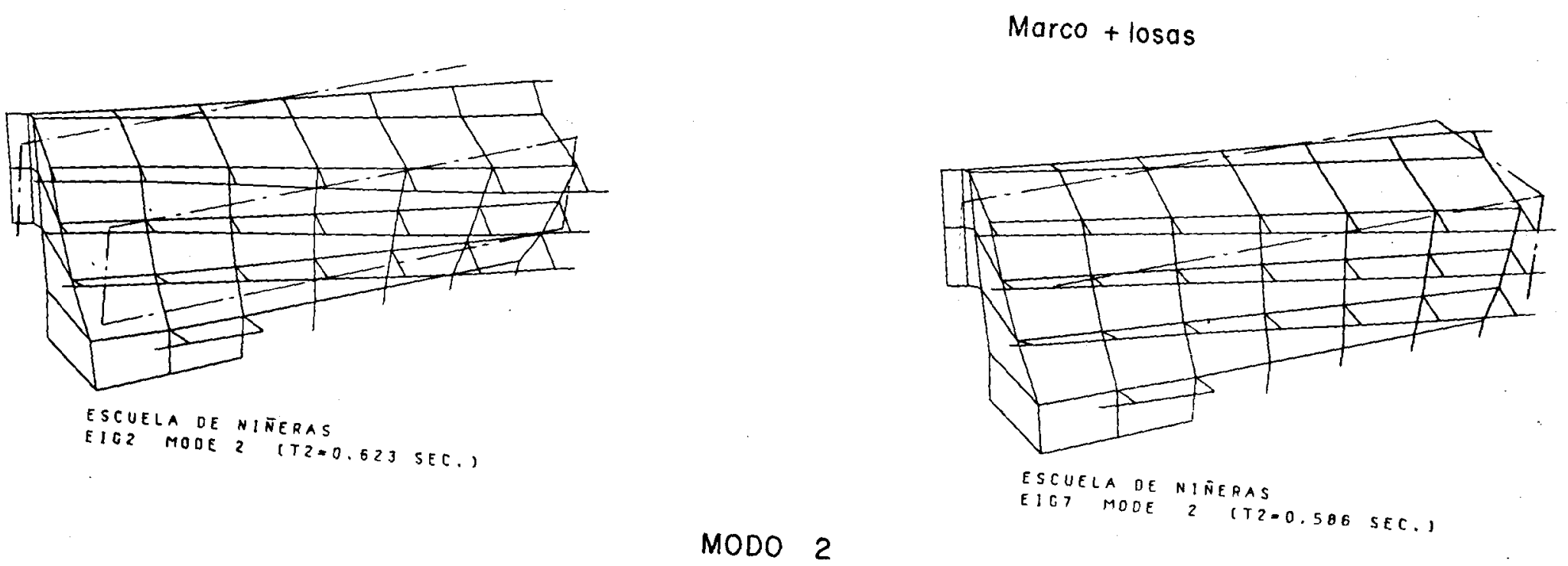

Marco + losas + muros

de relleno blando

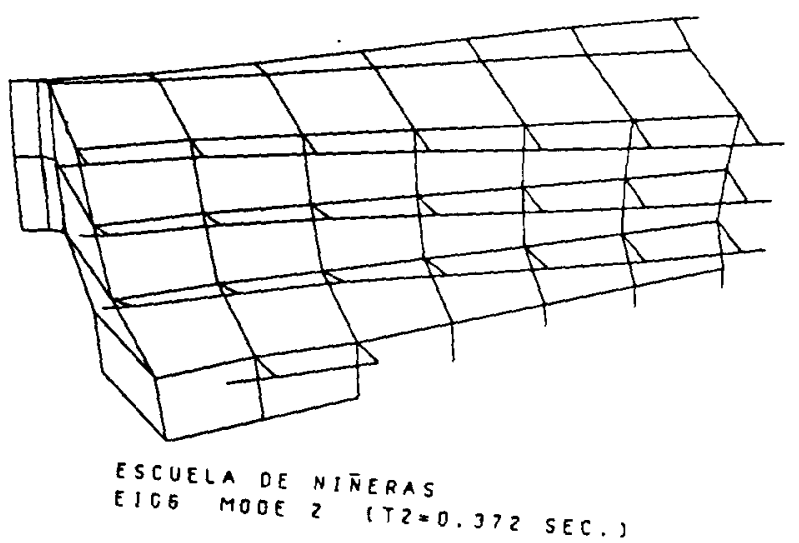

Marco + losas + muros

de relleno rígido

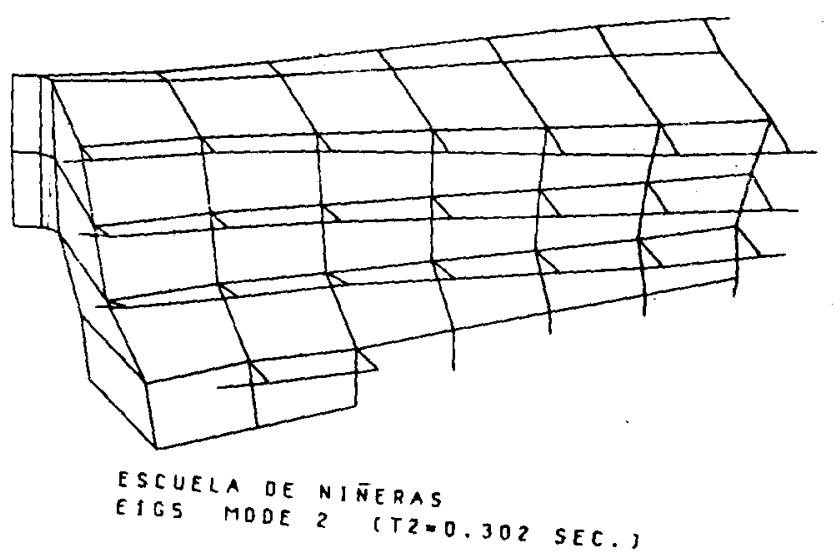

Fig 46. Escuela de Niñeras. Formas modales y periodos naturales 
Marco

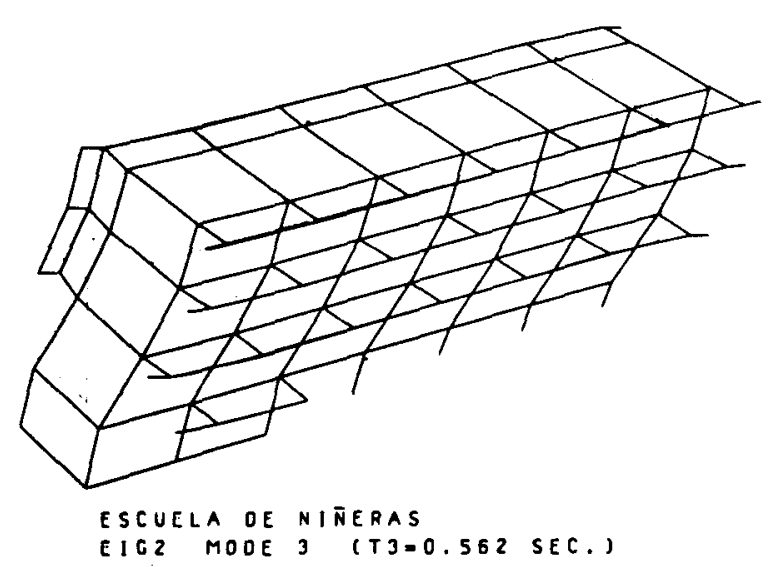

EIG2 MOOE 3 (TJ=0.562 SEC.)

Marco + losas + muros

de relleno blando

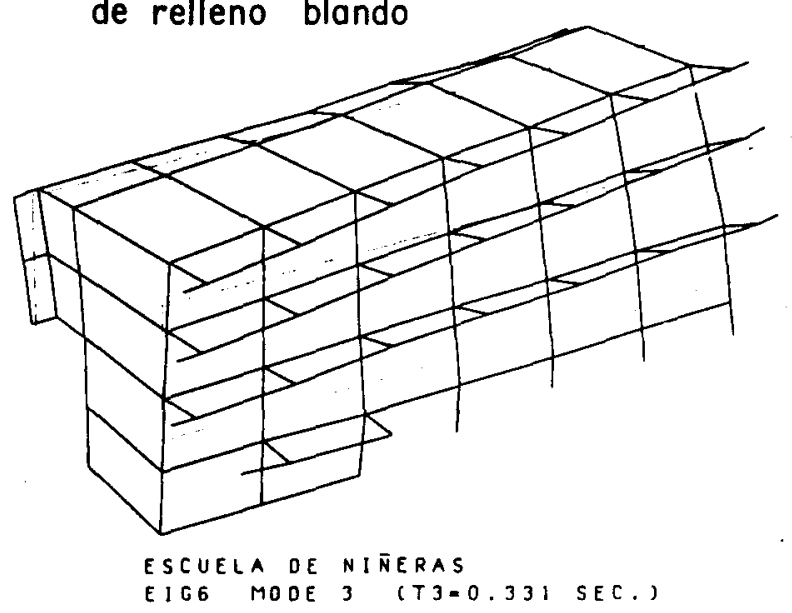

Marco + losas

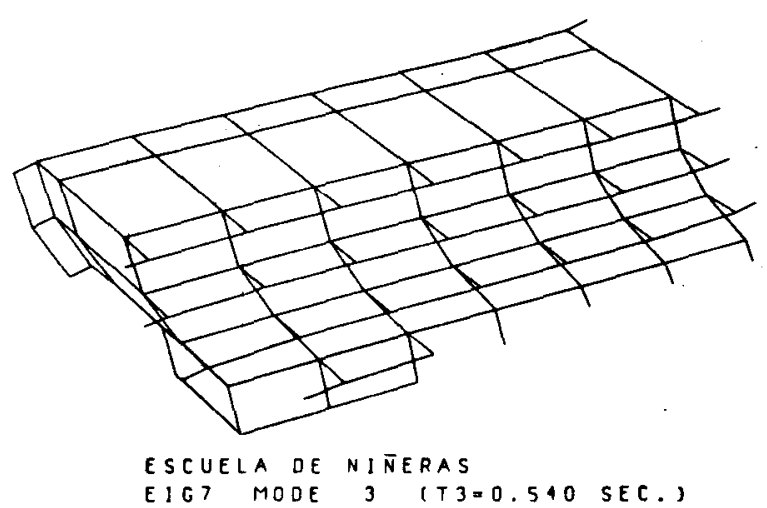

MODO 3
Marco + losas + muros

de relleno rigido

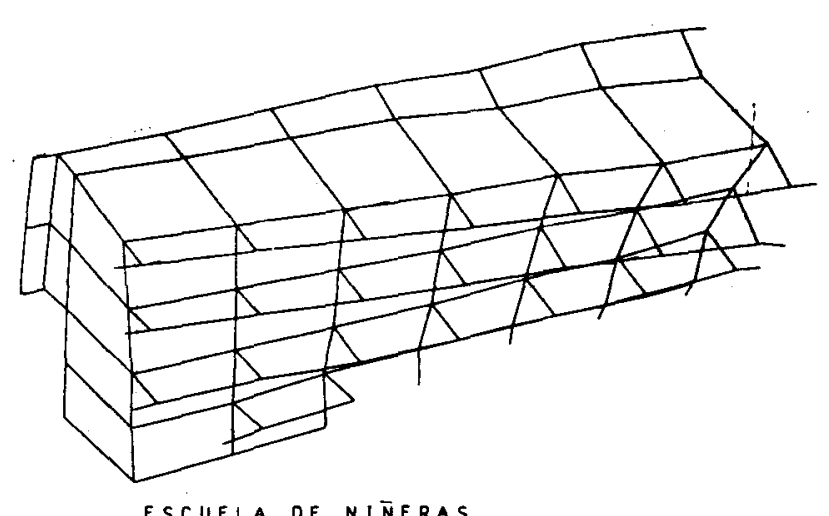

ESCUELA DE NINERAS
EIGS MOOE 3 (T300.246 SEC:')

Fig 47. Escuela de Niñeras. Formas modales y periodos naturales 
Marco

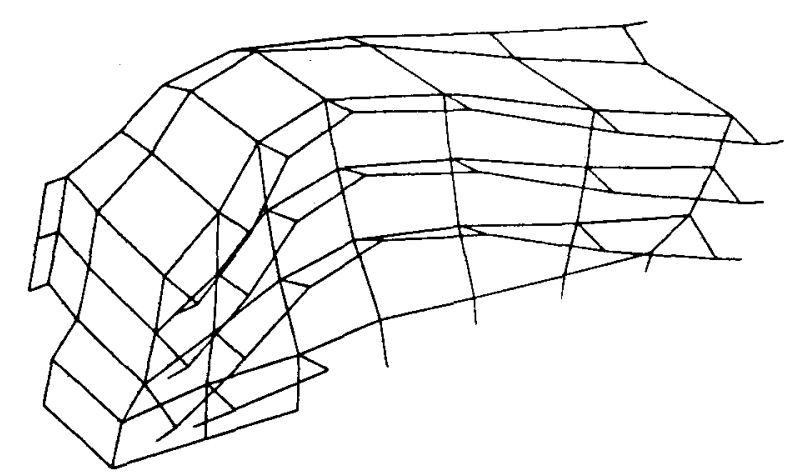

ESCUELA OE NINERAS

EIGZ MODE 4 (TA=0.356 SEC.)
Marco + losas

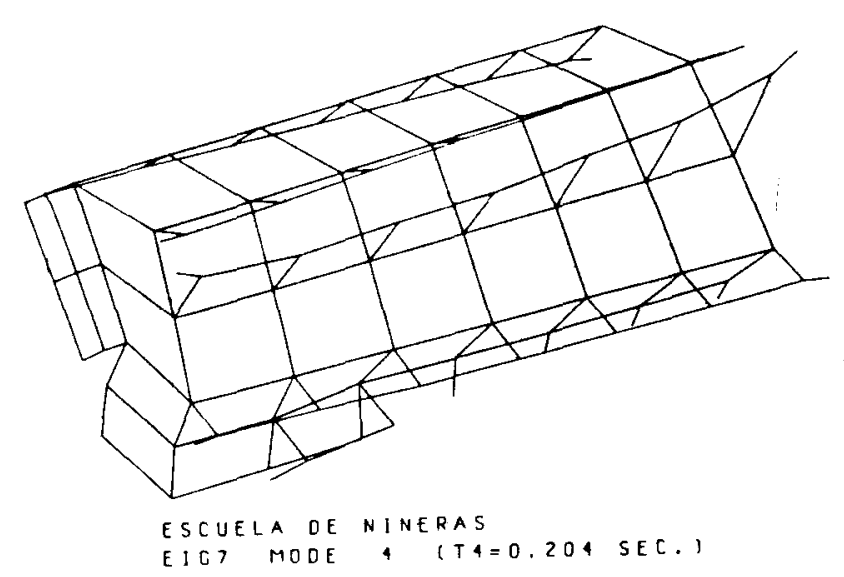

MODO 4

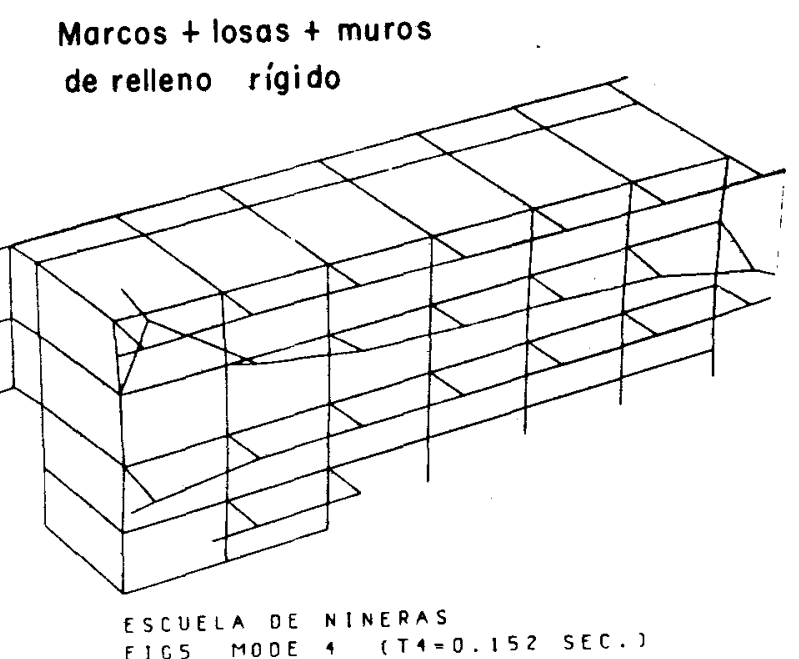

\section{Marco + losas + muros}

de relleno blando

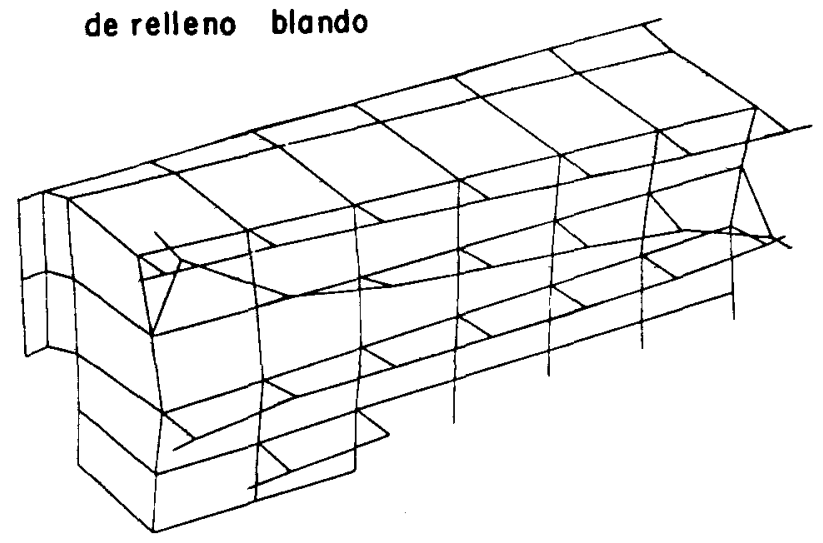

ESCUELA OE NINERAS

EICG MODE 4 (T4=0.159 SEC.)

Fig 48. Escuela de Niñeras. Formas modales y periodos naturales 


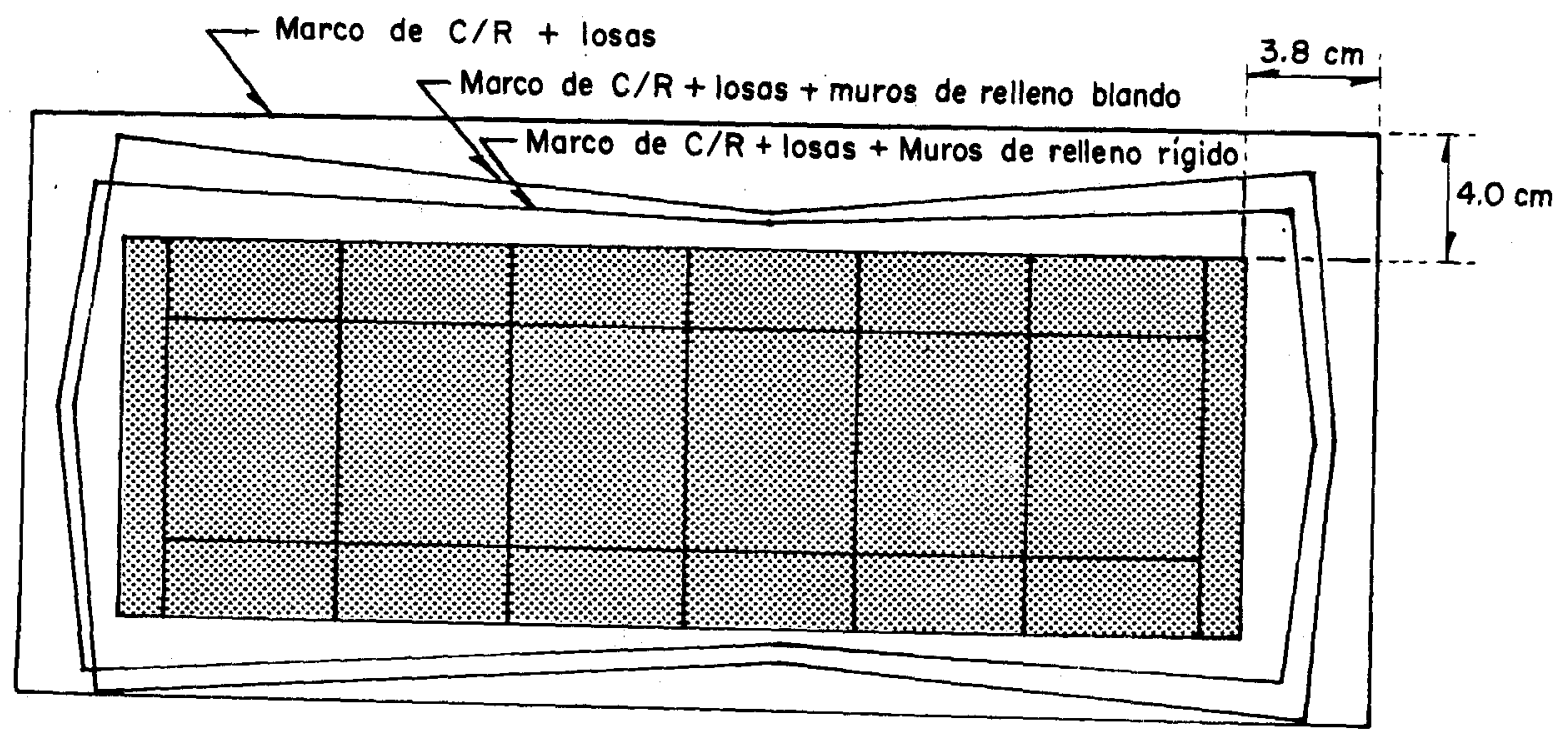

Fig 49. Escuela de Niñeras. Envolventes de desplazamientos de piso

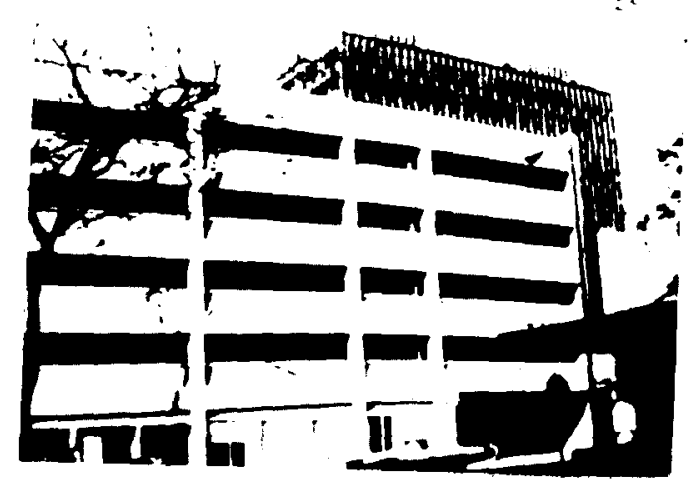

Fig 50. Edificio de estacionamiento. Sistema de vigas de borde de gran peralte $y$ columnas cortas

Fig 51. Colapso del sistema de vigas de borde de gran peralte y columnas cortas durante el sismo ocurrido en 1968 en Tockachi-Oki

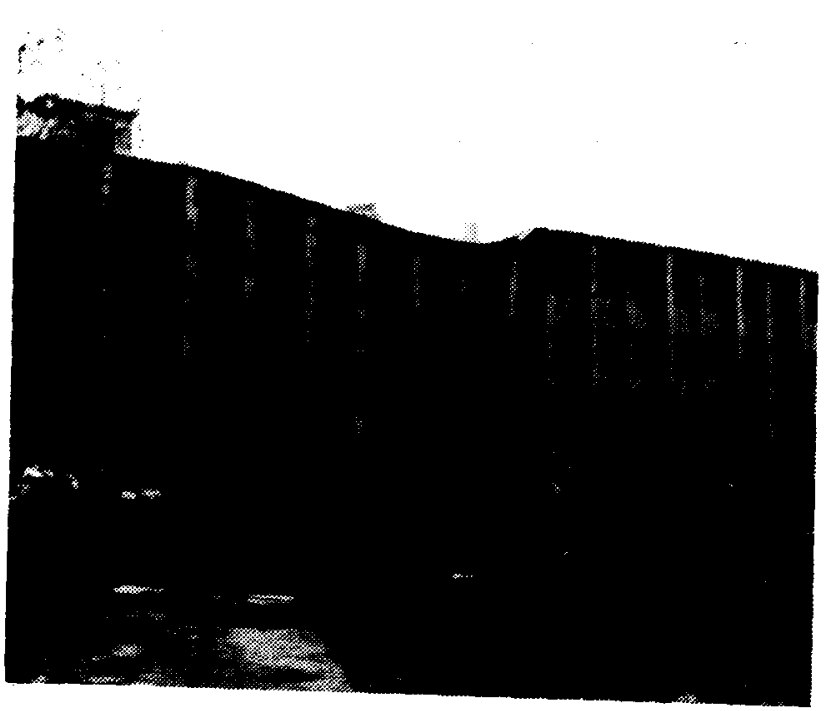




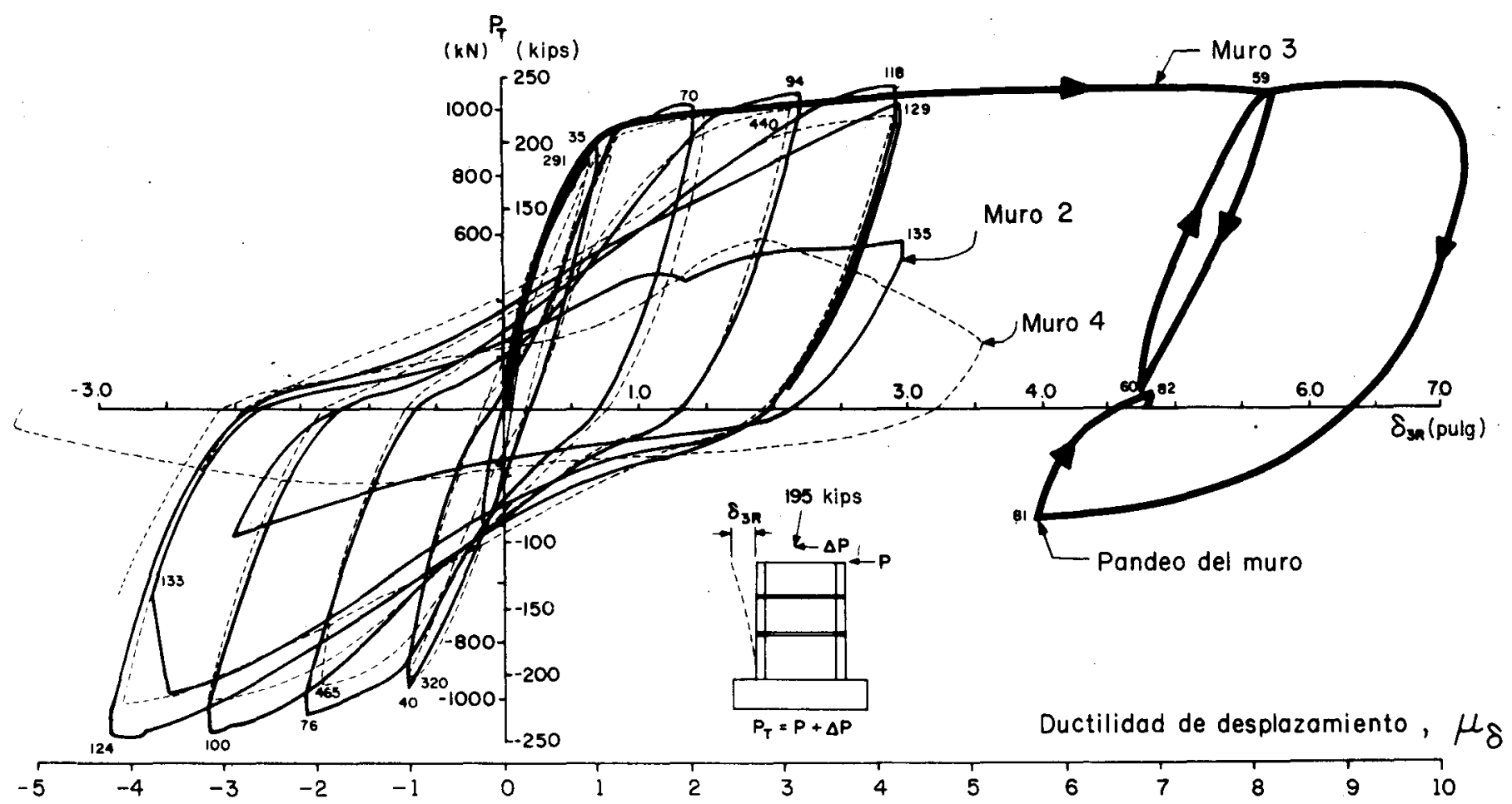

Fig 52. Muros de concreto reforzado. Comparación del comportamiento bajo carga monotónica (muro 3) con el comportamiento histerético bajo desplazamientos crecientes y reversibles (muros 2 y 4 )

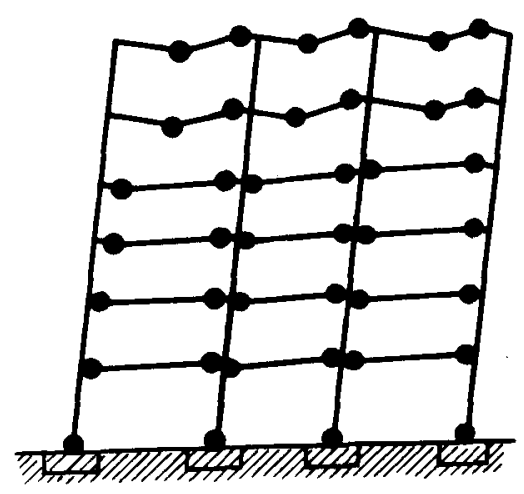

a) Colapso completo de un MRD

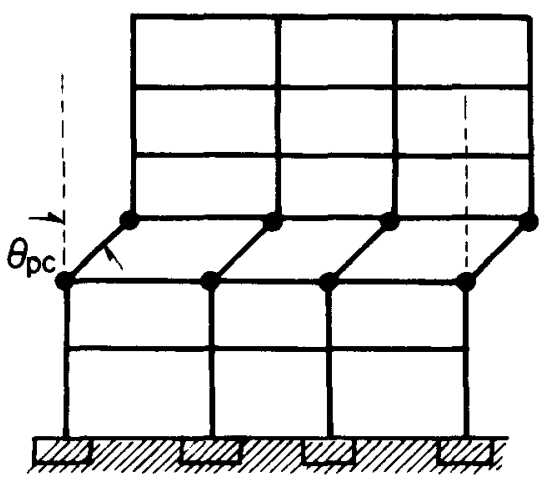

b) Colapso parcial con desplazamiento lateral en un entrepiso de un MRD

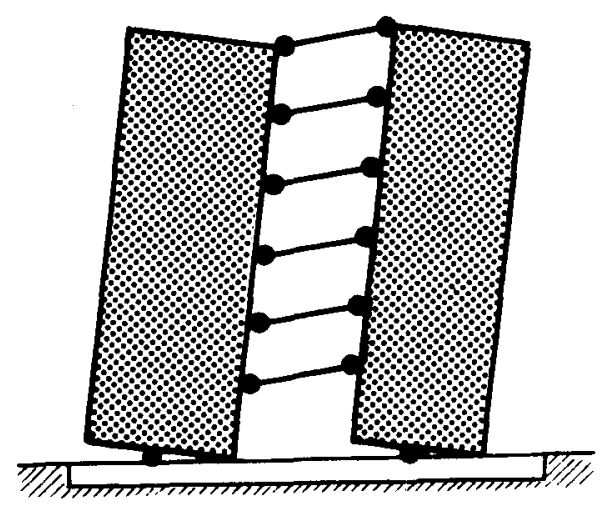

c) Colapso completo de un MA

Fig 53. Posibles mecanismos de colapso de marcos rigidos dúctiles (MRD) y sistemas de marcos acoplados (MA) 